Roberta Manzano Maria

\title{
Estudo do metabolismo de células de câncer de mama submetidas ao CLA usando RMN
}

Tese apresentada ao Instituto de Química de São Carlos da Universidade de São Paulo como parte dos requisitos para a obtenção do título de Doutor em Química.

Área de Concentração: Química Analítica e Inorgânica

Orientador: Dr. Luiz Alberto Colnago

São Carlos

2013 
Folha de Aprovação 


\section{Agradecimentos}

A Deus,

Aos meus pais, José Roberto e Roseli, pela oportunidade que me deram de poder estudar e pela enorme ajuda sempre presente. A minha irmã, Renata, pela paciência nestes anos todos e por sempre estar ao meu lado. Ao meu marido, Guilherme, pelo amor, apoio e palavras de incentivo. Agradeço de coração por tudo que vocês fizeram por mim, eu nunca vou esquecer.

Ao meu orientador, Dr. Luiz Alberto Colnago, pela orientação, por toda ajuda e principalmente pela paciência que teve comigo nestes anos de convívio. Agradeço pela amizade que fizemos durante o desenvolvimento deste trabalho e pela contribuição na minha formação acadêmica.

Ao Prof. Dr. Adriano Andricopulo, pela parceria estabelecida para que este trabalho de doutorado pudesse ser realizado.

Ao Prof. Dr. Tiago Venâncio e ao Prof. Dr. Antônio G. Ferreira, pela ajuda e disponibilidade dos equipamentos para que este trabalho pudesse ser concluído.

Ao Prof. Dr. Claudio José Magon e ao aluno de doutorado Tiago Bueno de Moraes pela possibilidade da aplicação do FDM neste trabalho.

Ao Prof. Dr. Richard Garrart e ao Dr. Napoleão Fonseca Valadares pela disponibilidade e ajuda.

À FAPESP, pela bolsa concedida que permitiu a realização deste trabalho através do processo 2009/17846-4.

Ao serviço de pós-graduação do Instituto de Química de São Carlos, especialmente à Andréia e Silvia, pela atenção e por toda ajuda nestes anos.

Aos amigos do grupo de RMN, Maria Gabriela Carósio, Paulo Cobra, Maiara Santos, Luiza Nunes, Matheus Postigo, Luiz Fernando Cabeça, Tatiana Santana, Fabiola Pereira, Danielli Golinelli, Poliana Santos,Tiago Bueno de Moraes, Fabiana Diuk e Lucinéia Vizotto.

Aos amigos da UFSCar, Lorena, Elenilson,Tatiana,Lyege e Clayton por toda ajuda e atenção.

À Wanessa Altei pela execução dos experimentos em células, mas principalmente por toda atenção e amizade que teve comigo nestes anos. 


\section{Resumo}

O ácido linoleico conjugado (CLA), um grupo de isômeros do ácido linoleico, é encontrado no leite e na carne de animais ruminantes, e apresenta propriedades anticarcinogênica, antidiabética, antiadipogênica e antiaterogênica. Neste trabalho de doutorado estudou-se o efeito do CLA (cis-9, trans-11) em duas linhagens de células de câncer de mama, MCF-7 e MDA-MB-231, com a técnica de RMN denominada HRMAS (High Resolution Magic Angle Spinning). O HR-MAS foi usado para identificar e quantificar os principais metabólitos das linhagens e também foi eficiente para observar mudanças significativas na variação dos metabólitos em função da adição de CLA ao meio de cultura. As células de câncer de mama, MCF-7 submetidas a 100 $\mu \mathrm{M}$ CLA tiveram aumento significativo do sinal de acetona. Esse padrão não foi observado para a MDA-MB-231. Também se observou que o teor de fosfocolina decresceu em ambas as linhagens celulares quando tratadas com $100 \mu \mathrm{M}$ CLA. Mediante esses resultados e simulação por modelagem molecular propôs-se que 0 CLA pode atuar inibindo a ação da enzima HMG-CoA redutase (HMGR), de maneira similar as estatinas. Ao se ligar a HMGR, o CLA impede a ligação do HMG-CoA (substrato), impedindo a sua conversão para mevalonato e consequentemente a biossíntese do colesterol. O HMG-CoA é então convertido para acetoacetato e posteriormente a acetona. Esse mecanismo pode explicar tanto o aumento da acetona quanto a redução da fosfocolina, uma vez que há controle positivo mútuo entre o colesterol e os fosfolipídios. Desta forma, pode-se concluir que a inibição da HMGR pelo CLA pode ser uma demonstração do mecanismo bioquímico tanto de sua ação anticarcinogênica quando das atividades antidiabética, antiadipogênica e antiaterogênica, relatadas na literatura. Neste trabalho também foi demonstrada a potencialidade do processamento dos sinais de HR-MAS no domínio do tempo pelo método de diagonalização filtrada. Essa técnica foi capaz de obter espectros de alta resolução, sem necessidade de supressão do sinal da água e filtro de $T_{2}$, para suprimir linhas largas.

Palavras-chave: Ressonância Magnética Nuclear, HR-MAS, células de câncer de mama, CLA, Metabolismo. 


\begin{abstract}
Conjugated linoleic acid (CLA), a group of isomers of linoleic acid,is found in milk and meat of ruminant animals, which have anticarcinogenic, antidiabetic, antiatherogenic and anthiadipogenic properties. In this thesis the effect of CLA (cis-9, trans-11) in two cell lines of breast cancer, MCF-7 and MDA-MB-231 was studied High Resolution Magic Angle Spinning (HR-MAS) NMR technique. HR-MAS was used to identify and quantify the metabolites of the two cells and was effective to observe significant changes in metabolites due to the addition of CLA to the culture medium. The breast cancer cells, MCF-7 subjected to $100 \mu \mathrm{M}$ CLA had a significantly higher acetone signal. This pattern was not observed for MDA-MB-231. It was noted that the content of phosphocholine decreased in both cell lines treated with $100 \mu \mathrm{M} \mathrm{CLA}$. Given these results and simulation with molecular modeling we are suggesting that CLA inhibits the enzyme HMG-CoA reductase (HMGR), similar to statins. By binding to HMGR, CLA prevents binding of the HMG-CoA (substrate), preventing their conversion to mevalonate, and consequently the cholesterol biosynthesis. The HMG-CoA is then converted to acetoacetate and then acetone. This mechanism explains the increase of acetone and decreased of phosphocholine, since there is mutual positive control with cholesterol and phospholipids. Therefore, the inhibition of HMGR by CLA may be the biochemical explanation for its anticarcinogenic activities as well as antidiabetic, antiatherogenic and antiadipogenic properties reported in the literature. It was also demonstrated the capability of Filter Diagonalization Method (FDM) to process time domain HR-MAS signals. FDM was able to obtain high-resolution spectra without the water suppression and $\mathrm{T}_{2}$ filter.
\end{abstract}

Keywords: Nuclear Magnetic Resonance, HR-MAS, Breast cancer cell, CLA, Metabolism. 


\section{Sumário}

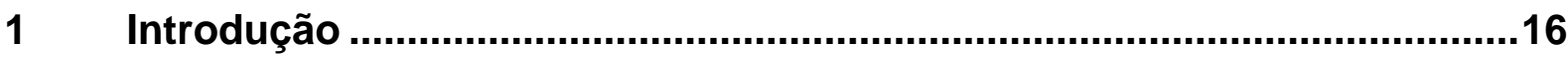

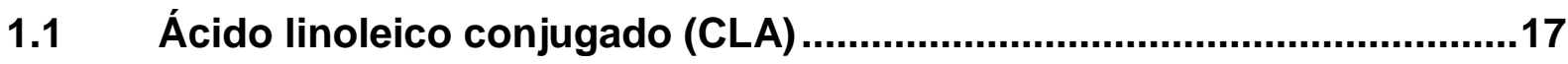

1.1.1 Síntese do CLA no rúmen ....................................................................18

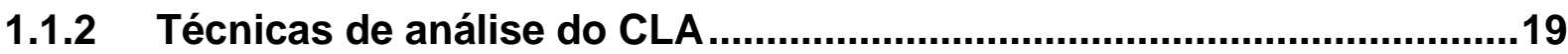

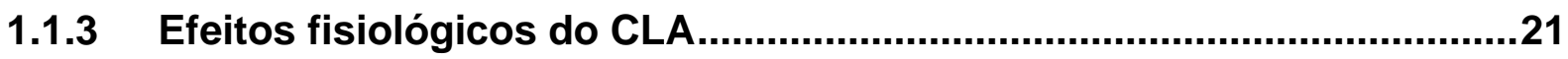

1.2 Metabolismo de células sadias e tumorais .................................................

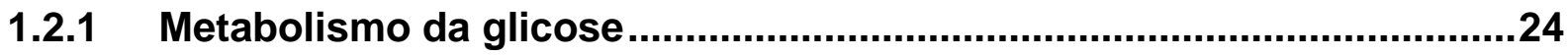

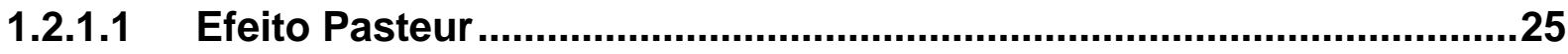

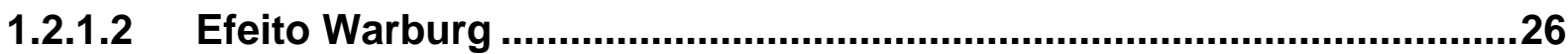

1.2.2 Metabolismo dos fosfolipídios de membrana .......................................26

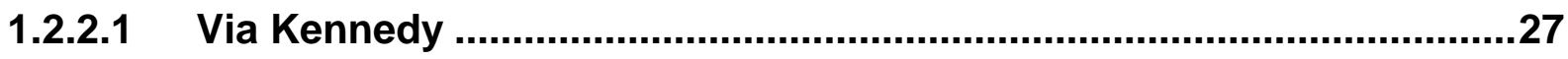

1.2.3 Colesterol: Membranas celulares e Hormônios ……................................28

1.3 Metabolômica e o câncer de mama ……................................................30

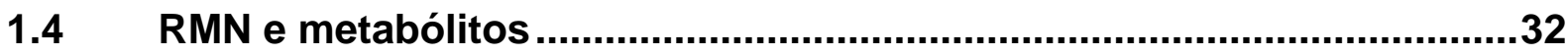

1.5 RMN em alta resolução com rotação no ângulo mágico (HR-MAS) ......33

1.5.1 Supressão do sinal da água nos espectros de RMN de ${ }^{1} \mathrm{H}$.....................35

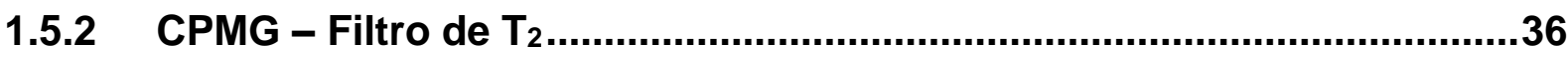

1.5.3 Estudos metabólicos com HR-MAS..........................................................

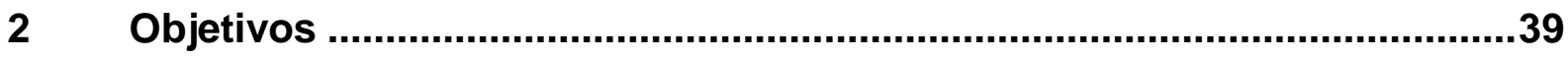

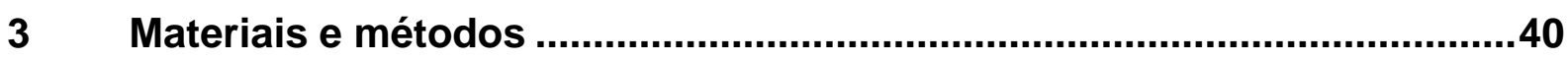

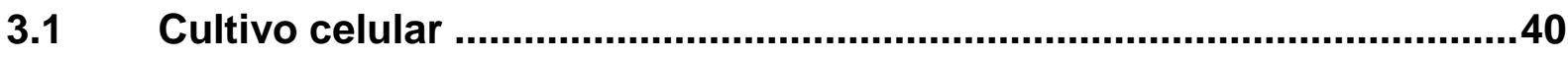

3.1.1 Cultivo Celular com CLA ….................................................................

3.2 Análise por Ressonância Magnética Nuclear ..........................................43

3.2.1 Método de supressão do sinal da água ..................................................44

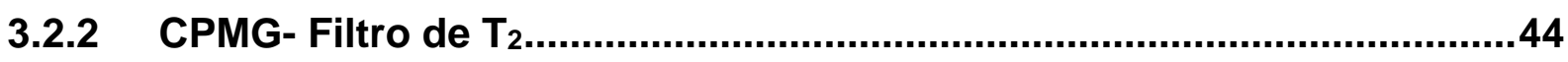

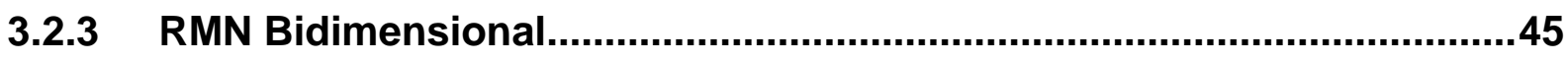

3.3 Utilização de base de dados para identificação dos metabólitos...........46 


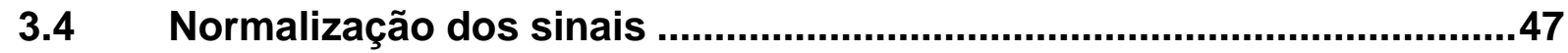

3.5 Método de diagonalização filtrada (FDM) ............................................48

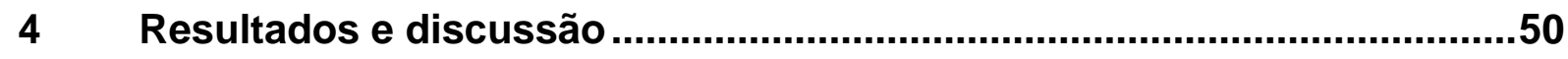

4.1 Análises de Ressonância Magnética Nuclear.........................................50

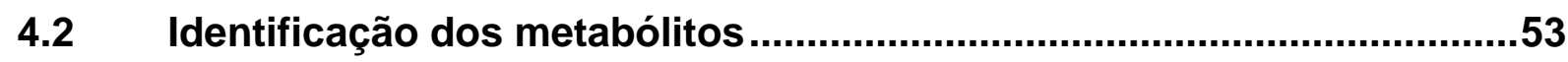

4.3 Quantificação relativa dos metabólitos...............................................60

4.4 Determinação da variabilidade da concentração dos metabólitos nas células de câncer de mama, por HR-MAS ......................................................61

4.5 Variação do perfil metabólico em função do estresse.............................63

4.6 Efeito do CLA no perfil metabólico das células tumorais .......................69

4.6.1 Hipótese para as mudanças metabólicas causadas pelo CLA ...............74

4.6.1.1 Inibição da HMG-CoA redutase como um dos mecanismos da atividade antitumoral do CLA .............................................................................

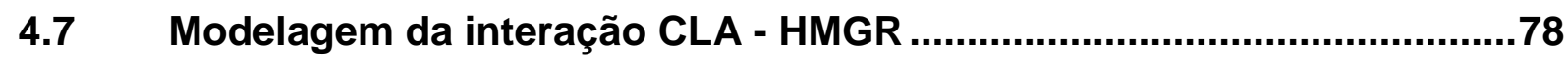

4.8 Uso do método da diagonalização filtrada para processamento do sinal

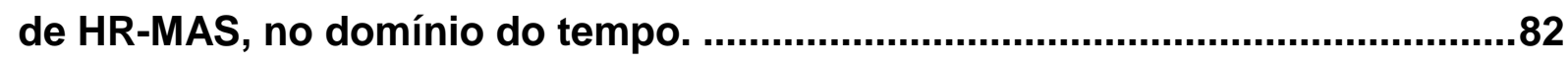

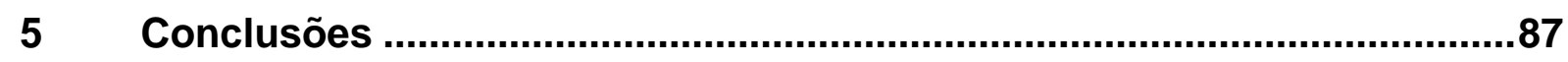

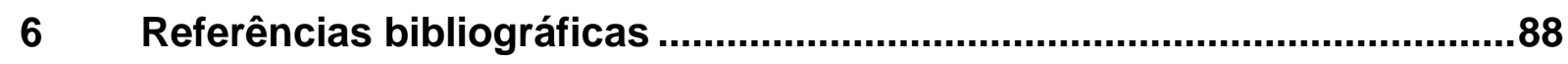




\section{Lista de figuras}

Figura 1 - Estruturas do ácido linoleico (A) e de seus isômeros cis-9, trans-11(B) e trans-10, cis-12 CLA (C).

Figura 2 - Metabolismo lipídico no rúmen e a origem do CLA na carne de ruminantes.

Figura 3 - Espectro de RMN de ${ }^{1} \mathrm{H}$ da gordura extraída do contra-filé (A) e a expansão da região de 5,0 a 6,5 ppm, na qual é possível observar os sinais característicos do CLA (B): na amostra analisada (acima) e na amostra padrão (abaixo)

Figura 4 - Correlação entre a quantidade de CLA em cortes cárneos analisado pelos métodos de $\mathrm{CG}$ e por ${ }^{1} \mathrm{H}$ RMN.

Figura 5 - Via bioquímica do metabolismo dos fosfolipídios de colina (Via Kennedy).

Figura 6 - A reprogramação metabólica das células tumorais. O metabolismo é reorganizado para aumentar as reações anabólicas ligadas ao crescimento e proliferação celular .33

Figura 7 - Esquema do giro do rotor no ângulo mágico (sonda HR-MAS). .35

Figura 8 - Imagens microscópicas das células de câncer de mama com receptores de estrogênio, MCF-7 (esquerda) e células de câncer de mama sem receptores de estrogênio, MDA-MB- 231 (direita).

Figura 9 - Esquema do processo de preparação das células para formar o pellet celular. (A) Garrafa de cultura utilizada para o crescimento celular. (B) Fotomicrografia de uma monocamada de células tumorais. (C) Pellet celular para análise em RMN.

Figura 10 - Câmara de Neubauer, utilizada para a contagem de células, permitindo o cálculo do volume necessário da suspensão celular para a obtenção da concentração desejada. Neste caso, é possível a visualização das células de câncer de mama, MCF-7, intactas.

Figura 11 - Rotor e acessórios utilizados para a sonda HR-MAS no espectrômetro DRX 400 BRUKER. (1- rotor; 2 - espaçador; 3- parafuso; 4- tampa seccionada; 5- parafuso). 
Figura 12 - Sequência de pulsos usada para aquisição do sinal HR-MAS. A sequência tem o pulso de pré-saturação e um trem de pulsos da sequência CPMG, para eliminar o sinal intenso da água e sinais largos, respectivamente....45

Figura 13 - Integração dos múltiplos sinais dos metabólitos obtidos com o sinal de referência em 3,78ppm. Em destaque sinal da creatina e taurina em 1 e 2 respectivamente.

Figura 14 - Espectro obtido a partir do segundo método de normalização. Através do somatório de todas as amplitudes do espectro igual a 1000 (A) e exemplo do cálculo das áreas dos sinais dos metabólitos de interesse, creatina e taurina em 1 e 2 respectivamente (B) .48

Figura 15 - Esquema das etapas realizadas no processamento com o FDM. 49

Figura 16 - Espectro de HR-MAS da amostra de células de câncer de mama (MCF-7) em $\mathrm{D}_{2} \mathrm{O}$. No espectro em preto se observa o sinal intenso da água. No espectro em vermelho está a expansão da escala vertical de 100X do mesmo espectro para a visualização dos sinais de interesse.

Figura 17 - Espectro de HR-MAS da amostra de células de câncer de mama (MCF-7) empregando a técnica de supressão do sinal da água, pré-saturação $(A)$ e espectro da mesma amostra anterior com o uso do filtro de T2 (CPMG). Com o uso da pré-saturação foi possível melhorar a observação dos sinais dos metabólitos, bem como com o uso do filtro de $\mathrm{T}_{2}$ permitiu eliminar os sinais largos das macromoléculas, presentes no espectro $A$ .52

Figura 18 - Ampliação da região do espectro COSY das células de câncer de mama (MCF-7) para possibilitar a visualização das correlações entre átomos de hidrogênio de grupos vizinhos.

Figura 19 - Ampliação da região do espectro de HSQC das células de câncer de mama (MCF-7) para possibilitar a visualização das correlações de hidrogênio e carbono ligados entre si. .55

Figura 20 - Ampliação da região do espectro de HMBC das células de câncer de mama (MCF-7) para possibilitar a visualização das correlações de hidrogênio e carbono à longa distância. .56

Figura 21 - Expansão de 4,5 a 1,0ppm do espectro de HR-MAS de células tumorais. O espectro das células MDA-MB-231 (vermelho) é comparado com 0 espectro das células MCF-7 (preto). Os números referem-se ao assinalamento de 9 sinais diferentes dos metabólitos. Os metabólitos 
(número do sinal entre parênteses) são mostrados: lactato (1), treonina (2), alanina (3), acetato (4), acetona (5), creatina (6), colina (7), fosfocolina (8), taurina (9). A letra $G$ corresponde ao sinal da glicina (3,78ppm) usado como referência para quantificação dos metabólitos. .58

Figura 22 - Triplicata dos espectros de HR-MAS das células de câncer de mama MCF7 (A) e MDA-MB-231 (B). Em ambos os espectros é possível visualizar uma quantidade grande de sinais referentes aos metabólitos intracelulares presentes na região de 0,5 a 4,0 ppm.

Figura 23 - Espectro de HR-MAS de células de câncer de mama (MCF-7) obtidos em 5 aquisições consecutivas.

Figura 24 - Espectro de HR-MAS de ${ }^{1} \mathrm{H}$ das células de câncer de mama (MDA-MB231) obtidos em 5 aquisições consecutivas. 66

Figura 25 - Comparação do sinal em 1,32 ppm referente ao metabólito lactato nas células de câncer de mama (- MCF-7; • MDA-MB-231).

Figura 26 - Comparação do sinal em 1,92 ppm referente ao metabólito acetato nas células de câncer de mama (- MCF-7; • MDA-MB-231).

Figura 27 - Comparação do sinal em 3,22 ppm referente ao metabólito fosfocolina nas células de câncer de mama (- MCF-7; • MDA-MB-231). 68

Figura 28 - Comparação do sinal em 3,20 ppm referente ao metabólito colina nas células de câncer de mama (- MCF-7; •MDA-MB-231). .68

Figura 29 - Espectros de células de câncer de mama MCF-7. Células controle (A),

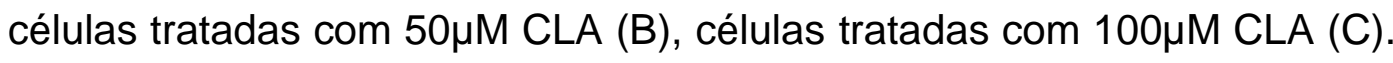
Em destaque o sinal da acetona intenso nas células submetidas com $100 \mu \mathrm{M}$ CLA. .70

Figura 30- Espectros de células de câncer de mama MDA-MB-231. Células controle

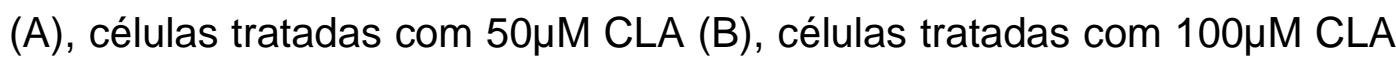
(C). Em destaque o sinal da acetona presente nas células controle (sem CLA). .71

Figura 31 - Quantidade relativa da acetona presente no espectro de HR- MAS das células MCF-7 controle (sem o CLA) e submetidas ao CLA (100 $\mu \mathrm{M})$......72

Figura 32 - Quantidade relativa da acetona presente no espectro de HR- MAS das células MDA-MB-231 controle (sem o CLA) e submetidas ao CLA (100 $\mu \mathrm{M})$. 
Figura 33 - Quantidade relativa da fosfocolina presente no espectro de HR- MAS das células MCF-7 controle (sem o CLA) e submetidas ao CLA (100 $\mu \mathrm{M})$......73

Figura 34 - Quantidade relativa da fosfocolina presente no espectro de HR-MAS das células MDA-MB-231 controle (sem o CLA) e submetidas ao CLA (100 $\mu \mathrm{M})$.

Figura 35 - Esquema resumido da via bioquímica para a produção do colesterol e corpos cetônicos. As duas vias bioquímicas ocorrem paralelamente. 74

Figura 36 - Via bioquímica resumida para a produção do colesterol e corpos cetonicos.

A possível alteração do metabolismo pela presença do CLA e a influência da síntese do colesterol na formação da fosfocolina. .77

Figura 37 - Ponte salina entre o terminal carboxilato da porção da HMG (verde) e a

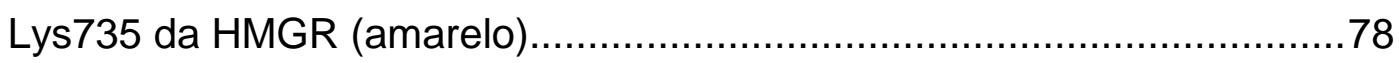

Figura 38 - Estrutura da Atorvastatina e da HMG, respectivamente. ......................79 Figura 39 - Posição ocupada pela atorvastatina (A) e o CLA (B) na enzima HMGR.

Figura 40 - Posição ocupada pelo CLA (vermelho) e pelo HMG-CoA (verde) na HMGR.

Figura 41- Hipótese da ligação do terminal carboxilato do CLA (verde) e a Lys735 da HMGR (amarelo). Interação similar entre o terminal carboxilato da porção da HMG e a Lys735 da HMGR.

Figura 42 - Ponte salina entre o terminal carboxilato da porção da HMG (laranja) e a Lys735 da HMGR (amarelo). Hipótese da ligação similar entre o terminal carboxilato do CLA (verde) e do ácido eicosanoide (magenta) e a Lys735. Posição do ácido miristico diferente dos demais compostos (Em destaque).

Figura 43 - Espectros de HR-MAS de células de câncer de mama (MCF-7) (A); espectro da mesma amostra (A) adquirido com HR-MAS e pré-saturação, de modo que o pico da água (4,7ppm) foi suprimido (B) e espectro de HRMAS com pré-saturação do sinal da água e CPMG, possibilitando melhor analise dos picos estreitos. Nos três espectros são apresentados apenas a componente real e foram obtidos com a $\mathrm{FT}$, processados no software ACD/NMR Processor 12.01.

Figura 44 - Espectros de HR-MAS processados por FDM, após a remoção dos picos do solvente, calculado em diferentes condições de filtro. (A) Picos com 
FWHI $>0,1 \mathrm{~Hz}$ foram negligenciados; (B) picos com $\mathrm{FWHI}<5 \mathrm{~Hz}$ foram negligenciados;(C) picos com $\mathrm{FWHI}>1 \mathrm{~Hz}$ ou $\mathrm{FWHI}<5 \mathrm{~Hz}$ foram negligenciados; (D) picos com $\mathrm{FWHI}<1 \mathrm{~Hz}$ e $\mathrm{FWHI}>5 \mathrm{~Hz}$ foram negligenciados. A soma dos espectros (B) e (C) resulta no espectro (A). 85 Figura 45 - Espectro processado por FDM de HR-MAS da Figura 44D na faixa de 0,75 a 3,1 ppm. Para comparação o espectro da Figura $43 \mathrm{C}$ foi reproduzido. . 86 


\section{Lista de tabelas}

Tabela 1- Distribuição proporcional dos dez tipos de câncer mais incidentes estimados para 2012.

Tabela 2 - Estrutura química e deslocamento químico $\left({ }^{1} \mathrm{H} \mathrm{e}{ }^{13} \mathrm{C}\right)$ para os metabólitos identificados nas células de câncer de mama MCF-7 e MDA-MB-231 ....59

Tabela 3 - Comparação das áreas dos sinais dos metabólitos intracelulares de células de câncer de mama (MCF-7) obtidos pelos dois métodos de normalização espectral.

60

Tabela 4 - Quantidade relativa de alguns importantes metabólitos identificados no espectro de HR-MAS das células MCF-7 e MDA-MB-231. Valores obtidos pela comparação do sinal normalizado da glicina $(1,00)$. 63 


\section{Lista de abreviaturas e símbolos}

ACAT- acil-CoA:colesterol-acil-transferase

ATP- trifosfato de adenosina

$\mathrm{CG}$ - cromatografia gasosa

CLA - Ácido Linoléico Conjugado

CDP- cytidine diphosphate

CMP- cytidine monophosphate

CoA- coenzima A

COSY- Correlation spectroscopy

CPMG - Carr- Purcell- Meiboom-Gill

CTP-phosphocholine cytidylyltransferase

DNA- Ácido Desoxirribonucléico

DMEM- (meio de cultura) Modified Dulbecco's Minimum Medium

EPA - ácido eicosapentanóico

ER - receptores de estrogênio

FDM- Filter Diagonalization Method

FID- Free induction decay

FWHI- Full Width at Half Intensity

HMG-CoA- hidroxi-metil-glutaril-CoA

HMBC- Heteronuclear multiple bond correlation spectroscopy

HMDB- Human Metabolome Database

HMGR- hidroxi-metil-glutaril-redutase

HR-MAS -High Resolution Magic Angle Spinning

HSQC- Heteronuclear single-quantum correlation spectroscopy

IARC- International Agency for Research on Cancer

INCA - Instituto Nacional do Câncer

KEGG- Kyoto Encyclopedia of Genes and Genomes

lb- Line Broadening

LDH- lactato desidrogenase

LDL- Low-density lipoprotein

MRS- Ressonância magnética in vivo

NAD- nicotinamida dinucleotídeo

NADP- nicotinamida adenina dinucleotídeo fosfato 
OMS- Organização Mundial da Saúde

p 53- proteína p53

PSB - (solução tampão) phosphate buffered saline

PUFAs- ácidos graxos poliinsaturados

RMN- Ressonância Magnética Nuclear

RMN 2D- Ressonância Magnética Nuclear Bidimensional

RPM- rotações por minuto

SREBPs- proteínas de ligação do elemento regulador de esterol

SFB- soro fetal bovino

SMPDB- Small Molecule Pathway Database

$\mathrm{T}_{2}$ - tempo de relaxação transversal

TMSP-d4- 3- (trimetilsilil)2,2,3,3-d4-propionato de sódio

TF - Transformada de Fourier 


\section{INTRODUÇÃO}

Apesar do grande progresso no diagnóstico precoce do câncer e do aprimoramento nas terapêuticas utilizadas, esta doença ainda é considerada devastadora com alto índice de mortalidade. A estimativa para o ano de 2012, válida também para o ano de 2013, apontava a ocorrência de aproximadamente 518.510 novos casos de câncer no Brasil'1. Os tipos mais incidentes são os cânceres de próstata e de pulmão, nos indivíduos do sexo masculino, e os cânceres de mama e do colo do útero, nos indivíduos do sexo feminino. Dessa forma, a abordagem sobre essa questão e ferramentas para diagnósticos tornam-se cada vez mais imprescindíveis.

A grande dificuldade encontrada no tratamento do câncer é o fato de que as células doentes podem se adaptar e sobreviver às terapias utilizadas, levando à resistência ao tratamento. Desta forma, a espectroscopia de Ressonância Magnética Nuclear (RMN) é uma importante técnica que fornece informações das condições fisiológicas e bioquímicas em ambas as condições in vitro e in vivo. O metabolismo de células intactas e tecidos pode ser analisado de forma contínua, sendo a técnica de RMN uma ferramenta para análise de forma não-destrutiva, permitindo a detecção de mudanças desses metabólitos de forma quase instantânea.

A análise metabólica de culturas celulares possui muitas aplicações potenciais e vantagens em relação aos métodos que atualmente são utilizados para testes em linhagem celulares. As concentrações dos metabólitos representam marcadores sensíveis tanto de mudanças genéticas quanto as fenotípicas. Dessa forma, com base em plataformas metabólicas, há várias aplicações da análise de cultura celulares, incluindo a compreensão das ações de drogas tanto in vitro quanto in vivo e também sua rápida incorporação aos novos ajustes terapêuticos².

A metabolômica também pode ser usada em pesquisas da biologia tumoral pela determinação molecular ou etiologia metabólica, identificando, por exemplo, as mudanças metabólicas que sejam a base para a metástase, contribuindo assim para melhoria do prognóstico e diagnóstico realizado. A compreensão das mudanças metabólicas que acompanham o crescimento tumoral, redução de apoptose e aumento na proliferação são também aspectos importantes. Adicionalmente, a caracterização da resposta do perfil metabólico do paciente aos agentes 
quimioterápicos pode conduzir a estratégias mais efetivas e personalizadas para conter o crescimento do tumor ${ }^{3}$.

A metabolômica possui várias aplicações na área farmacêutica, tendo como principal destaque as pesquisas para seleção de compostos (fármacos) efetivos e seguros, bem como a identificação de marcadores biológicos de toxicidade ${ }^{4}$. $\mathrm{Na}$ seleção de compostos efetivos e seguros, utiliza-se na maioria dos casos o ensaio in vitro. Esta aplicação pode ser elucidada, por exemplo, na análise de um composto que vem sido estudado exaustivamente quanto as suas propriedades benéficas à saúde humana, o ácido linoleico conjugado (CLA), estudado neste trabalho.

\section{1 Ácido linoleico conjugado (CLA)}

O ácido linoleico conjugado ou CLA (do inglês, conjugated linoleic acid) é uma mistura de isômeros posicionais e geométricos do ácido linoleico, C 18:2, cis-9, cis-12 (Fig.1A). O CLA tem o mesmo comprimento de cadeia que o ácido linoleico (C18), no entanto, no CLA as duplas ligações são conjugadas, sem a separação pelo grupo metileno, como ocorre no ácido linoleico.

O CLA é encontrado na natureza na carne de animais ruminantes, bem como no leite e seus derivados e tem potenciais efeitos benéficos na saúde humana, entre eles, a possível ação contra alguns tipos de cânceres.

A gordura de ruminantes (bovinos, ovinos, caprinos) contém muitos isômeros de CLA, correspondendo a cerca de $1 \%$ do total dos ácidos graxos. O isômero cis-9, trans-11 CLA (Fig. 1B) é o isômero predominante, representando 75 a 90\% do total de CLA na gordura de ruminantes, seguido pelo trans-10, cis-12 CLA (Fig. 1C) que corresponde de 3 a $5 \%$ do total de CLA ${ }^{5}$. Portanto, a carne de ruminantes e produtos laticínios (leite, manteiga, iogurte e queijo) são as principais fontes naturais de CLA da dieta humana 6 . 
Figura 1 - Estruturas do ácido linoleico (A) e de seus isômeros cis-9, trans-11(B) e trans-10, cis-12 CLA (A) (B) (B) (C)

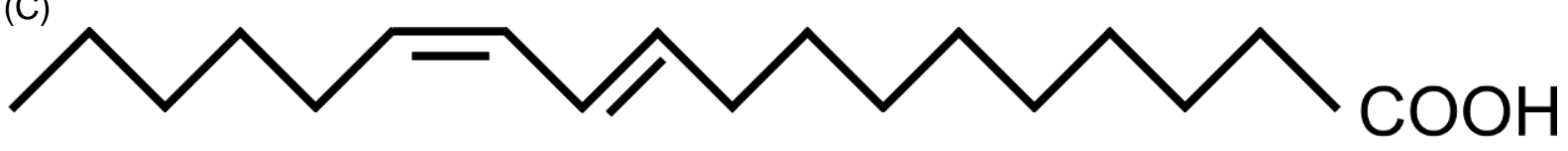

\subsubsection{Síntese do CLA no rúmen}

O CLA pode ser produzido sinteticamente ou no organismo de animais ruminantes. Origina-se especialmente da isomerização e/ou biohidrogenação dos ácidos graxos poliinsaturados pelas bactérias presentes no rúmen e da dessaturação do ácido graxo trans vacênico no tecido adiposo e glândula mamária (Fig. 2) ${ }^{7}$.

A primeira transformação que ocorre no rúmen após o animal ingerir o alimento é a hidrólise das ligações ésteres das moléculas de triglicerídeos (Fig. 2A) pelas lipases microbianas ruminais para a produção dos ácidos graxos livres e a molécula de glicerol. A segunda transformação é a biohidrogenação dos ácidos graxos poliinsaturados (Fig. 2B). Como se pode observar na Figura 20 isômero cis-9, trans11 CLA (Fig. 2C) é um intermediário da biohidrogenação do ácido linoleico a ácido trans-vacênico (C 18:1 trans-11) e, eventualmente, a ácido esteárico (C 18:0) ${ }^{8}$.

A redução do ácido trans-vacênico (C 18:1 trans-11) para o ácido esteárico (C 18:0) parece ser o passo limitante da biohidrogenação (Fig. 2D), tendendo a se acumular no rúmen. O composto $\mathrm{C}$ 18:1 trans-11 é absorvido pelo trato digestivo e transportado pela circulação para os tecidos (inclusive glândulas mamárias), onde é originada a forma cis-9, trans-11 CLA pela ação da enzima $\Delta 9$ dessaturase ${ }^{8}$ (Fig. 2E).

Dessa forma, a presença de CLA no leite e na carne de animais ruminantes se deve ao desvio da molécula cis-9, trans-11 CLA da completa biohidrogenação ruminal e a absorção do ácido graxo C 18:1 trans-11 nos tecidos com posterior síntese de 
CLA pela ação da enzima $\Delta$ 9-dessaturase (via 1 e 2 no esquema da Figura 2), respectivamente.

Figura 2 - Metabolismo lipídico no rúmen e a origem do CLA na carne de ruminantes.

Lipídios da dieta (especialmente triglicerideos)

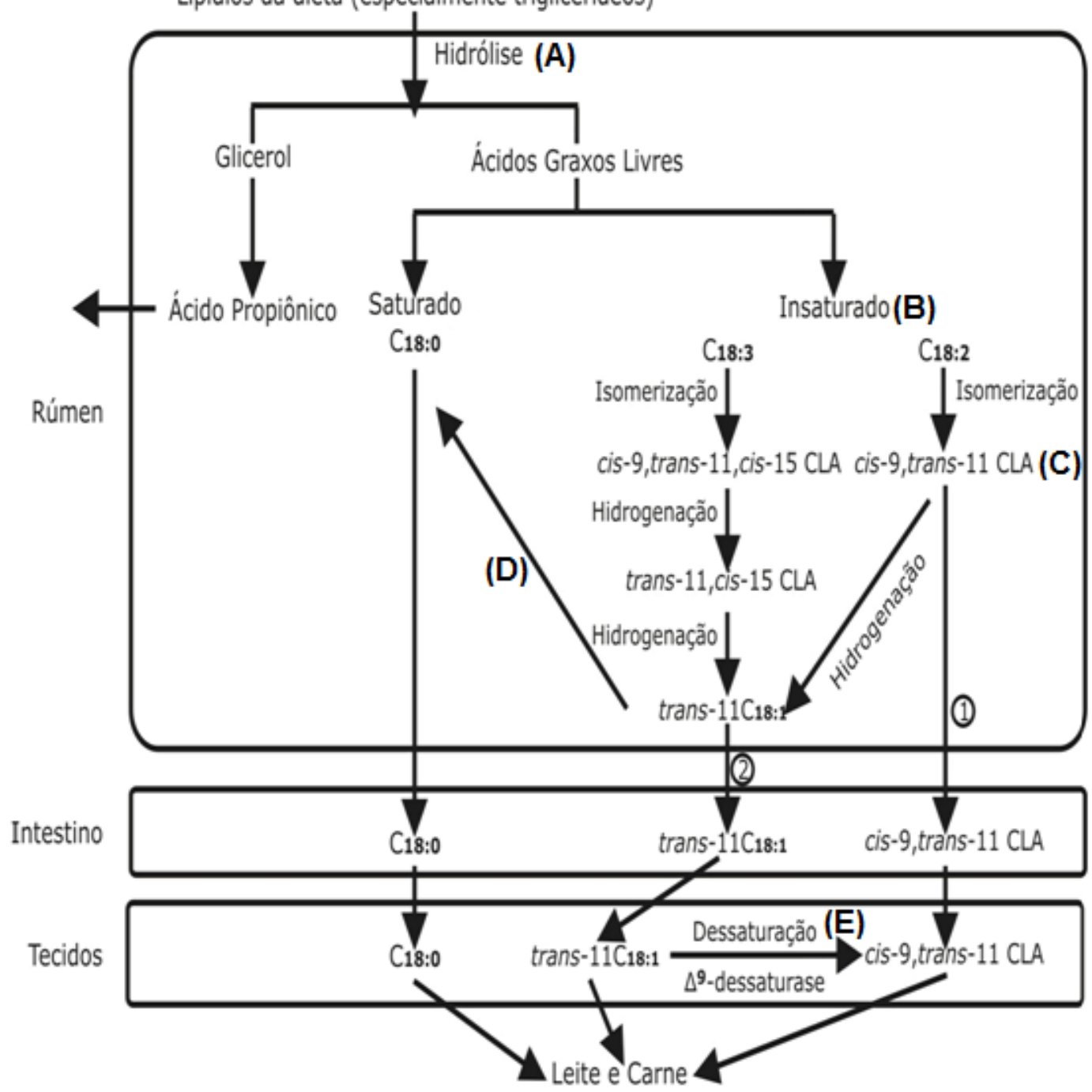

Fonte: TANAKA, K. Occurrence of conjugated linoleic acid in ruminant products and its physiological functions. Animal Science Journal. v.76. p. $301,2005^{9}$.

\subsubsection{Técnicas de análise do CLA}

O método padrão para análise de CLA é a análise dos ésteres metílicos dos ácidos graxos por cromatografia gasosa $(\mathrm{CG})^{10}$. Este método envolve várias etapas, sendo um método laborioso e demorado, considerando que o tempo para análise cromatográfica pode chegar até a uma hora. Para isso desenvolveu-se um método 
rápido para a determinação do teor do CLA na gordura de carne bovina, baseado na técnica de ressonância magnética nuclear de hidrogênio (RMN de $\left.{ }^{1} \mathrm{H}\right)(\mathrm{Fig} .3)^{11}$.

$\mathrm{Na}$ Figura 3, pode-se observar o espectro de RMN de uma amostra de gordura bovina contendo cerca de 1\% de CLA (Fig. 3A) e do isômero cis-9, trans-11 CLA padrão (Sigma-Aldrich) (Fig. 3B). Os sinais dos hidrogênios das duplas ligações conjugadas do CLA podem ser observadas na região de 5,00 a 6,50 ppm (Fig. 3). No espectro $B$ da Figura 3, pode-se perceber os quatro sinais dos hidrogênios insaturados da amostra pura do isômero cis-9, trans-11 CLA. O CLA foi quantificado pela integração das áreas dos sinais de 6,30 a 5,90 ppm, usando o sinal do glicerol em 4,20 ppm como padrão interno com a área relativa igual a 100 .

Figura 3 - Espectro de RMN de ${ }^{1} \mathrm{H}$ da gordura extraída do contra-filé (A) e a expansão da região de 5,0 a 6,5 ppm, na qual é possível observar os sinais característicos do CLA (B): na amostra analisada (acima) e na amostra padrão (abaixo).

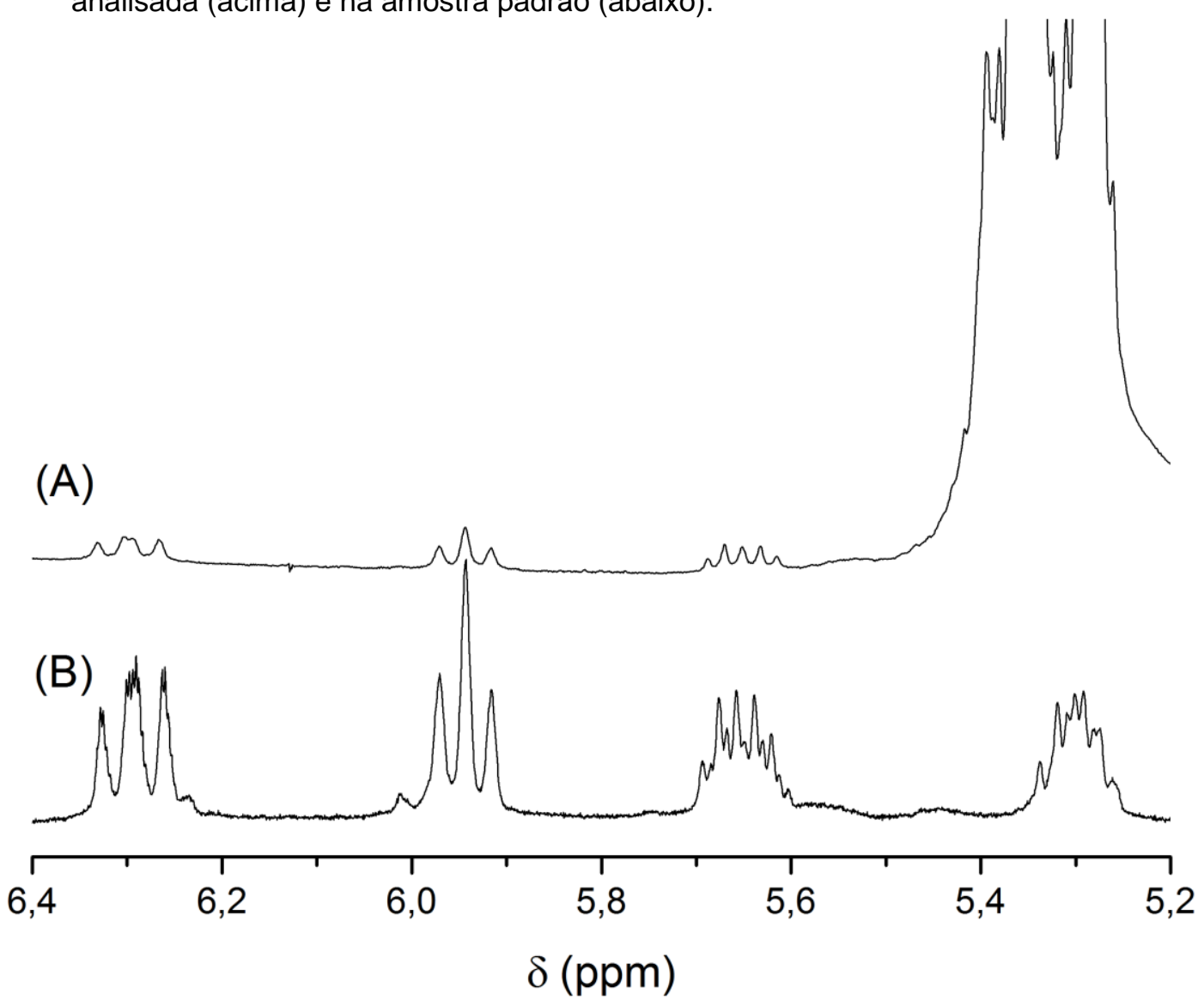

Fonte: MARIA,R.M.;COLNAGO,L.A.;FORATO,L.A.;BOUCHARD,D. Fast and Simple Nuclear Magnetic Resonance Method To Measure Conjugated Linoleic Acid in Beef. Journal of Agricultural and Food Chemistry.p.6563, 2010 ${ }^{11}$.

A Figura 4 mostra a correlação obtida entre as áreas médias dos sinais de CLA de 6,30 a 5,90 ppm, normalizado pelo sinal do glicerol em 4,20 ppm (100) por RMN e o valor medido por CG. O coeficiente de correlação foi de 0,97 , para 12 amostras, 
indicando a capacidade da RMN de quantificar o CLA presente em amostras bovinas ${ }^{11}$.

Figura 4 - Correlação entre a quantidade de CLA em cortes cárneos analisado pelos métodos de CG e por ${ }^{1} \mathrm{H}$ RMN.

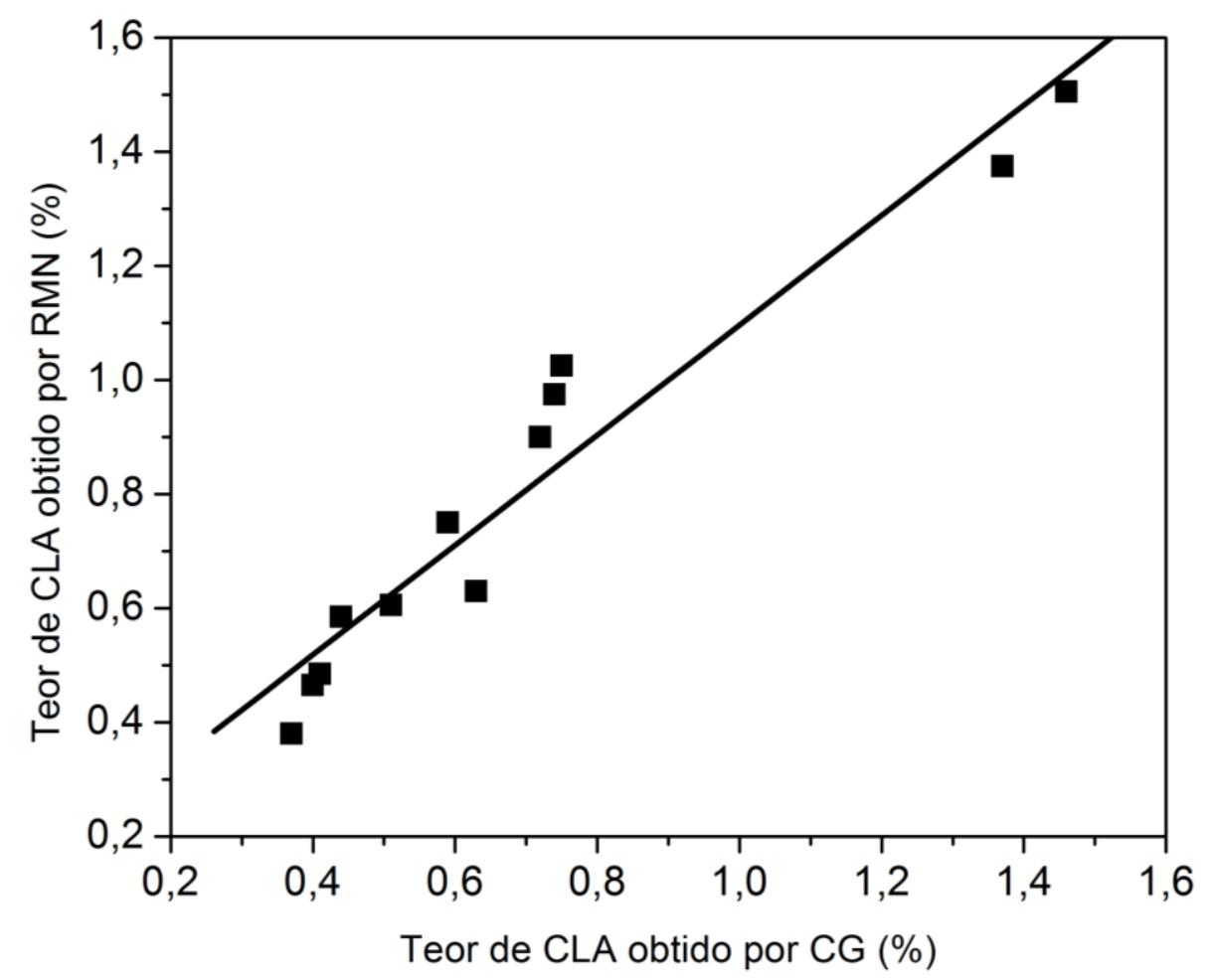

Fonte: MARIA,R.M.;COLNAGO,L.A.;FORATO,L.A.;BOUCHARD,D. Fast and Simple Nuclear Magnetic Resonance Method To Measure Conjugated Linoleic Acid in Beef. Journal of Agricultural and Food Chemistry.p.6563, 201011.

Os resultados mostraram que a utilização da RMN para a determinação do teor de CLA em carne bovina, além de ser coerente com os dados obtidos por cromatografia gasosa, representa uma abordagem mais rápida (minutos) e simples para a determinação do teor de CLA em carne bovina, uma vez que pode ser feita diretamente na gordura extraída com clorofórmio deuterado $\left(\mathrm{CDCl}_{3}\right)^{11}$.

\subsubsection{Efeitos fisiológicos do CLA}

O CLA tem sido relatado como substância nutracêutica que atua sobre o câncer, doenças cardiovasculares, diabetes entre outras ${ }^{12}$. Embora esses resultados derivem 
de experimentos com animais, esta é uma área de grande interesse de pesquisa, pois os resultados com humanos ainda não são conclusivos $^{12}$.

Foi observado que o ácido linoleico conjugado diminui a gênese de tumores em animais. Estudos mostram que o CLA inibe o desenvolvimento de tumores na epiderme e estômago de ratos, bem como câncer de mama em ratazanas ${ }^{13}$. Não há estudos suficientes contendo dados epidemiológicos em humanos, porém muitos estudos em animais têm mostrado a relação dose-resposta com a quantidade de CLA na ração e a extensão do crescimento tumoral ${ }^{13}$.

O acúmulo preferencial do CLA em lipídios neutros de adipócitos, células características do tecido mamário, explica, em parte, a sensibilidade dos tumores da glândula mamária ao efeito do CLA. Segundo o autor, um "efeito parácrino" em relação ao crescimento das células epiteliais ocorre com o depósito do CLA nos adipócitos, sendo os dois isômeros (cis-9, trans-11 e o trans-10, cis-12) envolvidos nesse processo $^{14}$.

A quantidade ótima de CLA ingerida precisa ser estabelecida. Foi sugerido que 95 mg de CLA por dia são suficientes para mostrar efeitos positivos na redução de câncer de mama em mulheres. Por outro lado, a partir de estudos com ratos ${ }^{15}$, a quantidade de $350 \mathrm{mg}$ de CLA diários seriam necessários para promover benefícios na saúde humana. Todos esses valores representam estimativas aproximadas e são baseados principalmente em estudos com animais. Deste modo, eles devem ser interpretados cautelosamente até que informações de análise em humanos estejam disponíveis ${ }^{16}$.

Estudos com tumores de animais mostraram que o consumo de CLA alcança considerável benefício no câncer de próstata e de mama. Em estudos com células cancerosas, estes ácidos graxos puderam inibir a proliferação celular e induzir a célula à morte. Neste caso, o CLA aumentou a regulação dos sinais celulares na expressão dos genes responsáveis pela indução da apoptose (morte celular programada) em células cancerígenas de mama e de próstata em humanos. Os dados encontrados sustentam os efeitos anticancerígenos do CLA encontrado em animais modelos e indicam efeitos similares que podem ocorrer em humanos ${ }^{17}$.

A partir da presença da mistura de isômeros do CLA na alimentação de animais experimentais, observou-se que a indução da tumorigênese nas mamas, pele e cólon foi quimicamente reduzida. Muitos isômeros do CLA são metabolizados, sugerindo que esses compostos devem ser importantes agentes anticancerígenos. $O$ 
mecanismo de inibição da carcinogênese parece incluir redução da proliferação celular, alterações nos componentes do ciclo celular e indução da apoptose ${ }^{18}$.

O CLA inibiu a tumorigênese mamária em animais e atenuou, tanto em animais quanto em humanos, a proliferação celular do câncer. Foi observada a determinação da modulação do efeito do CLA na expressão do maior proto-oncogene que regula a proliferação celular e a apoptose em células tumorais de mama ${ }^{9}$.

A apoptose oferece proteção contra a carcinogênese via morte programada das células. A dieta com CLA induziu a apoptose em numerosos tecidos e em cultura de células mamárias epiteliais. Isto devido a indução da apoptose associada com a redução do bcl-2, uma proteína relacionada com a sinalização para a morte celular programada 9 .

A linhagem de células do câncer de mama, MCF-7, tratadas com isômeros do CLA foi analisada e a ocorrência de mudanças nas características morfológicas e a fragmentação no DNA confirmaram a apoptose. Os dados encontrados sugerem que a incorporação do CLA na membrana mitocondrial induz à mediação da apoptose na célula e pode realçar o efeito anti-proliferativo do CLA em células MCF-720.

O CLA é um poderoso agente anticâncer em inúmeros sistemas de modelos tumorais, embora, o mecanismo de ação permaneça indescritível. O isômero trans10, cis-12 CLA dispara a apoptose via p53 modificado nas células tumorais da mama através do caminho mitocondrial, tendo como alvo o bcl-2 (genes que inibem a apoptose atuando no bloqueio de liberação do citocromo c pela mitocôndria) ${ }^{21}$.

Relatos do efeito do CLA sobre a angiogênese também têm sido abordados. A angiogênese, que normalmente acompanha a proliferação celular, é a formação de novos capilares a partir de pequenos vasos sanguíneos preexistentes que promovem o crescimento do tumor ${ }^{22}$.

Os isômeros cis-9, trans-11 e trans-10, cis-12 CLA foram efetivos na inibição da angiogênese in vitro de forma dose-dependente. A capacidade do CLA na inibição da angiogênese deve contribuir com eficácia como um agente preventivo ${ }^{23}$.

Além disso, resultados indicam que a administração de CLA reduziu significativamente a angiogênese no cerebelo. Os autores relataram o primeiro estudo sobre o efeito anti-angiogênico do CLA no cérebro, e sugerem que o CLA deve ser explorado no tratamento terapêutico para câncer e tumores no cérebro ${ }^{24}$.

Fica claro que várias mutações, translocações, amplificações e deleções podem contribuir para o desenvolvimento do câncer, e que esta variedade mutacional pode 
diferir entre tumores idênticos histopatologicamente. No entanto, atualmente torna-se claro que muitas vias importantes de sinalização oncogênicas convergem para a adaptação do metabolismo celular para suportar o crescimento celular, bem como sua sobrevivência ${ }^{25}$. A partir disto, este trabalho de doutorado enfatiza que é necessário que as alterações do metabolismo celular sejam também consideradas como marcadores cruciais do câncer.

\subsection{Metabolismo de células sadias e tumorais}

Todas as células do corpo humano precisam constantemente de suprimento externo de oxigênio e nutrientes. A energia é necessária para todas as funções celulares, como a contração muscular e comunicação neural ${ }^{26}$. No entanto, os nutrientes externos não são a única fonte para a produção desta energia necessária. Há também um processo constante de reciclagem de componentes de proteínas e membranas, principalmente para adaptação a novas situações. Para compreender as mudanças metabólicas que serão apresentadas a seguir, é necessário descrever resumidamente as principais rotas metabólicas celulares.

\subsubsection{Metabolismo da glicose}

A D-glicose é o principal combustível da maioria dos organismos e ocupa uma posição central no metabolismo. Quando as demandas energéticas aumentam subitamente, a glicose pode ser liberada rapidamente do armazenamento intracelular e ser empregada para produzir ATP de maneira aeróbica ou anaeróbica. Na glicólise, uma molécula de glicose é degradada em uma série de reações catalisadas por enzimas para liberar duas moléculas do composto piruvato ${ }^{26}$. Durante as reações da glicólise, parte da energia liberada da glicose é conservada na forma de ATP e NADH. O piruvato formado pela glicólise pode tomar três rotas catabólicas alternativas:

- em organismos ou tecidos em condições aeróbicas, a glicólise constitui o primeiro estágio da degradação completa da glicose. O piruvato é oxidado, com perda de seu 
grupo carboxila como $\mathrm{CO}_{2}$, para liberar o grupo acetila da acetilcoenzima $\mathrm{A}$, a qual é então totalmente oxidada a $\mathrm{CO}_{2}$ pelo ciclo do ácido cítrico. Os elétrons originados dessas oxidações são passados para o oxigênio por meio de uma cadeia de transportadores na mitocôndria, formando a água. A energia liberada nas reações de transferência de elétrons permite a síntese de ATP nas mitocôndrias ${ }^{26,27}$.

- em condições anaeróbicas, o piruvato é reduzido a lactato através da fermentação do ácido láctico. Em condições de hipóxia (baixa pressão de oxigênio) o NADH não pode ser reoxidado a $\mathrm{NAD}^{+}$, e este é necessário como receptor de elétrons para que o piruvato continue ser oxidado. Assim, o piruvato é reduzido a lactato por recepção dos elétrons do $\mathrm{NADH}$ e consequente regeneração do $\mathrm{NAD}^{+}$necessário para que o fluxo glicolítico prossiga.

- o piruvato pode ser convertido anaerobicamente em etanol e $\mathrm{CO}_{2}$, em um processo chamado fermentação alcoólica.

O fluxo de glicose através da via glicolítica é regulado para manter constante a concentração de ATP. Para isso, este ajuste é obtido através da regulação das enzimas fosfofrutoquinase, hexoquinase e piruvato quinase. Estas enzimas são reguladas alostericamente o que reflete o equilíbrio celular entre a produção e o consumo de ATP.

Vale ressaltar que o piruvato também pode ter destinos anabólicos, podendo, por exemplo, fornecer esqueleto carbônico para a síntese do aminoácido alanina ${ }^{27}$.

\subsubsection{Efeito Pasteur}

A velocidade da fermentação e a quantidade total de glicose consumida são maiores em condições anaeróbicas do que em condições aeróbicas, fenômeno conhecido como Efeito Pasteur. Isto porque, o rendimento em ATP da glicólise em condição anaeróbica (2 ATP por molécula de glicose) é muito menor que o obtido na oxidação completa da glicose até $\mathrm{CO}_{2}$ e $\mathrm{H}_{2} \mathrm{O}$ em condição aeróbica (30 a 36 ATP por molécula de glicose). Portanto, para produzir a mesma quantidade de ATP é necessário consumir perto de 18 vezes mais glicose em condições anaeróbicas do que nas condições aeróbicas ${ }^{27}$. 


\subsubsection{Efeito Warburg}

De uma maneira peculiar, mesmo em concentrações adequadas de oxigênio, as células cancerosas produzem energia preferencialmente pela glicólise anaeróbica ${ }^{28}$ em detrimento a fosforilação oxidativa mitocondrial. A primeira identificação de anormalidade bioquímica em oncogenes foi identificada em 1920 por Otto Warburg ${ }^{28}$. Conhecido desde então como Efeito Warburg, este fenômeno consiste no deslocamento da glicose da fosforilação oxidativa para a glicólise "aeróbica", indicando que os tumores exibem metabolismo anaeróbico (produção do lactato através da glicólise) mesmo na presença adequada de oxigênio.

Em células tumorais, o transporte de glicose para dentro da célula é aumentado através de transportadores de glicose na membrana celular ${ }^{29}$.

O piruvato pode ser então metabolizado diretamente para lactato pela ação da lactato desidrogenase (LDH). Como dito anteriormente, o fluxo da glicólise é regulado alostericamente para manter constante a concentração de ATP. No caso de células tumorais, as mudanças metabólicas são relatadas por alterações das atividades cinéticas das enzimas. Por exemplo, o aumento da produção do lactato é acompanhado pelo aumento da atividade das enzimas chaves da glicólise, como a hexoquinase 1 e 2, fosfofrutoquinase, aldolase, piruvato quinase e a LDH. Em adição à super atividade de enzimas da glicólise, a baixa atividade de enzimas relacionadas ao ciclo do ácido cítrico é reportada, como por exemplo, a inibição da piruvato dehydrogenase ${ }^{29}$.

\subsubsection{Metabolismo dos fosfolipídios de membrana}

A característica central na arquitetura das membranas biológicas é uma dupla camada de lipídios que atua como uma barreira à passagem de moléculas polares e íons. Os glicerofosfolipídios, o principal componente lipídico das membranas biológicas, possuem regiões hidrofóbicas que são compostas por dois ácidos graxos ligados ao fosfoglicerol. A fosfatidilcolina, um tipo de glicerofosfolipídio, tem a colina como grupo polar da cabeça da estrutura ${ }^{26}$. 


\subsubsection{Via Kennedy}

Como dito anteriormente, a fosfatidilcolina é um dos principais constituintes dos glicerofosfolípidios da membrana celular. No câncer, o metabolismo da fosfatidilcolina é caracterizado pela elevação da fosfocolina e dos componentes contendo colina. Este aumento da fosfocolina, observado em células tumorais, não indica apenas uma produção de fosfolipídios aumentada, necessária para a proliferação celular, mas também representa o resultado da ativação de enzimas no ciclo da fosfatidilcolina, resultado das alterações genéticas mediada pelas vias de sinalização celular. A biossíntese de novo da fosfatidilcolina ocorre através das etapas da via Kennedy, em que a colina é fosforilada para fosfocolina pela ação da colina quinase. A fosfocolina é convertida em CDP-colina e esta é então incorporada para fosfatidilcolina ${ }^{29}$ (Fig. 5).

Moléculas chaves são alteradas no metabolismo da colina no câncer. A principal causa molecular do aumento da fosfocolina e dos componentes contendo colina em células tumorais inclui o aumento da expressão da atividade da colina quinase (Fig. $5 A$ ), a alta taxa do transporte de colina e aumento da atividade da fosfolipase $C$ e $D$ (Fig. 5B), e várias fosfolipases $A_{2}$ (Fig. $5 C$ ). Estas alterações fazem com que ocorram significativas diferenças no metabolismo da colina em células tumorais, diferenciandoas das células normais. Como exemplo, a glicerofosfocolina é predominante em células não malignas de mama e ovário, enquanto que a significativa presença da fosfocolina é observada em células de câncer de mama e ovário ${ }^{30,31}$.

As análises de RMN de células tumorais revelaram que a concentração de fosfocolina em tecidos tumorais de mama é maior quando comparado a tecido normais deste mesmo tecido, demonstrando que este metabólito representa um biomarcador de transformação malignas em câncer de mama ${ }^{32}$. 
Figura 5 - Via bioquímica do metabolismo dos fosfolipídios de colina (Via Kennedy).

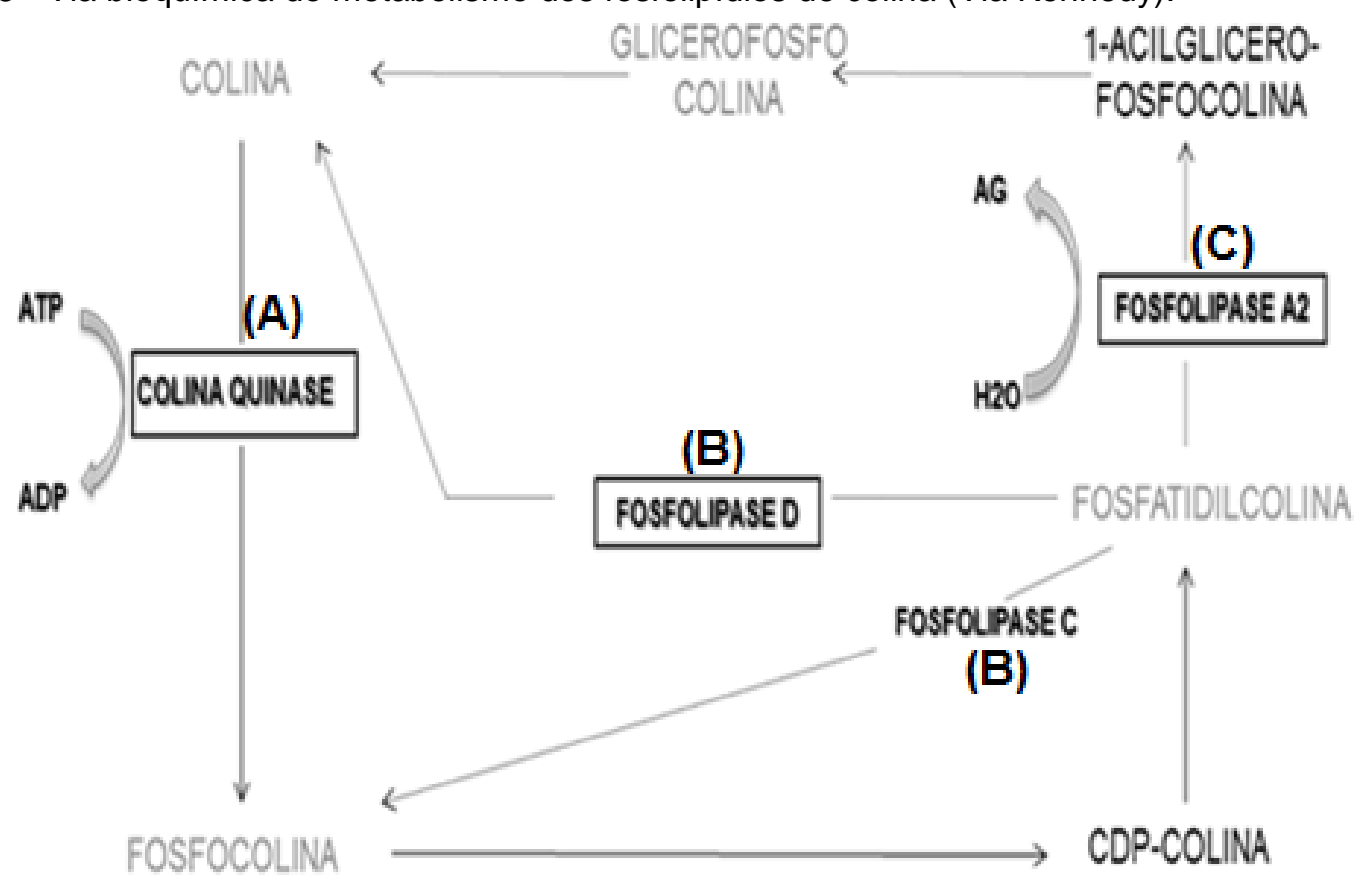

Fonte: MERZ,A.L.;SERKOVA,N.J. Use of nuclear magnetic resonance-based metabolomics in detecting drug resistance in cancer. Biomark medicine. p.300,200929.

\subsubsection{Colesterol: Membranas celulares e Hormônios}

O colesterol é um constituinte vital das membranas celulares, elementar para o crescimento e proliferação celular, acompanhando muitos processos de diferenciação ${ }^{33}$, sendo também um precursor dos hormônios esteroides bem como dos ácidos biliares. Em um organismo sadio, o equilíbrio é mantido entre a biossíntese, utilização e o transporte de colesterol ${ }^{27}$.

A biossíntese de colesterol percorre uma rota extensa, porém basicamente, moléculas de acetato são convertidas em unidades de isopreno, as quais são condensadas para formar uma molécula linear com 27 carbonos, que se cicliza, formando a estrutura de quatro anéis do colesterol ${ }^{27}$.

No entanto, é fundamental ser abordado que todo o controle do metabolismo do colesterol, desde a biossíntese ao transporte, é regulado por alguns fatores, tais como: controle da taxa da síntese de receptor de LDL através das proteínas de ligação do elemento regulador de esterol (SREBPs), pela taxa de esterificação de colesterol pela acil-CoA:colesterol-acil-transferase (ACAT) e principalmente pela atividade da hidroximetilglutaril(HMG) - CoA redutase ${ }^{33}$. 
A HMG-CoA redutase (HMGR) é a enzima limitante da biossíntese de colesterol e, consequentemente, o principal ponto de regulação da rota. A HMG-CoA redutase é uma enzima de 887 resíduos ligada à membrana do retículo endoplasmático e o principal mecanismo de regulação é o controle em longo prazo, por retroalimentação da quantidade de enzima presente na célula. Quando os níveis de colesterol ou mevalonato caem, o nível de HMG-CoA redutase pode subir em até 200 vezes, devido a um aumento na síntese da enzima associado com uma diminuição na sua degradação ${ }^{34}$.

Como descrito anteriormente, a membrana lipídica requer uma atividade sincronizada de várias vias metabólicas que são orquestradas em múltiplos níveis. O principal meio para a coordenação global é centralizado na ação dos fatores de transcrição que diretamente expressam múltiplos genes necessários para a síntese lipídica. Dentro deste cenário, várias enzimas e reguladores da biossíntese de lipídios são alvos de quinases, cuja atividade auxilia a sinalização dos fatores de crescimento para o metabolismo lipídico, controle do ciclo celular e status metabólico. 0 crescimento da membrana é mais observado em resposta à certas formas de estresse e/ou à capacidade espacial dos compartimentos celulares ${ }^{33}$.

Nos mamíferos, o colesterol também é o precursor metabólico dos hormônios esteróides, substâncias que regulam uma grande variedade de funções fisiológicas. Há cinco classes de hormônios esteroides: testosterona (andrógenos), estradiol (estrógeno); progesterona (progestina); cortisol (glucocorticóide) e aldosterona (mineralocorticóides). Assim, a disponibilidade adequada de substrato de colesterol é um requerimento crítico para ótima produção de hormônios esteroidais ${ }^{35}$.

Em destaque neste trabalho, está a classe dos estrógenos, que são sintetizados pelo ovário e pela placenta e, em pequena quantidade, pelos testículos e pelo córtex da supra-renal. Há três estrógenos endógenos nos humanos: estradiol, estrona e estriol, sendo o estradiol o mais potente e o principal estrógeno secretado pelo ovário. Destaca-se, em particular, o efeito estrogênico nas ações vasculares rápidas, iniciado pela interação com receptores de membrana ${ }^{30}$. 


\subsection{Metabolômica e o câncer de mama}

Desde o sequenciamento do genoma humano, o principal objetivo da genômica funcional tem sido determinar a função dos produtos dos genes identificados, bem como determinar aqueles que possam ser alvos terapêuticos ${ }^{36}$. A estratégia da genômica funcional tem centrado esforços principalmente em estudos da expressão gênica (transcriptoma) e do perfil proteico (proteoma). No entanto, a medida da concentração dos metabólitos de baixa massa molecular, in vivo e in vitro (metaboloma e/ou metabonoma), tem ganhado destaque recentemente, pois reflete 0 estado dinâmico do comportamento celular ${ }^{36}$.

O metaboloma é definido como a análise sistemática de todos os metabólitos de um organismo ou amostra biológica. Já o termo metabonoma está relacionado à análise da alteração dos metabólitos mediante condições de estresse, medicamentos, intervenção patofisiológica ou modificação genética ${ }^{37}$.

Embora as tecnologias "omas" sejam complementares, a análise dos metabólitos é uma abordagem especialmente útil, capaz de identificar as vias bioquímicas alteradas em determinadas doenças.

A metabolômica/metabonômica pode ser usada para monitorar o crescimento e regressão tumoral e pode auxiliar na compreensão dos mecanismos patológicos, bem como no efeito dos tratamentos do metabolismo celular. Esta estratégia apresenta inúmeras vantagens práticas, incluindo o preço relativamente baixo da análise por amostra e a automatização do procedimento, quando comparada ao transcriptoma e proteoma. Além disso, o metaboloma/metabonoma pode ser facilmente comparado entre espécies diferentes, já que muitos metabólitos permanecem conservados, enquanto que as sequências gênicas podem apresentar variações que dificultam comparações $^{29}$.

O câncer de mama é a segunda causa de morte em mulheres no mundo 1 . Embora o tratamento desta doença em estágio inicial seja eficaz, principalmente com quimioterapia e radioterapia, não existem terapias eficazes para o tratamento do câncer quando em estágios avançados. Neste estágio há um tratamento paliativo para diminuição dos sintomas, bem como para a melhoria de qualidade da sobrevida da mulher. 
Apesar da comprovada eficácia dos medicamentos utilizados atualmente, casos de intolerância e insucesso são recorrentes ${ }^{1}$. Isto porque, a grande dificuldade encontrada no tratamento do câncer é o fato de as células doentes se adaptarem e sobreviverem às terapias utilizadas, levando à resistência a terapêutica. Além disso, a quimioterapia aplicada no tratamento da doença utiliza medicamentos para destruir as células doentes que formam o tumor, no entanto, a farmacodinâmica fica comprometida, pois cada paciente pode responder de maneira diferente a um mesmo medicamento ${ }^{1}$.

Tabela 1- Distribuição proporcional dos dez tipos de câncer mais incidentes estimados para 2012.

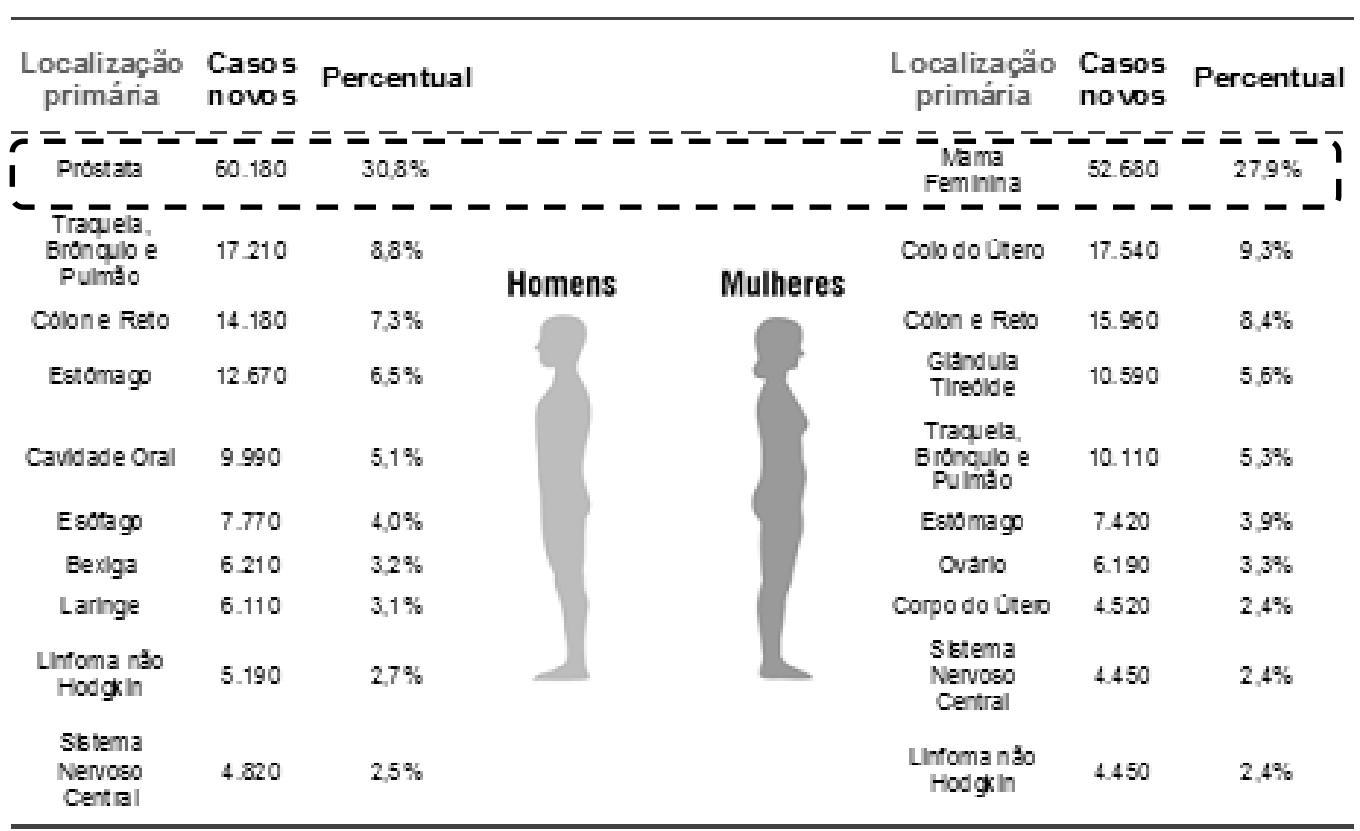

Fonte:INCA.Estatísticas do câncer. <http://www.inca.gov.br/estimativa/2012/>Acesso em :20 jun.2013.

Uma área de grande interesse na pesquisa médica e bioquímica tem sido a análise dos metabólitos envolvidos no processo tumoral, já que consiste em uma forma de análise dos processos celulares em geral. Esta área de pesquisa tem como objetivo o desenvolvimento de novos métodos de análise laboratorial, contribuindo tanto para o prognóstico precoce quanto o monitoramento preciso da terapêutica, pois a regulação metabólica está altamente intricada com a progressão tumoral. Consequentemente, o metabolismo das células influencia na morte ou vida celular.

Dentre estas ferramentas de análise de metabólitos, a espectroscopia de Ressonância Magnética Nuclear (RMN) vem se tornando uma técnica de grande destaque, pois fornece informações das condições fisiológicas e bioquímicas tanto in vitro quanto in vivo. Assim, a RMN foi utilizada neste trabalho para estudar 
principalmente o metabolismo de células intactas de câncer de mama submetidas ao CLA.

\subsection{RMN e metabólitos}

Técnicas de RMN têm sido empregadas para diferenciar linhagens tumorais e monitorar processos metabólicos que ocorrem nas células ${ }^{29,}{ }^{36}$, permitindo a análise simultânea de uma classe específica de componentes e dos principais metabólitos presentes dentro da célula. Com o uso da técnica da RMN, a análise pode ser realizada com o custo aproximado de um dólar por amostra, apresentando um tempo de aquisição analítica de aproximadamente 10 minutos $^{36}$.

A análise de extratos obtidos de tecidos por RMN em alta resolução tem sido largamente utilizada para distinguir diferentes linhagens celulares e tipos tumorais. A análise do perfil metabólico por RMN permite o monitoramento da atividade de inúmeros processos celulares, pois muitas vias metabólicas estão conectadas (Fig. 6). No entanto, o processo de análise de extratos, além de ser laborioso, demorado e impossibilitar a comparação histopatológica, pode também provocar alterações na composição original dos metabólitos envolvidos nas vias bioquímicas celulares ${ }^{38}$.

A técnica de RMN em alta resolução usando rotação no ângulo mágico HR-MAS (High Resolution Magic Angle Spinning) permite a obtenção de espectros em alta resolução mesmo de amostras heterogêneas, como células intactas ou tecidos ${ }^{40,41}$.

Essa abordagem tem inúmeras vantagens sobre a espectroscopia de RMN para análise de extratos, pois é um método não destrutivo e tanto os metabólitos aquosos quanto os lipídicos podem ser observados simultaneamente in situ.

A HR-MAS tem sido utilizada para monitorar os efeitos de vários agentes terapêuticos nas células tumorais tanto in vitro quanto in vivo ${ }^{36}$. Além disso, a análise metabolômica através dessa técnica também tem sido utilizada para estudar as mudanças que ocorrem nas células tumorais em condições de hipóxia, situação presente na maioria dos desenvolvimentos cancerígenos ${ }^{36}$. 
Figura 6 - A reprogramação metabólica das células tumorais. O metabolismo é reorganizado para aumentar as reações anabólicas ligadas ao crescimento e proliferação celular.

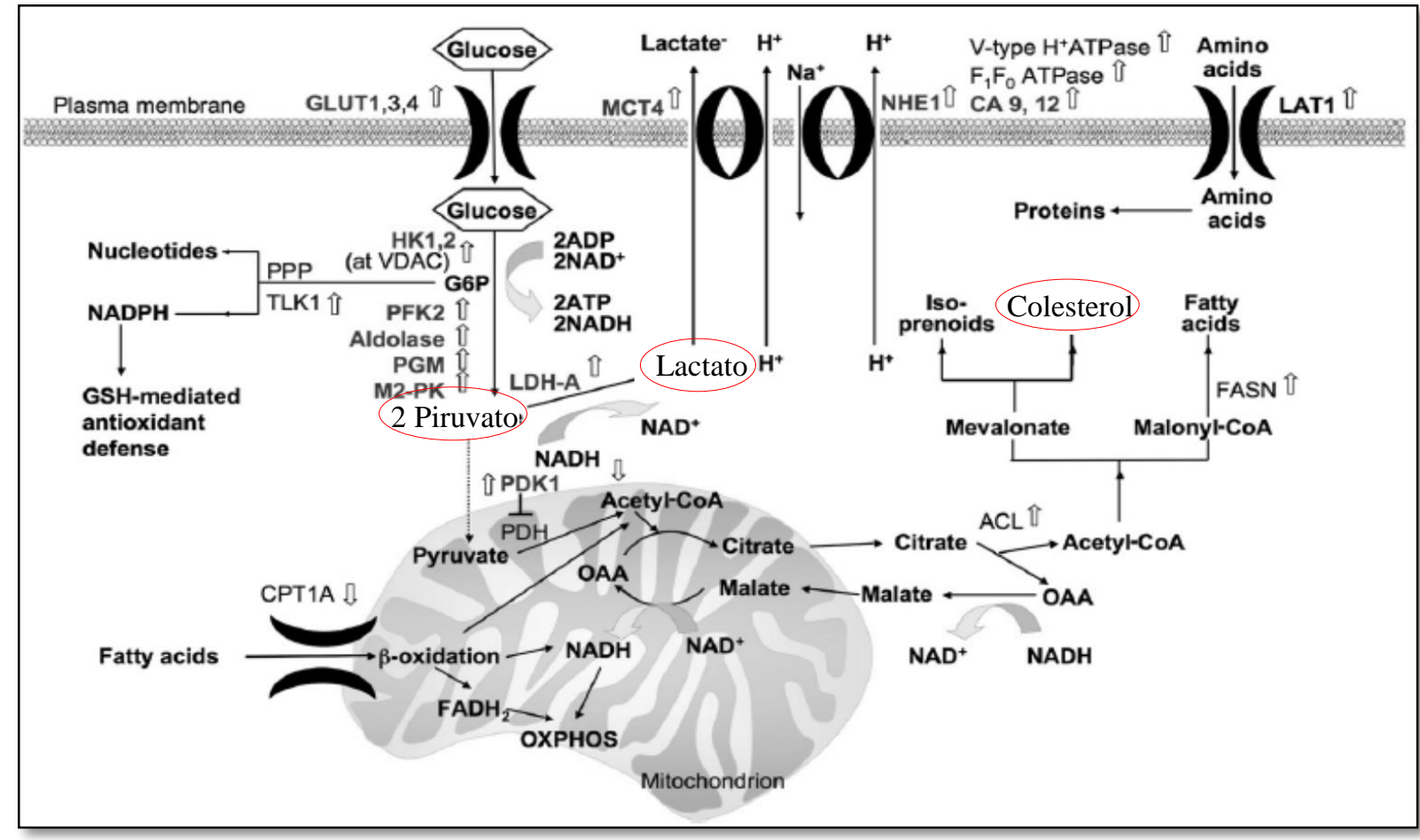

Fonte: KROEMER G.; POUYSSEGUR J. Tumor cell metabolism: Cancer's Achilles'Heel. Cell Press.p.473, 2008 ${ }^{39}$.

\subsection{RMN em alta resolução com rotação no ângulo mágico (HR-MAS)}

Os espectros de RMN de amostras sólidas ou heterogêneas obtidos com os métodos convencionais possuem resolução espectral muito limitada devido a fatores relacionados ao movimento molecular restrito ${ }^{42}$.

Para aumentar a resolução espectral, tem sido aplicada a técnica de rotação rápida da amostra, em altas velocidades, em torno do ângulo de 54,74 (ângulo mágico), que é denominada de MAS (Magic Angle Spinning). A técnica MAS reduz drasticamente $\mathrm{o}$ alargamento de linhas causado pelo acoplamento dipolar, anisotropia do deslocamento químico, bem como os efeitos da diferença de susceptibilidade magnética, proveniente da heterogeneidade da amostra ${ }^{43}$.

A técnica de HR-MAS alia as vantagens da RMN do estado sólido (MAS) às do estado líquido (lock e shimming). Assim, reduz a largura de linhas dos sinais em espectros de amostras heterogêneas, fornecendo uma resolução espectral semelhante àquela encontrada nos líquidos. A técnica HR-MAS vem sendo usada 
para aumentar a resolução espectral de amostras heterogêneas, como tecidos animais e vegetais ${ }^{41}$.

Acoplamento dipolar

O acoplamento dipolar, isto é, a interação direta entre os momentos magnéticos dos núcleos, consiste em um fenômeno no qual os spins nucleares interagem magneticamente através do espaço, sem nenhuma interação de outros átomos ou elétrons ${ }^{44}$. Isto significa que, dependendo da posição relativa entre dois núcleos, 0 campo magnético gerado pelo spin de um núcleo pode reforçar ou diminuir a força do campo magnético aplicado que o núcleo vizinho esta sujeito ${ }^{43}$. Em amostras que permitam o movimento molecular livre, por exemplo, no caso dos líquidos pouco viscosos, o movimento molecular rápido e isotrópico das moléculas faz com que os efeitos do acoplamento dipolar sejam eliminados. Em casos de amostras heterogêneas, em que a mobilidade molecular é restrita, os efeitos dos acoplamentos dipolares são observados, causando alargamento dos sinais espectrais.

\section{Deslocamento químico anisotrópico}

O deslocamento químico de um núcleo é dado pelos elétrons que o blindam em relação ao campo magnético aplicado. Dessa forma, o movimento aleatório das moléculas em solução faz com que uma frequência média (frequência isotrópica) seja observada para cada local químico distinto. No entanto, em amostras heterogêneas, nas quais existem restrições dos movimentos moleculares, os deslocamentos químicos anisotrópicos também causam alargamento das linhas, como resultado das diversas orientações das moléculas em relação ao campo magnético principal $\left(\mathbf{B}_{0}\right)$.

\section{A rotação da amostra no ângulo mágico}

A diferença entre os campos magnéticos locais, $\mathbf{B}_{\text {loc, experimentada por spins }}$ nucleares equivalentes, é a causa de o acoplamento dipolar e o deslocamento químico anisotrópico contribuírem para o alargamento dos sinais. Os campos magnéticos locais estão relacionados ao momento magnético dos spins nucleares segundo a equação:

Onde:

$$
\mathrm{B}_{\mathrm{loc}}= \pm \mu_{\mathrm{s}} r_{I S}^{-3}\left(3 \cos ^{2} \theta_{I S}-1\right)
$$




$$
\begin{aligned}
& \text { Boc }=\text { campo magnético local experimentado por um núcleo I } \\
& \mu_{\mathrm{S}}=\text { momento magnético do núcleo } \mathrm{S} \\
& r_{I S}=\text { distância intermolecular } \\
& \theta=\text { ângulo entre o vetor intermolecular e o campo } \mathrm{B}_{0}
\end{aligned}
$$

Assim como o acoplamento dipolar, o deslocamento químico anisotrópico é dependente do termo $3 \cos ^{2} \theta-1$ e quando o ângulo $\theta$ for igual a $54,74^{\circ}$, este termo torna-se zero e o campo local (Bloc) é anulado ${ }^{43}$.

Dessa forma, se a amostra for inclinada e girar no ângulo 54,74을 (Fig. 7) em relação ao campo magnético principal $\left(\mathbf{B}_{0}\right)$, os efeitos de acoplamento dipolar e deslocamento químico anisotrópico podem ser eliminados e consequentemente, o efeito do campo magnético local ( $\left.\mathbf{B}_{\text {loc }}\right)$.

Figura 7 - Esquema do giro do rotor no ângulo mágico (sonda HR-MAS).

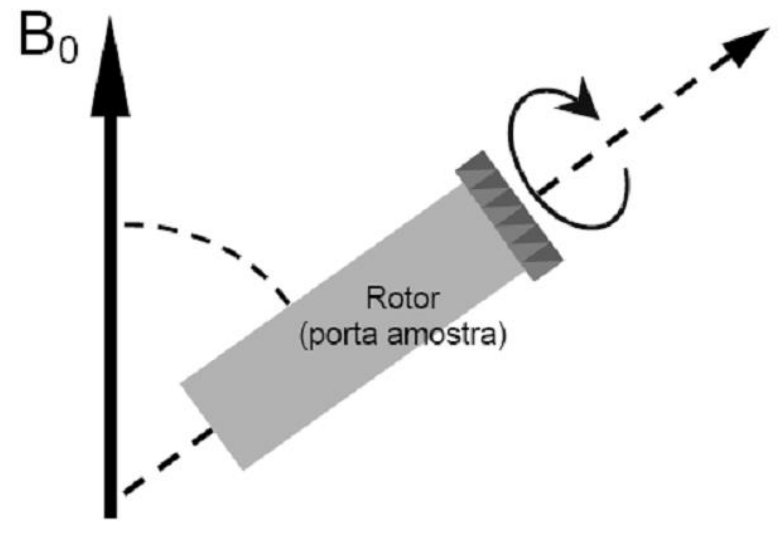

Para que a rotação no ângulo mágico supere os efeitos de deslocamento químico anisotrópico, a frequência de rotação deve ser ao menos comparável aos deslocamentos por anisotropia, em torno de $3-6 \mathrm{kHz}$ para amostras heterogêneas ${ }^{43}$.

\subsubsection{Supressão do sinal da água nos espectros de RMN de ${ }^{1} \mathrm{H}$}

Devido a sua alta abundância natural (em torno de 99\%) e a uma alta razão magnetogírica $(\gamma)$, o hidrogênio é um dos núcleos mais estudados por RMN.

Como amostras biológicas, mais especificamente células, possuem uma grande quantidade de água em relação aos metabólitos, seus espectros apresentam um sinal 
bastante intenso, referente aos hidrogênios da água, o qual se sobrepõe a sinais de menor intensidade dos metabólitos.

Além disso, a elevada intensidade do sinal da água interfere no ganho do receptor, pois o valor deste será baseado no sinal de maior intensidade, neste caso a água, e não nos analitos de interesse (metabólitos). Caso seja empregado o valor de ganho do receptor baseado nos sinais menos intensos, sem que haja a eliminação do sinal da água, haverá a saturação do detector gerando um "clipping" no FID e, após a transformada de Fourier, distorções na linha de base ${ }^{45}$.

Várias técnicas podem ser utilizadas para a supressão do sinal da água ${ }^{46}$, como a "jump-return" e a técnica utilizada neste trabalho de doutorado que é a présaturação, bastante utilizada devido a sua simplicidade.

\subsubsection{CPMG - Filtro de $\mathrm{T}_{2}$}

Embora os espectros obtidos com a técnica HR-MAS apresentem melhora na resolução espectral, as interações dipolares e a anisotropia do deslocamento químico das macromoléculas, membrana entre outros, não são totalmente eliminadas e por isso contribuem para o alargamento dos sinais. Para eliminar os sinais largos, que apresentam tempo de relaxação transversal $\left(\mathrm{T}_{2}\right)$ mais curto do que o $\mathrm{T}_{2}$ dos sinais estreitos, usa-se um filtro de $\mathrm{T}_{2}{ }^{45}$. O filtro de $\mathrm{T}_{2}$ mais usado na HR-MAS é a sequência CPMG (Carr-Purcell-Meiboom-Gill) ${ }^{45}$. Neste método aplica-se o trem de pulsos da sequência CPMG até que os sinais dos componentes com $\mathrm{T}_{2}$ curto desapareçam (ou sejam minimizados) e se possa adquirir o sinal dos componentes com $\mathrm{T}_{2}$ longo, ou seja, com linhas estreitas. Como durante o tempo de decaimento dos sinais largos também ocorre o decaimento dos sinais estreitos, demonstraremos neste trabalho que os procedimentos de supressão do sinal da água e filtro de sinais largos com CPMG podem ser desnecessários quando utilizado o método de diagonalização filtrado FDM (Filter Diagonalization Method) para processar os sinais no domínio do tempo, como os obtidos a partir de experimentos de HR-MAS com células de câncer de mama. 


\subsubsection{Estudos metabólicos com HR-MAS}

Estudos de tecidos intactos com a HR-MAS vêm sendo realizados desde 1996. A HR-MAS com filtro de $T_{2}$ foi usada para avaliar o comportamento dos nódulos linfáticos axilares saudáveis e dos metastáticos, na tentativa de detectar a presença de células malignas infiltradas. $\mathrm{O}$ espectro de $\mathrm{RMN}$ de ${ }^{1} \mathrm{H}$ HR-MAS para a detecção das mudanças químicas celulares devidas à presença do tumor pode ser obtido em poucos minutos. Este método melhorou a detecção dos metabólitos presentes em baixas concentrações e em tecidos com mobilidade restrita ${ }^{47}$.

Um ano depois, em 1997 publicou-se o primeiro estudo analisando tecido humano. Neste trabalho, a HR-MAS proporcionou significativa melhora na resolução espectral tanto em RMN unidimensional (1D) quanto bidimensional (2D) para análise de espectros de lipoma (benigno) e lipossarcoma (maligno), possibilitando uma análise mais detalhada da composição lipídica destes tecidos quando comparados a métodos de RMN sem MAS. Este estudo colaborou com a análise da composição lipídica do tumor e demonstrou a expressiva importância da técnica nesta área ${ }^{48}$.

Em 1998, realizou-se um estudo preliminar em tumores cerebrais humanos. Estes autores corroboraram que é possível melhorar consideravelmente a resolução espectral de tecidos intactos usando HR-MAS e também correlacionar o status da doença com os resultados espectroscópicos obtidos a partir das análises de tecidos. Para os autores, o método de análise usado possui vantagens como: tempo reduzido de análise, diferentemente da análise histopatológica; preservação da estrutura do tecido intacta durante as medidas; produção de resultados de relevância fisiológica, ao contrário da extração química; e medição de um volume variável de tecido ( $\mu \mathrm{L}-\mathrm{mL}$ ). Além disso, a HR-MAS foi útil para resolver espectros de ${ }^{1} \mathrm{H}$ em diferentes tipos de tumores cerebrais e as medidas do metabolismo tumoral obtidas por HR-MAS mostraram ter fortes implicações para a compreensão da biologia celular e para o desenvolvimento de novas metodologias de diagnóstico do tumor ${ }^{49}$.

Também no ano de 1998, foram analisados com HR-MAS carcinomas mamários humanos de um grupo de mulheres. A técnica apresentou capacidade para analisar com alta resolução espectral o metabolismo celular de tecido intacto removido cirurgicamente. Nestas análises, o método de HR-MAS se mostrou uma ferramenta 
rápida e objetiva para analisar a evolução tumoral e para diferenciar o tecido normal do carcinoma através do metabolismo celular distinto ${ }^{41}$.

Em 2001, amostras de próstata humana foram analisadas, comparando a relação dos níveis de espermina (poliamina envolvida no metabolismo celular) com o crescimento do câncer de próstata. Estabeleceu-se uma relação entre os níveis de espermina e as células epiteliais prostáticas normais, possibilitando explorar a possível relação entre o mecanismo deste metabólito com as células sadias, bem como com as tumorais 50 .

No ano de 2008, os biomarcadores metabólicos como lactato e alanina no câncer de próstata foram investigados usando a HR-MAS. Este estudo demonstrou a baixa concentração destes metabólitos em biopsias de tecidos benignos de próstata, enquanto que a concentração de ambos os metabólitos aumentou quando na presença do tumor ${ }^{51}$.

Em 2011, a técnica de HR-MAS demonstrou ser promissora na compreensão das mudanças ocorridas nas células durante o estresse celular e em sua morte in vitro, revelando alterações metabólicas durante estes processos. Estas alterações, segundo os autores, podem contribuir para melhorar a eficácia do tratamento in vivo ${ }^{52}$.

Neste contexto, a espectroscopia de RMN tem se mostrado uma importante ferramenta analítica, fornecendo informações das condições fisiológicas e bioquímicas in vitro e in vivo. O metabolismo de células e tecidos intactos pode ser analisado de forma contínua, sendo a técnica de RMN não invasiva, esta permite a detecção instantânea das alterações metabólicas. É, portanto, uma alternativa eficiente no monitoramento do crescimento e da regressão tumoral, possibilitando a compreensão dos mecanismos celulares e auxiliando no desenvolvimento de novas abordagens terapêuticas.

Desta forma, a análise metabolômica por meio de HR-MAS é uma abordagem promissora para identificação dos biomarcadores, os quais podem ser usados de forma não invasiva para monitorar as terapias anticâncer, particularmente aquelas indutoras de apoptose. 


\section{OBJETIVOS}

O principal objetivo desta tese de doutorado foi avaliar o efeito do ácido linoleico conjugado no perfil metabólico de células intactas de câncer de mama, usando a técnica de RMN denominada de HR-MAS.

As metas desse trabalho foram:

-Estabelecer um protocolo confiável para o cultivo e crescimento das células de câncer de mama;

-Aperfeiçoar o método de preparo para análise por HR-MAS;

-Analisar as amostras intactas de células de câncer de mama por HR-MAS;

-Identificar os metabólitos presentes nas amostras através de experimentos bidimensionais e bases de dados online;

-Correlacionar os metabólitos encontrados com as vias bioquímicas distintas;

-Analisar o perfil metabólico das células tumorais mediante condição de estresse (falta de oxigênio e nutrição adequado);

-Analisar o perfil metabólico das células de câncer de mama submetidas à diferentes concentrações de CLA;

-Identificar as possíveis modificações do metabolismo celular mediante o tratamento com CLA e

-Avaliar o processamento dos dados de HR-MAS, no domínio do tempo, pelo método de diagonalização filtrada (FDM) como alternativa aos métodos tradicionais de supressão do sinal da água, filtro de $T_{2}$ e transformada de Fourier. 


\section{MATERIAIS E MÉTODOS}

As amostras de células de câncer de mama, MCF-7 e MDA-MB-231, foram cedidas pelo grupo do Prof. Dr. Adriano D. Andricopulo, do Laboratório de Química Medicinal e Computacional - Centro de Biotecnologia Molecular Estrutural, IFSC USP.

\subsection{Cultivo celular}

Neste trabalho foram analisadas duas linhagens celulares de câncer de mama, a MCF-7 e a MDA-MB-231. Na Figura 8 estão as imagens microscópicas das células das duas linhagens. A linhagem MCF-7 possui diversas características de um epitélio mamário diferenciado, incluindo a habilidade de processar o estradiol por meio de receptores de estrogênio citoplasmático $\left(E R^{+}\right)$e capacidade de formação de nódulos ${ }^{53}$. A linhagem MDA-MB-231, por sua vez, não possui receptores de estrogênio (ER) e se apresenta pouco diferenciada, isto é, não forma nódulos (Fig. 8).

Figura 8 - Imagens microscópicas das células de câncer de mama com receptores de estrogênio, MCF7 (esquerda) e células de câncer de mama sem receptores de estrogênio, MDA-MB- 231 (direita).
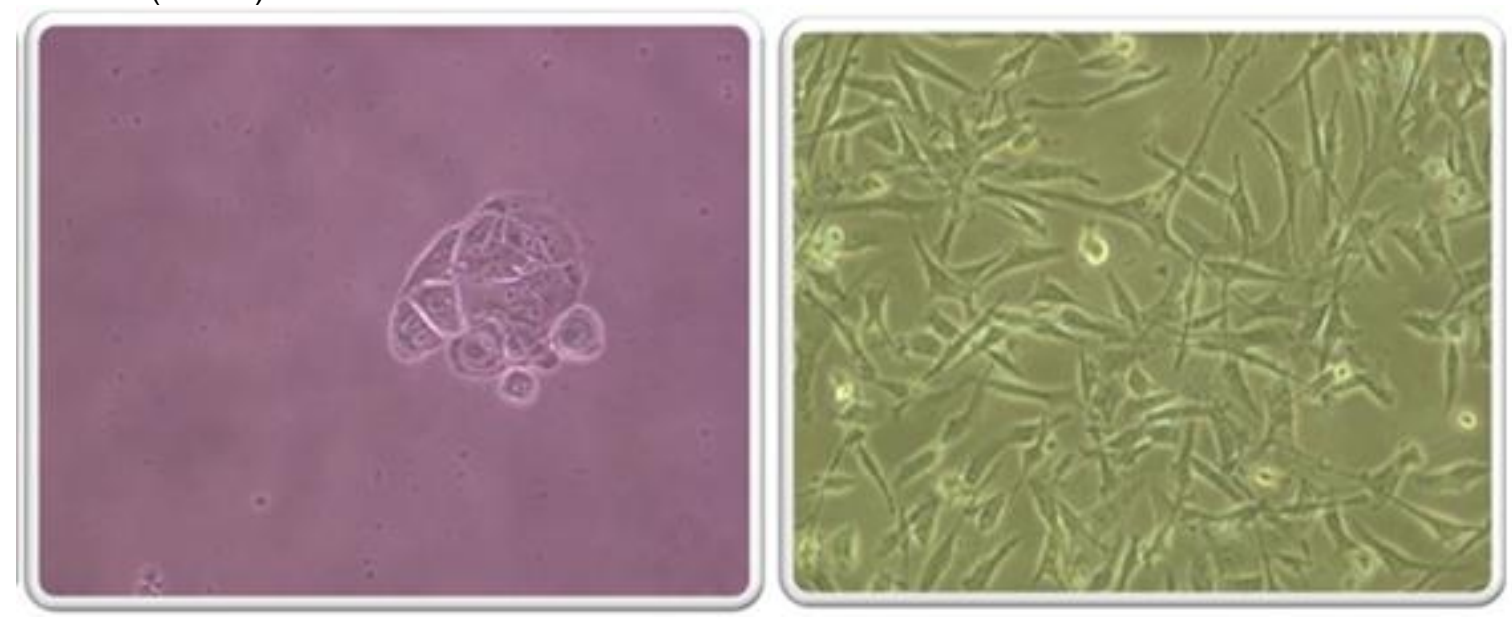

As duas linhagens celulares foram cultivadas em meio DMEM (modified Dulbecco's Minimum Medium - Cultilab), suplementado com 10\% de soro fetal bovino (Cultilab). As culturas celulares foram mantidas a $37^{\circ} \mathrm{C}$ com $5 \%$ de $\mathrm{CO}_{2}$ e as células 
aderidas à superfície da garrafa de cultura, BD FalconTM $75 \mathrm{~cm}^{2}$ (Fig. 9A) em que cresceram na forma de monocamada (Fig. 9B).

Após as células ficarem aderidas à superfície da garrafa, retirou-se o meio de cultura. Em seguida as células foram lavadas com $8 \mathrm{~mL}$ de uma solução tampão PBS (2M NaCl, 2M KCl, 0,2 $\mathrm{M} \mathrm{Na}_{2} \mathrm{HPO}_{4}, 1 \mathrm{M} \mathrm{KH}_{2} \mathrm{PO}_{4}$ ). Para a coleta das células, foi necessário incubá-las por 2 minutos em uma solução de tripsina em PBS (1:3). Após a tripsinização, meio de cultura foi adicionado à garrafa para inativar a tripsina e evitar danos às células. Em seguida, a suspensão celular foi centrifugada a 1500 rpm por 5 minutos (Eppendorf 5702) e o meio de cultura foi aspirado com os devidos cuidados para que o pellet não se desfizesse (Fig. 9C). O pellet foi ressuspenso em água deuterada e centrifugado novamente a $1000 \mathrm{rpm}$ por 5 minutos, para assim formar 0 pellet que foram usadas nas análises por RMN.

Figura 9 - Esquema do processo de preparação das células para formar o pellet celular. (A) Garrafa de cultura utilizada para o crescimento celular. (B) Fotomicrografia de uma monocamada de células tumorais. (C) Pellet celular para análise em RMN.

(A)

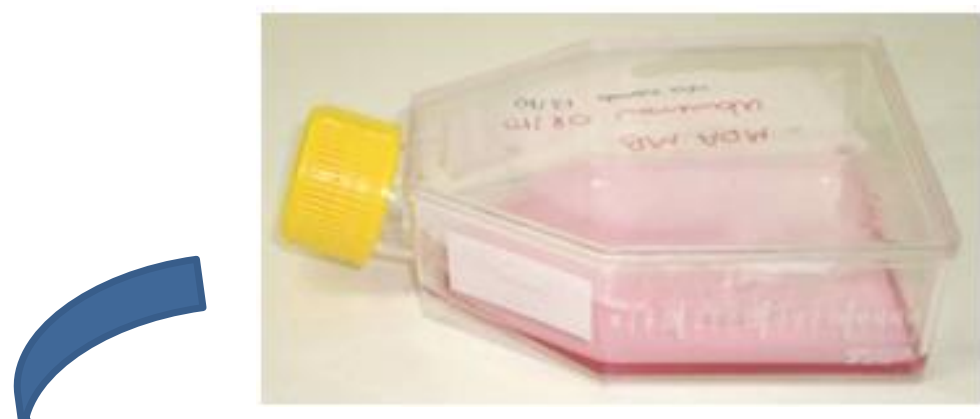

(C)
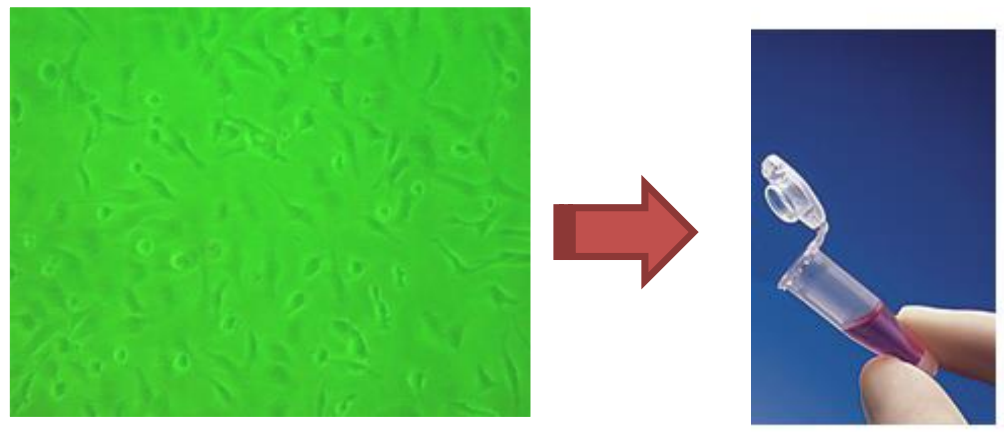

(B)

Para a análise da viabilidade celular, as células foram coradas com Trypan Blue e analisadas em câmara de Neubauer (hemocitomêtro) (Fig. 10), o que permitiu a visualização das células intactas, condição necessária para a análise metabolômica por RMN. 
Figura 10 - Câmara de Neubauer, utilizada para a contagem de células, permitindo o cálculo do volume necessário da suspensão celular para a obtenção da concentração desejada. Neste caso, é possível a visualização das células de câncer de mama, MCF-7, intactas.

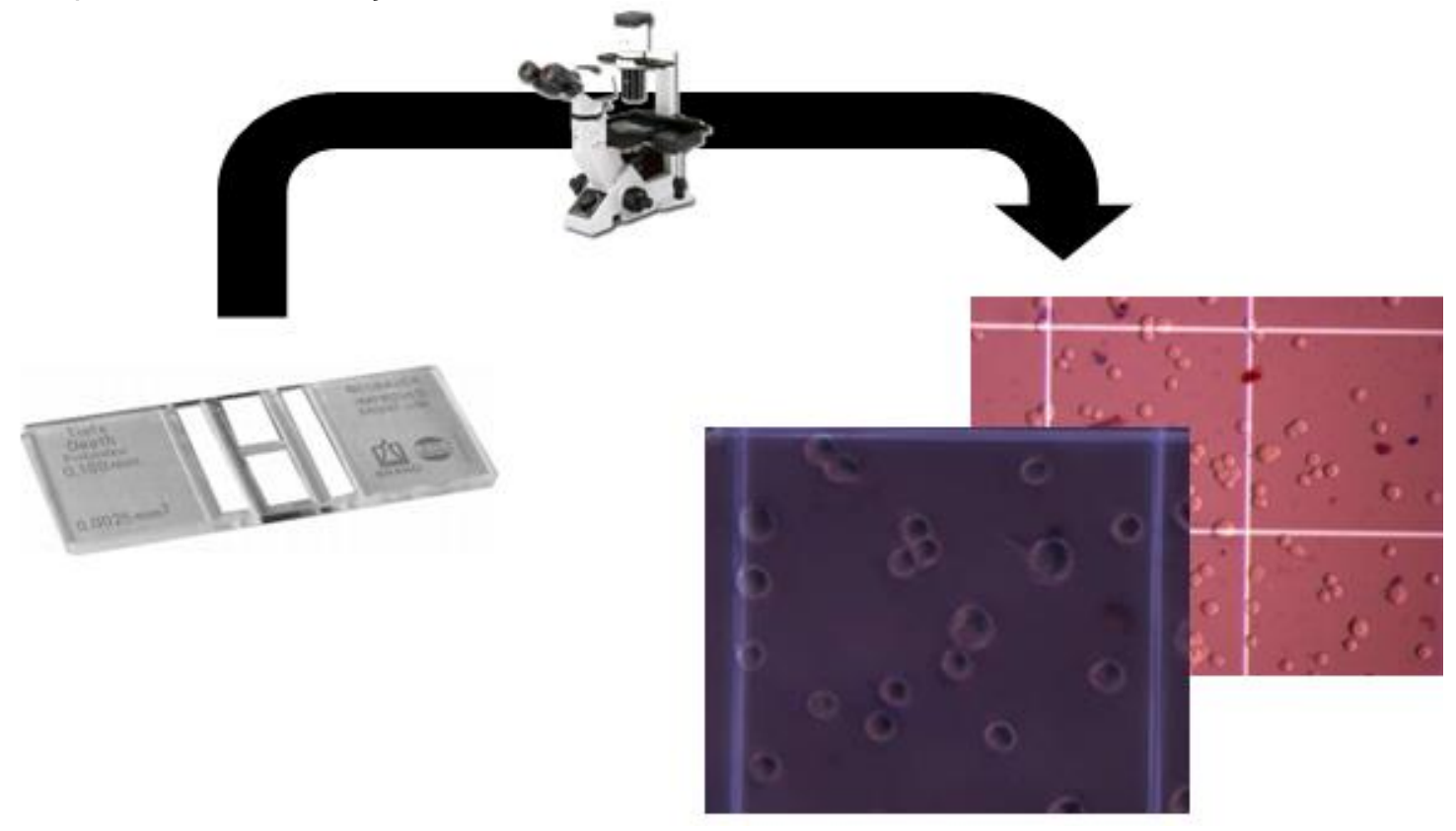

\subsubsection{Cultivo Celular com CLA}

Para obter os meios de cultura suplementados com CLA, foi preparada uma solução estoque de CLA (1 mM) em soro fetal bovino (SFB). Esta solução foi filtrada em filtro 0,22 $\mu$ m e diluída nos meios de cultura DMEM e L-15 para soluções contendo 50 e $100 \mu \mathrm{M}$ de CLA. Antes dos experimentos, os meios de cultura foram suplementados com 10\% de SFB. As células de MDA-MB-231 e MCF-7 foram cultivadas separadamente em três garrafas de cultura de $75 \mathrm{~cm}^{2}$ em uma densidade inicial de aproximadamente de $1,4 \times 10^{6} \mathrm{cels} / \mathrm{mL}$. Após três dias em estufa a $37^{\circ} \mathrm{C}$ e $5 \% \mathrm{CO}_{2}$, o meio de cultura das células foi trocado pelo meio sem e com CLA nas concentrações $(50 \mu \mathrm{M}$ e $100 \mu \mathrm{M})$. Após três dias de exposição ao CLA, as células foram tripsinizadas, centrifugadas, ressuspensas em água deuterada e recentrifugadas. As células precipitadas foram então submetidas às análises por RMN. Este procedimento foi aplicado para as três concentrações diferentes de CLA, para as duas linhagens celulares. As análises para investigar o efeito do CLA nas células tumorais foram realizadas em quadruplicada. 


\subsection{Análise por Ressonância Magnética Nuclear}

As análises de HR-MAS foram realizadas em uma sonda dual ${ }^{1} \mathrm{H} /{ }^{13} \mathrm{C}$ HR-MAS, no espectrômetro DRX 400 BRUKER de 9,4 Tesla $(400,21 \mathrm{MHz}$ para a frequência do hidrogênio) a uma temperatura de $23^{\circ} \mathrm{C}$, com detecção inversa e gradiente de campo na coordenada z. A rotação da amostra foi de $5 \mathrm{KHz}$. Estes experimentos foram realizados no Departamento de Química da Universidade Federal de São Carlos (UFSCar).

Utilizaram-se rotores de zircônia de $4 \mathrm{~mm}$ de diâmetro externo, com a adição de volume total do rotor $(50 \mu \mathrm{L})$, de uma solução de TMSP-d4 (3-(trimetilsilil)2,2,3,3-d4propionato de sódio) em $\mathrm{D}_{2} \mathrm{O}$ para a calibração dos espectros e ajuste da homogeneidade do campo magnético principal, respectivamente. Neste caso, a amostra ficou contida entre o rotor e um espaçador, que possui um orifício para que o excesso de amostra fosse eliminado. Após a inserção do espaçador, foi fixado um parafuso, a fim de garantir que a amostra não fosse expelida durante a aquisição. Finalmente, tampou-se o rotor com uma tampa seccionada, o que fez com que o rotor girasse na velocidade adequada (Fig. 11).

Antes das aquisições realizadas com as células tumorais, foram realizadas análises da presença de impurezas no rotor utilizando uma solução de TMSP-d4 (3(trimetilsilil)2,2,3,3- $\mathrm{d}_{4}$-propionato de sódio) em $\mathrm{D}_{2} \mathrm{O}$. Em todos os casos somente os sinais referentes ao sinal da água e o padrão utilizado foram observados.

Figura 11 - Rotor e acessórios utilizados para a sonda HR-MAS no espectrômetro DRX 400 BRUKER. (1- rotor; 2 - espaçador; 3- parafuso; 4- tampa seccionada; 5- parafuso).

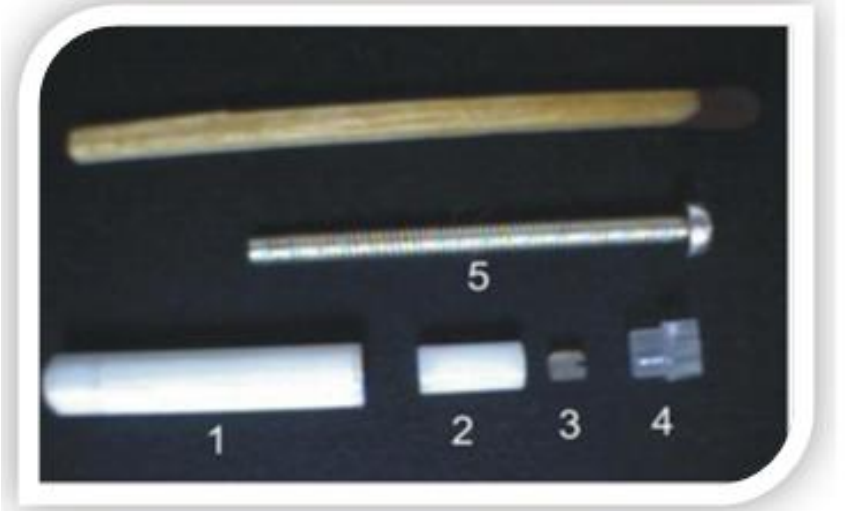

Fonte: Tese Lucinéia Vizzotto. Universidade Federal de São Carlos. 


\subsubsection{Método de supressão do sinal da água}

Os espectros de HR-MAS obtidos inicialmente foram realizados com a sequência padrão de hidrogênio, no entanto, devido à abundante quantidade de água presente nas amostras, tornou-se necessário a utilização da sequência para suprimir o sinal da água. Neste trabalho de doutorado foi utilizada a de pré-saturação. Esta é a sequência mais amplamente utilizada devido a sua simplicidade, consistindo apenas na aplicação de um pulso seletivo longo (Fig.12) e de baixa potência na frequência do sinal que se deseja suprimir. Isto faz com que ocorra a saturação dos níveis de população dos spins e, consequentemente, as transições dos estados de spins não são observadas. Após este pulso, é aplicado outro mais curto e de alta potência para, em seguida, fazer-se a aquisição dos sinais de interesse.

Neste caso, os espectros de ${ }^{1} \mathrm{H}$ foram adquiridos utilizando-se um pulso de présaturação de $1,5 \mathrm{~s}$ com tempo de aquisição de $4,63 \mathrm{~s}$, 32k pontos em uma janela espectral de $7062,15 \mathrm{~Hz}$ e com 128 transientes.

\subsubsection{CPMG- Filtro de $\mathrm{T}_{2}$}

O método mais comum para se obter um filtro de tempos de relaxação $\left(T_{2}\right)$ é a utilização de sequências de pulsos denominada CPMG (Carr-Purcell-Meiboom-Gill) ${ }^{45}$.

Durante a aplicação dos pulsos da sequência CPMG, os sinais provenientes de macromoléculas e estruturas supramoleculares, em que o $T_{2}$ curto decaem mais rápido (resultando nas linhas largas) do que os sinais das moléculas pequenas, que tem $\circ \mathrm{T}_{2}$ longo (resultando nas linhas estreitas) podem ser minimizados. Com a escolha de um tempo de duração da sequência de pulso CPMG (Fig. 12) pode-se eliminar a contribuição dos sinais largos, deixando o espectro apenas com os sinais com menor largura de linha, que são os sinais de interesse. Na sequência CPMG usou um tempo de eco (otimizado para as análises realizadas neste trabalho) de 1,2 ms e 120 pulsos de refocalização em $\mathrm{Y}$, acumulados com 256 transientes. Para os espectros utilizados nas análises sequenciais (realizadas para análise do estresse celular) acumularam-se 512 transientes com um tempo total de aquisição de cerca de 
uma hora. O processamento desses espectros foi realizado com $32 \mathrm{k}$ pontos, acrescidos de uma multiplicação exponencial utilizando um fator $\mathrm{lb}=1 \mathrm{~Hz}$ e correção automática de linha de base.

Figura 12 - Sequência de pulsos usada para aquisição do sinal HR-MAS. A sequência tem o pulso de pré-saturação e um trem de pulsos da sequência CPMG, para eliminar o sinal intenso da água e sinais largos, respectivamente.

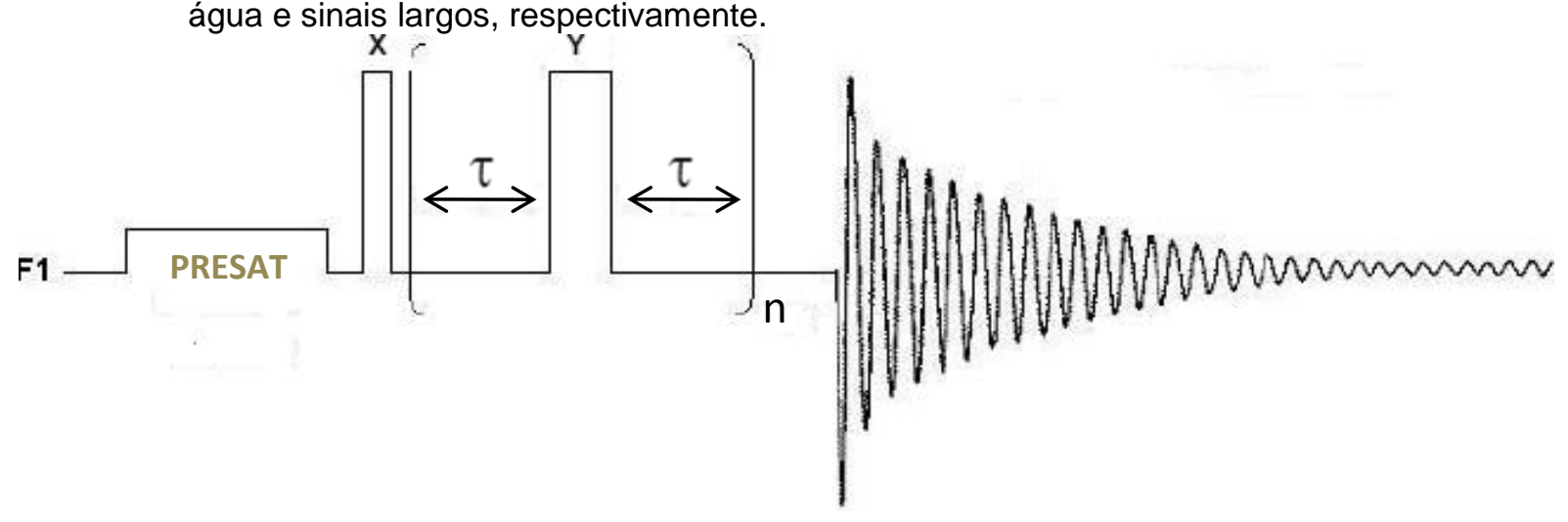

\subsubsection{RMN Bidimensional}

Para a identificação dos metabólitos, as células intactas de câncer de mama foram analisadas com técnicas bidimensionais, tais como: COSY (Correlation spectroscopy), HSQC (Heteronuclear single-quantum correlation spectroscopy) e HMBC (Heteronuclear multiple bond correlation spectroscopy). Devido à baixa concentração dos metabólitos intracelulares, estes experimentos foram adquiridos em um espectrômetro BRUKER (14,1Tesla), com uma frequência de ressonância para o ${ }^{1} \mathrm{H}$ de $600,233 \mathrm{MHz}$ e $150,943 \mathrm{MHz}$ para o ${ }^{13} \mathrm{C}$. Foram utilizados:

g-COSY : Para gerar a segunda dimensão, foram obtidos 256 incrementos (F1) com 24 scans e um tempo de aquisição de $0,17 \mathrm{~s}$, ou 4096 pontos (F2) para cada um deles. A janela utilizada foi de $12.019,23 \mathrm{~Hz}$ (em ambas as dimensões, F1 e F2), sendo o intervalo entre scans de $1 \mathrm{~s}$;

g-HSQC: para gerar a segunda dimensão foram obtidos 256 incrementos (F1) com 56 scans e um tempo de aquisição de $0,17 \mathrm{~s}$, ou 4096 pontos (F2) para cada um deles. A janela utilizada foi de $12.019,23 \mathrm{~Hz}$ em F2 $\left({ }^{1} \mathrm{H}\right)$ e para a segunda dimensão foi utilizada uma janela de $36.057,69 \mathrm{~Hz}\left({ }^{13} \mathrm{C}, \mathrm{F} 1\right)$. O intervalo entre scans foi de $1 \mathrm{~s}$; 
g-HMBC:Para gerar a segunda dimensão foram obtidos 256 incrementos (F1) com 96 scans e um tempo de aquisição de 0,17s, ou 4096 pontos (F2) para cada um deles. A janela utilizada foi de $12.019,23 \mathrm{~Hz}$ em F2 $\left({ }^{1} \mathrm{H}\right)$ e para a segunda dimensão, foi utilizada uma janela de $36.057,69 \mathrm{~Hz}\left({ }^{13} \mathrm{C}, \mathrm{F} 1\right)$. O intervalo entre scans foi de $1 \mathrm{~s}$.

\subsection{Utilização de base de dados para identificação dos metabólitos}

Neste trabalho foram utilizadas as bases de dados online HMDB, Madison Metabolomics, KEGG Metabolic Pathways e a SMPDB para auxiliar na identificação dos metabólitos celulares e a correlação com as vias metabólicas. Isto se fez necessário porque amostras biológicas são muito complexas devido à grande quantidade de compostos provenientes do metabolismo celular. A base de dados Human Metabolome Database (HMDB) desenvolvida pelo projeto Genome Alberta (Canadá), tem como foco informações em escala molecular sobre os metabólitos, enzimas e transportadores associados. Possui informações sobre as estruturas químicas, além da ocorrência das mesmas em determinadas matrizes, bem como suas informações de RMN de ${ }^{1} \mathrm{H}$ e ${ }^{13} \mathrm{C}$. A base de dados Madison Metabolomics Consortium Database contém as informações de espectros de RMN e de Massa. Essa base de dados também contém informações sobre os metabólitos em diferentes condições fisiológicas, e está relacionada com outras bases de dados, auxiliando na compreensão dos metabólitos encontrados. Utilizou-se também a base de dados Metabolomics, auxiliando na identificação de metabólitos humanos através da espectroscopia de RMN.

Para melhor compreensão dos metabólitos encontrados, bem como para a análise das vias bioquímicas, foram utilizadas bases de dados como, por exemplo, KEGG Metabolic Pathways, que incluem mapas de vias metabólicas para a maioria dos metabólitos encontrados em organismos vivos. Outra base utilizada para o estudo de vias bioquímicas foi a SMPDB (Small Molecule Pathway Database), que descreve moléculas envolvidas especificamente em vias bioquímicas humanas.

Empregando essas bases de dados, bem como os experimentos 2D realizados, foi possível identificar alguns dos metabólitos presentes nas amostras de células tumorais estudadas e o envolvimentos destes em vias bioquímicas específicas. 


\subsection{Normalização dos sinais}

Para a quantificação dos metabólitos nas células tumorais obtidos através da HRMAS, foram utilizados dois métodos de normalização.

O primeiro baseou-se na normalização do sinal da glicina, em 3,78 ppm, cuja intensidade foi considerada igual a 1. Este sinal foi escolhido como referência, visto que esteve presente em todos os espectros. No entanto, não foi alvo direto do estudo das vias bioquímicas e permaneceu com largura de linha constante (ou seja, mesma área). Assim, a concentração relativa de todos os sinais dos metabólitos foram calculados através da integração destes sinais através do software Origin 8.0 (OriginLab Corporation, Northampton, Mass. USA) tendo como referência a área do sinal da glicina.

Para exemplificar o método utilizado, discrimina-se no espectro (Fig. 13) os sinais que foram integrados. No caso da Figura 13 , foram discriminados os sinais referentes a creatina e taurina, sinais 1 e 2 respectivamente.

Para evitar que possível diferença do shimming interferisse nos cálculos das áreas, optou-se por estipular regiões espectrais iguais para todos os espectros, de forma que todo o sinal do metabólito fosse analisado sempre da mesma forma.

Outro método de normalização também foi utilizado a fim de se comparar os resultados obtidos anteriormente. No segundo método de normalização, foi determinado o somatório de todas as amplitudes do espectro como 1000. Isso elimina a dependência de apenas um sinal, como ocorre no método acima. A partir desta normalização, fez-se a integração dos sinais de interesse, como mencionado no método anterior (Fig.14). 
Figura 13 - Integração dos múltiplos sinais dos metabólitos obtidos com o sinal de referência em $3,78 \mathrm{ppm}$. Em destaque sinal da creatina e taurina em 1 e 2 respectivamente.

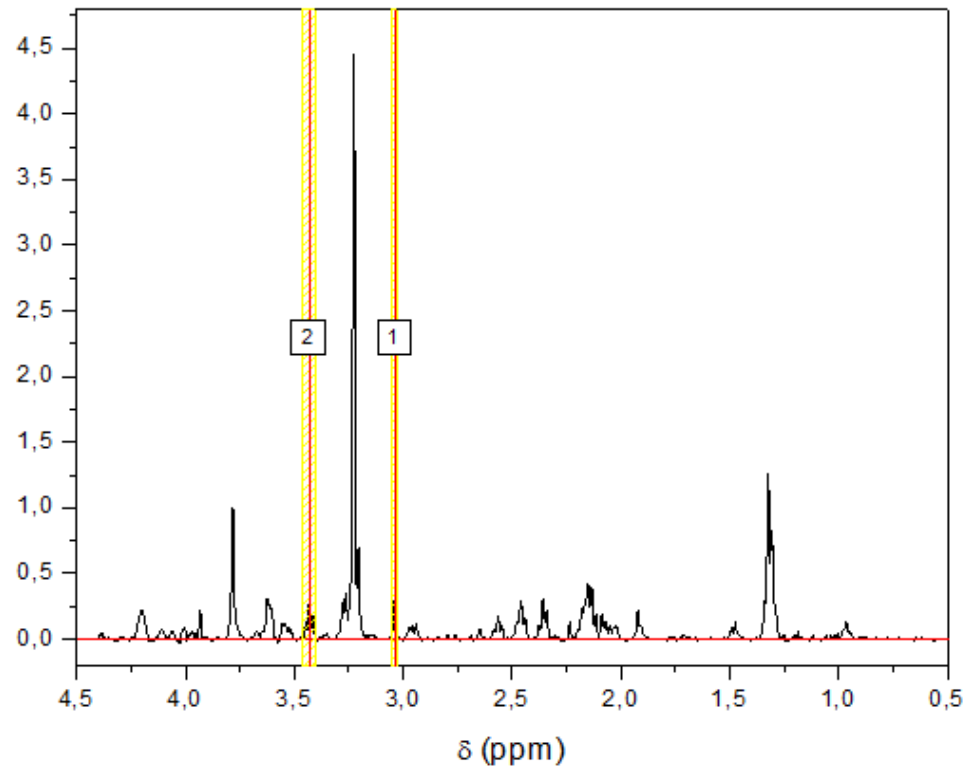

Figura 14 - Espectro obtido a partir do segundo método de normalização. Através do somatório de todas as amplitudes do espectro igual a 1000 (A) e exemplo do cálculo das áreas dos sinais dos metabólitos de interesse, creatina e taurina em 1 e 2 respectivamente (B).

(A)

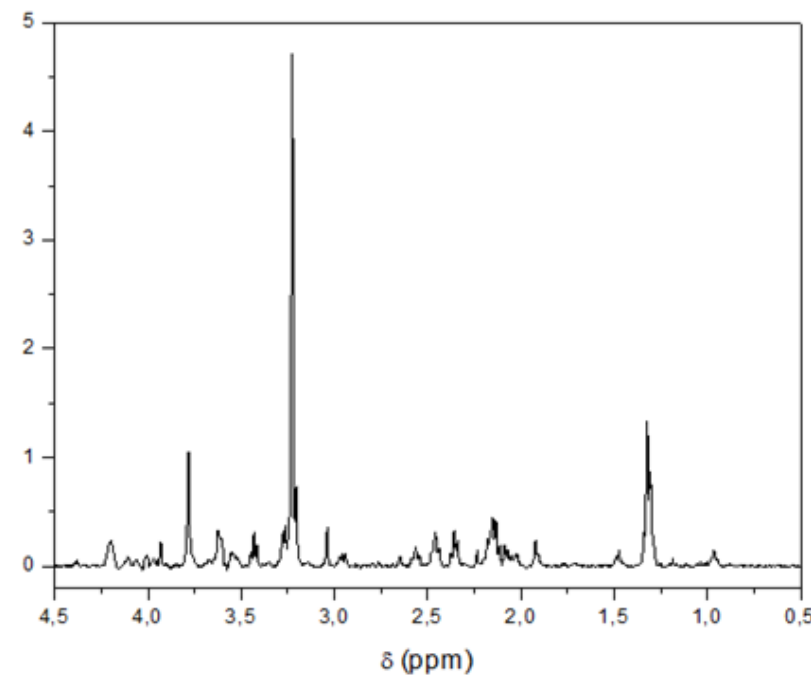

(B)

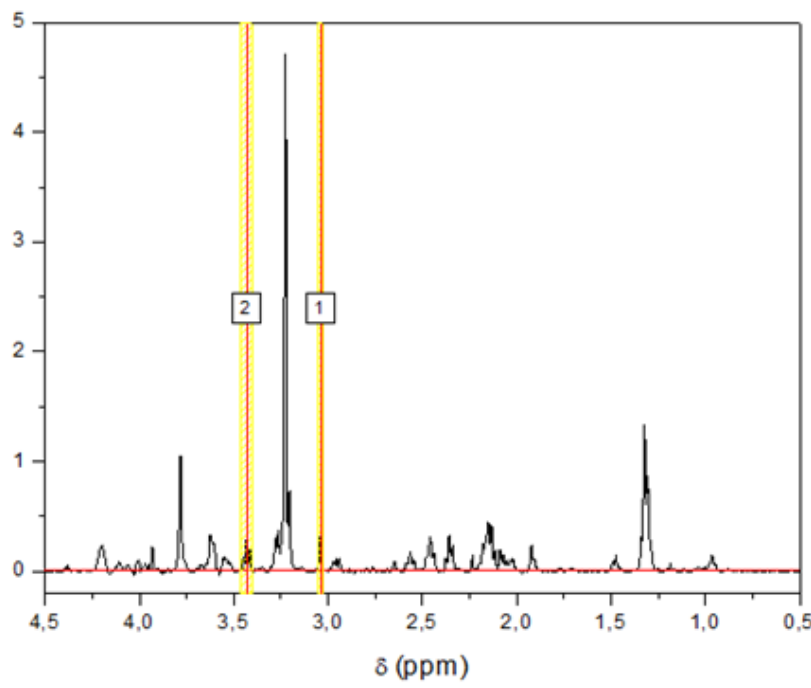

\subsection{Método de diagonalização filtrada (FDM)}

Além do estudo do metabolismo de células de câncer de mama tratadas com CLA, avaliou-se o uso do método de diagonalização filtrada - FDM (Filter Diagonalization Method) para o processamento do sinal de HR-MAS no domínio do tempo. 
Apesar de a transformada de Fourier (TF) ser o método padrão para conversão do sinal de RMN no domínio do tempo para o domínio da frequência ${ }^{45}$, outros métodos matemáticos também têm sido utilizados. Um destes métodos é o FDM, que foi introduzido por Mandestam ${ }^{54}$ como uma ferramenta alternativa para processar espectros de RMN. Consiste em um método de ajuste de sinais que possibilita inúmeras aplicações em processamento de dados. Isto é, o FDM consiste em um método paramétrico não-linear para ajuste dos sinais (fitting procedures) no domínio do tempo, e não de transformação, como no caso da TF55.

O software do FDM utilizado foi desenvolvido pelo Prof. Dr. Cláudio José Magon, do Instituto de Física de São Carlos-USP, e foi implementado em linguagem $\mathrm{C} / \mathrm{C}++$ no ambiente Code Builder do OriginPro-8 (OriginLab Corporation , Northampton, Mass., USA).

A Figura 15, apresenta um esquema do procedimento realizado. O sinal das células de câncer de mama, MCF-7, adquirido através do HR-MAS (Fig.15a) foi primeiramente processado pelo FDM gerando uma lista de parâmetros que descrevem todas as componentes espectrais (Fig. 15b). A partir da determinação das componentes do sinal da água, foi possível subtrair do FID original o FID da água (Fig. 15c), desse modo, obteve-se um FID sem a presença do sinal da água (Fig. 15d). Através do reprocessamento pelo FDM, podem-se gerar espectros aplicando diferentes filtros, separando picos largos e estreitos (Fig. 15e).

Figura 15 - Esquema das etapas realizadas no processamento com o FDM.

(a)
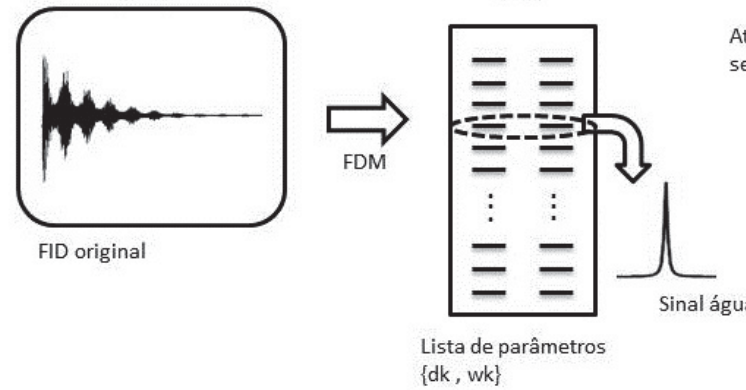

(e)

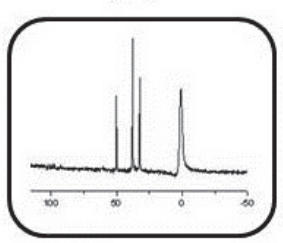

Espectro FDM sem sinal água (b)

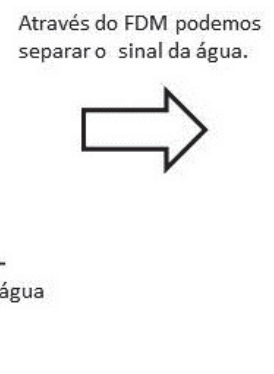

(c)

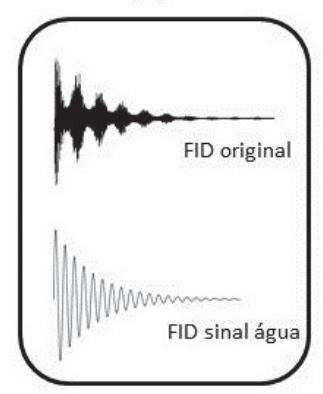

(d)

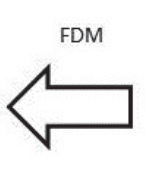

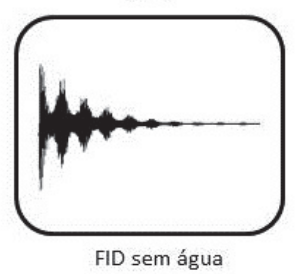

FID sem água

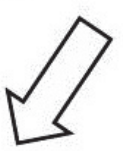

Subtraindo do FID original o FID do sinal da água, obtemos o FID sem sinal da água.

Fonte: Tiago Bueno de Moraes. 


\section{RESULTADOS E DISCUSSÃO}

\subsection{Análises de Ressonância Magnética Nuclear}

As análises por RMN só foram realizadas quando as células estavam viáveis. Com a viabilidade celular estabelecida, foram analisadas inicialmente amostras em diversas concentrações ( $1 \times 10^{2}$ a $1 \times 10^{6}$ células). A concentração que resultou em sinais com boa razão sinal ruído foi a apresentada pela amostra coletada à partir da cultura com aproximadamente $10^{6}$ células.

Os experimentos de HR-MAS foram inicialmente obtidos com a sequência padrão de hidrogênio (Fig.16). Na Figura 16, pode-se observar o espectro em preto no qual o sinal intenso da água prejudica a visualização dos sinais de interesse (metabólitos). Somente após a expansão vertical de 100 vezes (em vermelho), alguns sinais dos metabólitos podem ser vistos. No entanto, independentemente da ampliação, as informações de possíveis sinais sobrepostos pelo sinal da água podem ser perdidas. Considerando este fato, foi necessária a supressão do sinal da água. Para isto, utilizou-se o método de pré-saturação e tornou possível uma melhor observação dos sinais dos metabólitos, ou seja, uma grande quantidade de sinais correspondentes a pequenas moléculas presentes no interior das células (Fig. 17A).

Para melhorar a resolução espectral dos experimentos de HR-MAS, além da supressão do sinal da água, foi necessário também minimizar as intensidades dos sinais largos provenientes principalmente de macromoléculas e membranas. Para isto, foi aplicado um filtro de $T_{2}$ baseado na sequência de pulso CPMG (Carr-PurcellMeiboom-Gill). Na Figura 17B, está apresentado o espectro de HR-MAS obtido com a mesma amostra de células de câncer de mama (MCF-7) da Figura 17A, mas com a utilização do filtro de $T_{2}$ (CPMG). Realizando uma comparação entre as Figura 17A e Figura 17B, pode-se verificar a diferença entre as larguras de linha dos sinais obtidos, sendo que no espectro $B$, os sinais mais largos são suprimidos e pode-se observar com detalhes os sinais mais estreitos, relacionados aos metabólitos de interesse. 
Figura 16 - Espectro de HR-MAS da amostra de células de câncer de mama (MCF-7) em $\mathrm{D}_{2} \mathrm{O}$. No espectro em preto se observa o sinal intenso da água. No espectro em vermelho está a expansão da escala vertical de 100X do mesmo espectro para a visualização dos sinais de interesse.

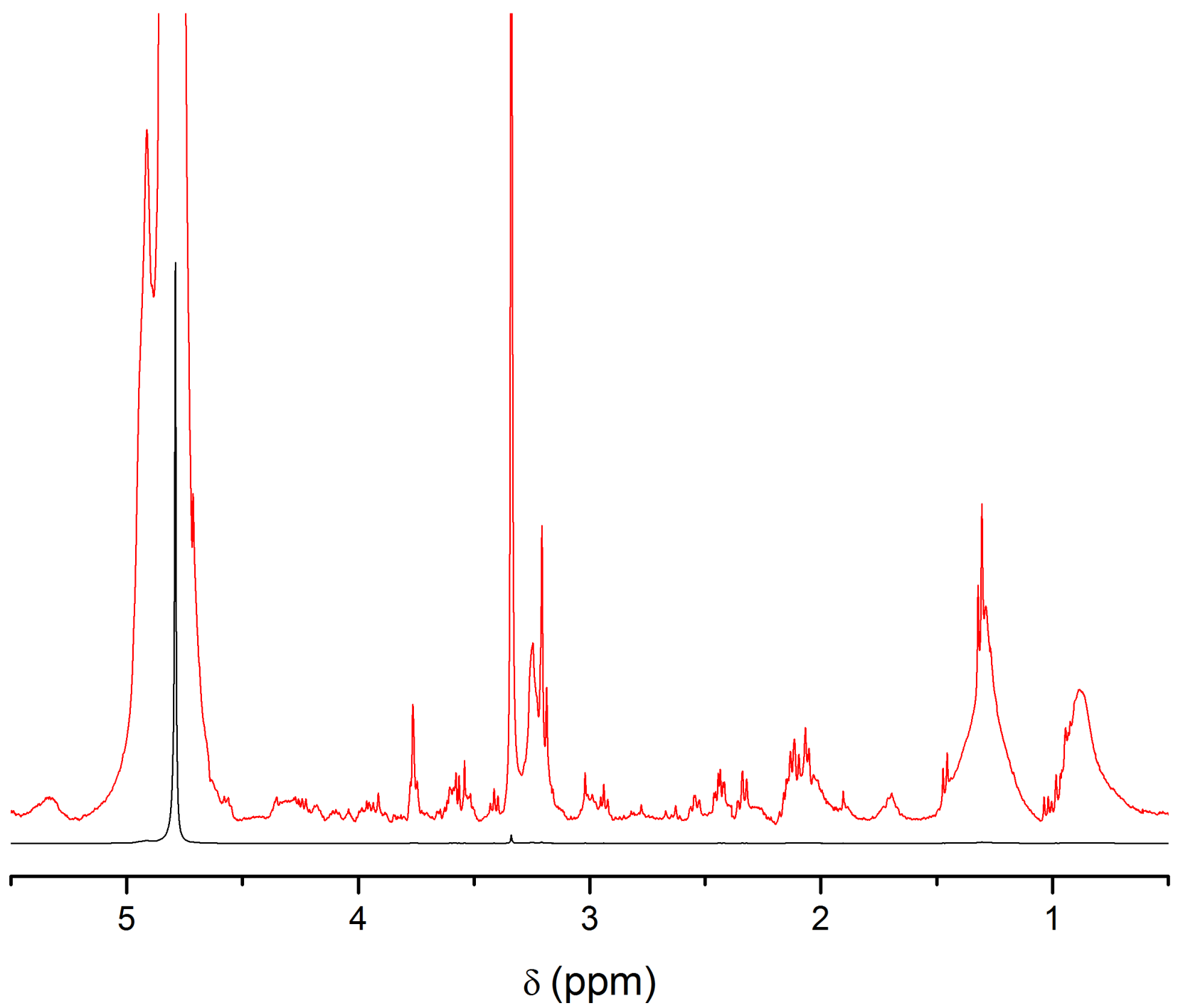


Figura 17 - Espectro de HR-MAS da amostra de células de câncer de mama (MCF-7) empregando a técnica de supressão do sinal da água, pré-saturação (A) e espectro da mesma amostra anterior com o uso do filtro de $T_{2}$ (CPMG). Com o uso da pré-saturação foi possível melhorar a observação dos sinais dos metabólitos, bem como com o uso do filtro de $\mathrm{T}_{2}$ permitiu eliminar os sinais largos das macromoléculas, presentes no espectro $\mathrm{A}$.

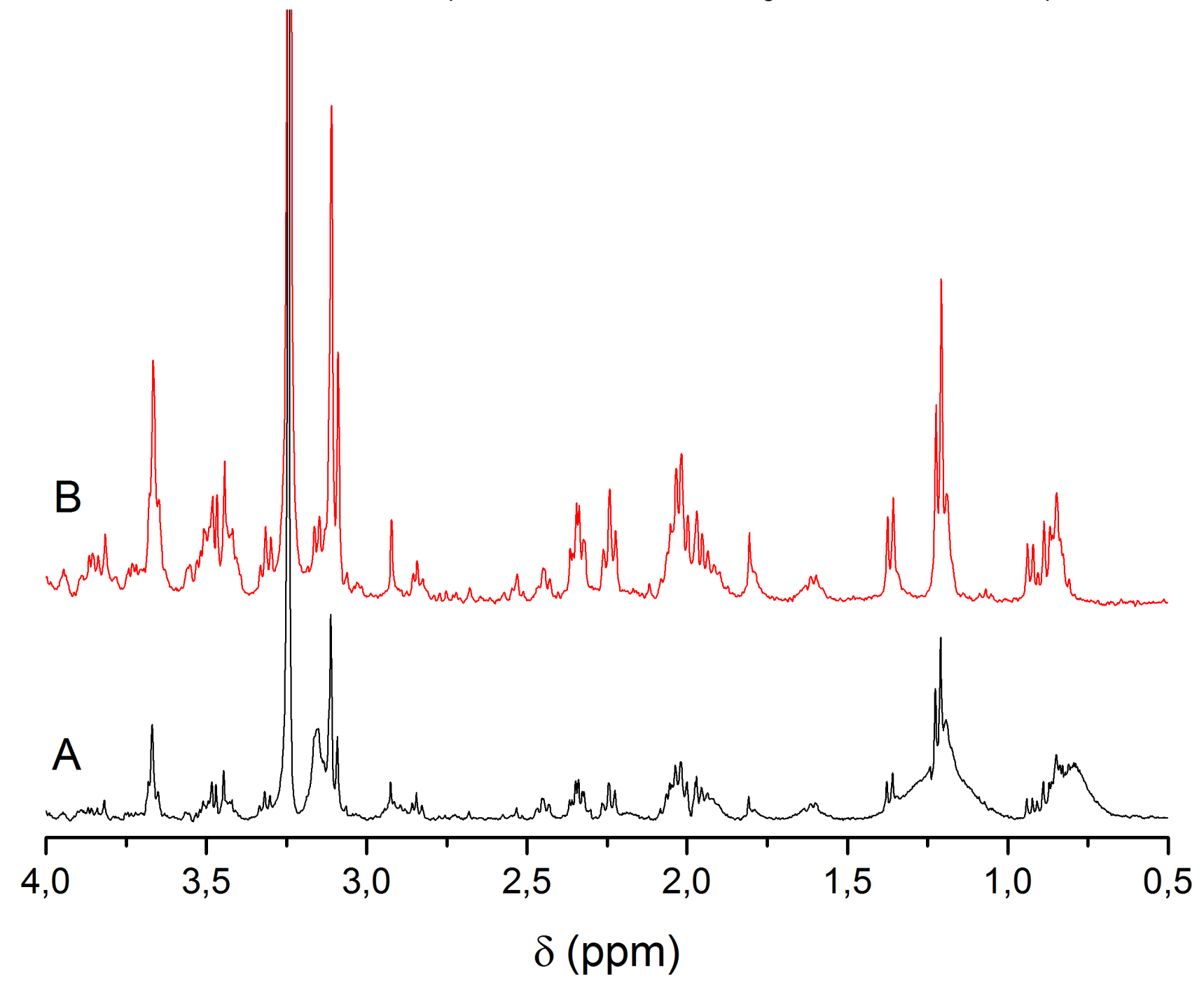




\subsection{Identificação dos metabólitos}

Os metabólitos presentes nas células de câncer de mama analisadas foram identificados nos espectros de HR-MAS com o uso de parâmetros espectrais, tais como deslocamento químico, acoplamento spin-spin (unidimensional) e correlações bidimensionais homonucleares e heteronucleares. Os experimentos bidimensionais usados foram: COSY, técnica homonuclear que permite a verificação de acoplamentos diretos entre hidrogênios em grupos vizinhos; HSQC, que possibilita a análise de acoplamentos entre ${ }^{1} \mathrm{H}$ e ${ }^{13} \mathrm{C}$ ligados entre si e $\mathrm{HMBC}$, utilizado para verificar acoplamentos entre ${ }^{1} \mathrm{H}$ e ${ }^{13} \mathrm{C}$ a longa distância.

Para exemplificar o assinalamento dos sinais encontrados nos espectros de RMN, será feita uma descrição detalhada da identificação da alanina. Na região em torno de 1,48 ppm, destaca-se um dubleto, o qual possui deslocamento químico na região esperada para o grupo metila da alanina (Fig. 17B). Ao analisar este sinal no espectro COSY, Figura 18, nota-se que este sinal possui correlação com outro sinal, cujo deslocamento químico é 3,79 ppm, região onde se observam os hidrogênios dos $\mathrm{C} \alpha$ dos aminoácidos. Como outras moléculas podem ter deslocamentos químicos similares e para confirmar esse assinalamento, foram realizadas também medidas de correlação heteronuclear $\mathrm{H}-\mathrm{C}$, de curto e longo alcance, utilizando as sequências HSQC e HMQC.

Na Figura 19, está apresentado o espectro HSQC, destacando-se as regiões em que há correlação entre o sinal de hidrogênio em 1,48 ppm e o carbono em 19,07 ppm, ou seja, entre os hidrogênios e o carbono do grupo metila da alanina.

Para a visualização das correlações a longa distância, utilizou-se o espectro HMBC (Fig. 20), no qual o sinal de hidrogênio em 1,48 ppm possui correlação a longa distância com C $\alpha$ em 53,38 ppm e com o grupo carboxila em 178,89 ppm.

Esse mesmo tipo de procedimento foi usado para identificar os outros metabólitos, ou seja, os assinalamentos dos sinais dos espectros monodimensionais foram confirmados por meio das correlações dos espectros bidimensionais. 
Figura 18 - Ampliação da região do espectro COSY das células de câncer de mama (MCF-7) para possibilitar a visualização das correlações entre átomos de hidrogênio de grupos vizinhos.

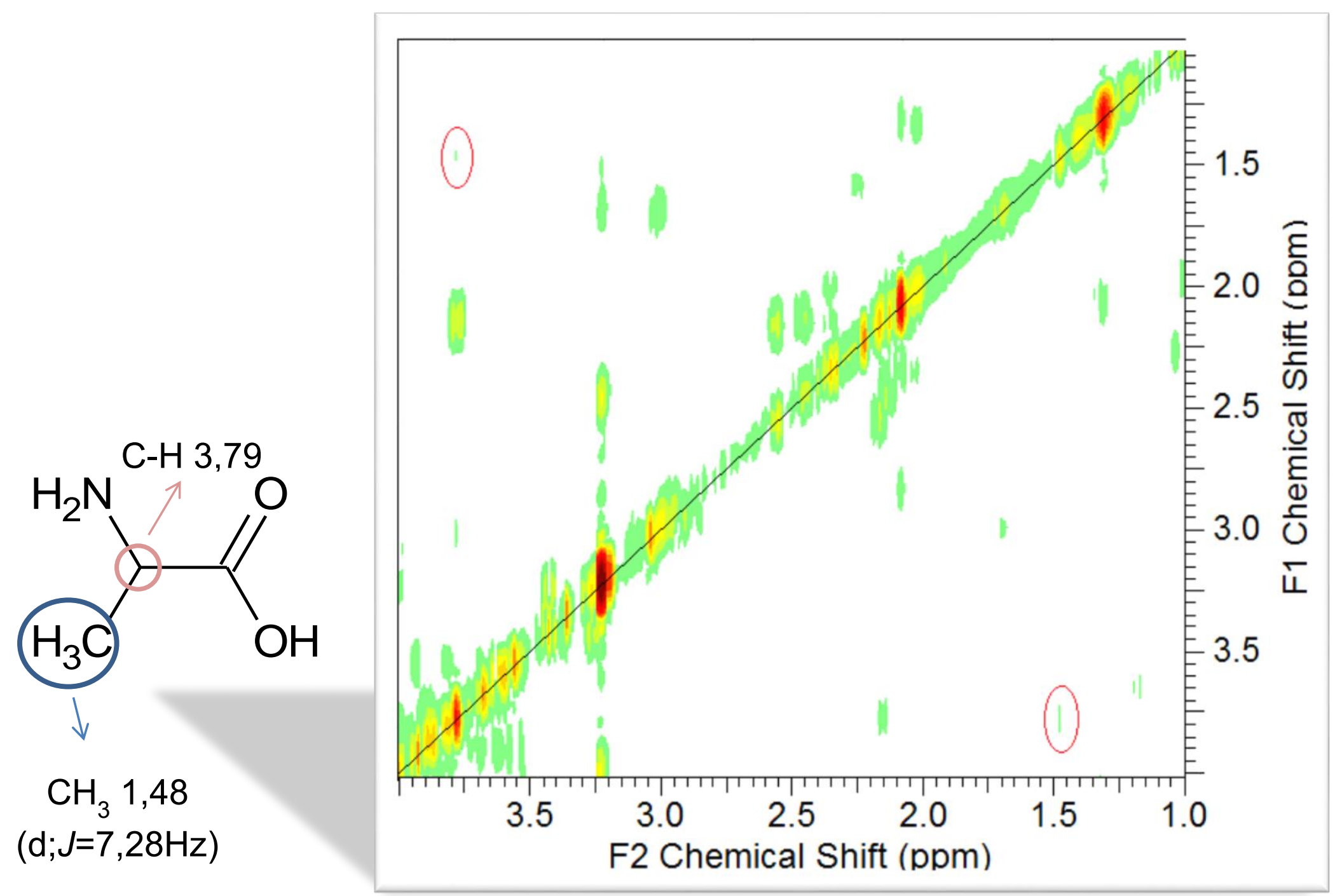


Figura 19 - Ampliação da região do espectro de HSQC das células de câncer de mama (MCF-7) para possibilitar a visualização das correlações de hidrogênio e carbono ligados entre si.

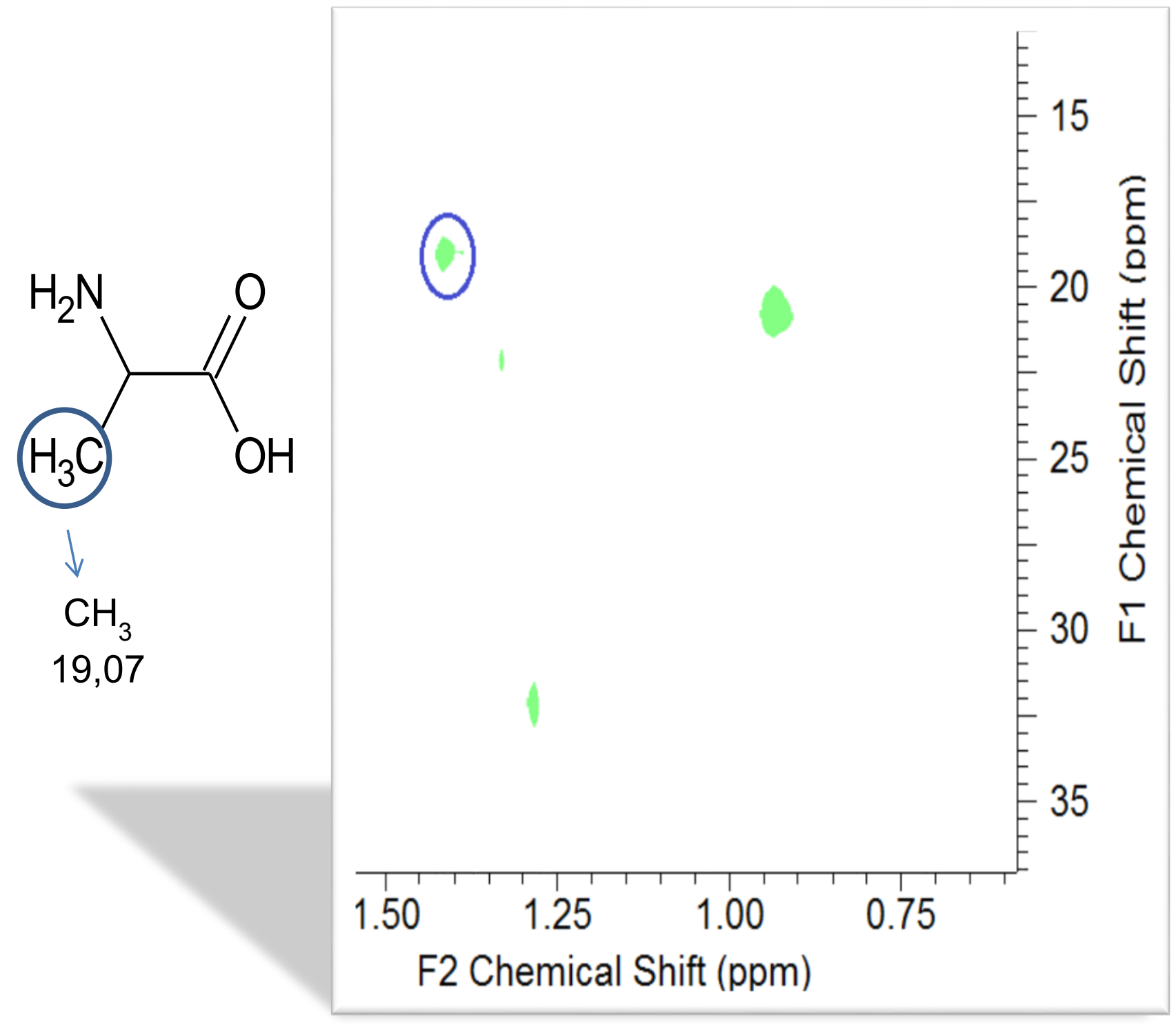


Figura 20 - Ampliação da região do espectro de HMBC das células de câncer de mama (MCF-7) para possibilitar a visualização das correlações de hidrogênio e carbono à longa distância.

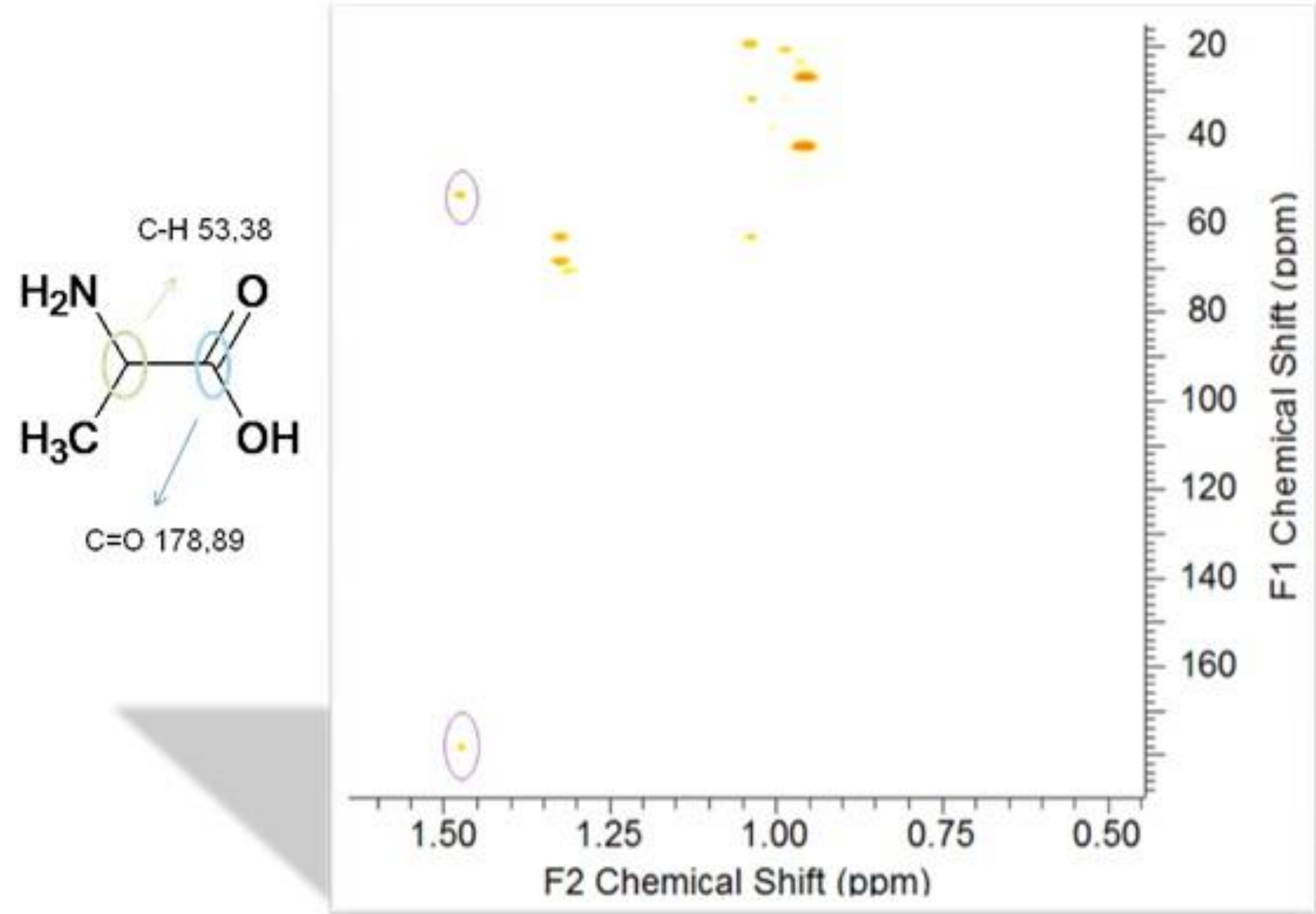


O sinal em 2,23 ppm, presente no espectro unidimensional (Figura 21), é assinalado como a acetona, isto porque nos experimentos HSQC demonstraram que o sinal em 2,23 ppm está correlacionado ao sinal em 32,86 ppm relativo ao carbono do grupo metila da acetona, e nos experimentos de HMBC o mesmo sinal está correlacionado ao sinal em 217,95 ppm, do carbono carbonílico da acetona ${ }^{56}$.

Com os experimentos bidimensionais e as informações obtidas das bases de dados de metaboloma, foi possível o assinalamento dos principais metabólitos nas células tumorais (Figura 21 e Tabela 2). Além da alanina, assinalaram-se principalmente os metabólitos lactato, treonina, acetato, acetona, creatina, colina, fosfocolina, taurina e glicina. 
Figura 21 - Expansão de 4,5 a 1,0ppm do espectro de HR-MAS de células tumorais. O espectro das células MDA-MB-231 (vermelho) é comparado com o espectro das células MCF-7 (preto). Os números referem-se ao assinalamento de 9 sinais diferentes dos metabólitos. Os metabólitos (número do sinal entre parênteses) são mostrados: lactato (1), treonina (2), alanina (3), acetato (4), acetona (5), creatina (6), colina (7), fosfocolina (8), taurina (9). A letra G corresponde ao sinal da glicina $(3,78 \mathrm{ppm})$ usado como referência para quantificação dos metabólitos.

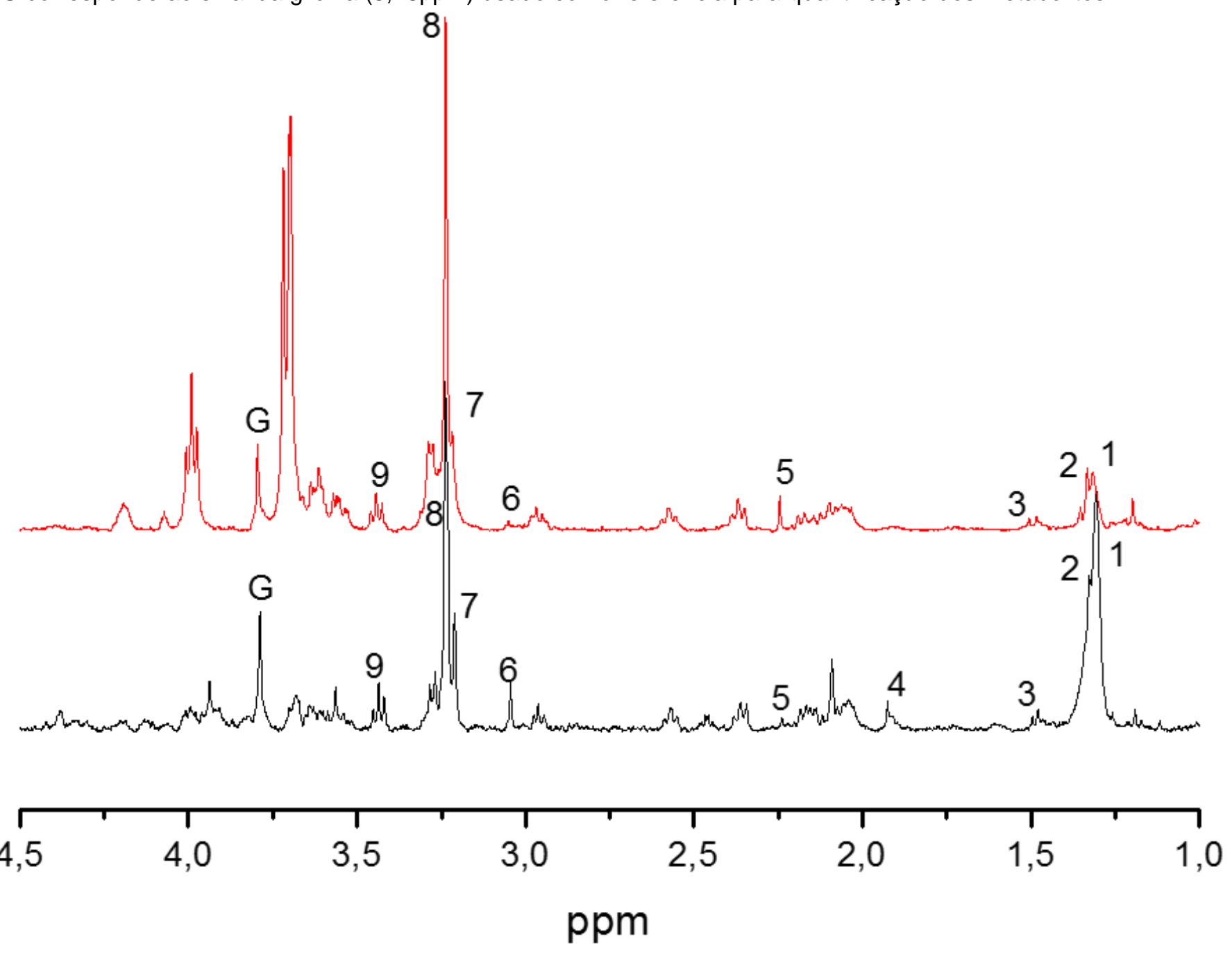


Tabela 2 - Estrutura química e deslocamento químico $\left({ }^{1} \mathrm{H} \mathrm{e} \mathrm{e}{ }^{13} \mathrm{C}\right)$ para os metabólitos identificados nas células de câncer de mama MCF-7 e MDA-MB-231.

Metabólito

Lactato (1)

Treonina (2)

Estrutura<smiles>C[C@H](O)C(=O)[O-]</smiles><smiles>C[C@@H](O)[C@H](N)C(=O)O</smiles><smiles>C[C@H](N)C(=O)O</smiles><smiles>CC(=O)[O-]</smiles><smiles>CC(=O)CO</smiles><smiles>CN(CC(=O)O)C(=N)N</smiles>

Creatina (6)

Colina (7)<smiles>C[N+](C)(C)CCO</smiles>

$\mathrm{N}-\mathrm{CH}_{3} 3,20$

$\beta \mathrm{CH}_{3} 1,48$
(d; $J=7,28 \mathrm{~Hz}$ )

$\mathrm{CH}_{3} 19,07$

(d; $J=7,5 \mathrm{~Hz}$ )

$\mathrm{BCH}_{3} 22,43$

CH 70,90

$\mathrm{C}=\mathrm{O} \quad 184,97$

$\gamma \mathrm{CH}_{3} 1,33$

$\gamma \mathrm{CH}_{3} 22,19$

$\beta \mathrm{CH} 68,69$

$\alpha \mathrm{CH} 63,17$

Acetona (5)

$\mathrm{CH}_{3} 2,23$

$\mathrm{CH}_{3} 32,86$

$C=0 \quad 217,95$

$\mathrm{N}-\mathrm{CH}_{3} 3,03$

$\mathrm{N}-\mathrm{CH}_{3} 41,75$

$\alpha \mathrm{CH}_{2} 56,72$

Fosfocolina (8)<smiles>C[N+](C)(C)CCOP(=O)(O)O</smiles>

$\mathrm{N}-\mathrm{CH}_{3} 3,22$

$\mathrm{N}-\mathrm{CH}_{3} 56,62$

$\beta \mathrm{CH}_{2} 69,19$

C-O 59,63

Taurina (9)<smiles>NCCS(=O)(=O)O</smiles>

$\beta \mathrm{CH}_{2} 3,43$

(t; J=6,47Hz)

C-S 49,89

C-N 38,10

*Valores obtidos a partir das correlações observadas no experimento HSQC. 


\subsection{Quantificação relativa dos metabólitos}

Para a quantificação dos metabólitos nas células tumorais presente nos espectros de HR-MAS, dois métodos de normalização foram utilizados.

O primeiro baseou-se na normalização pelo sinal da glicina, em 3,78 ppm, cuja intensidade foi considerada igual a 1. Este sinal foi escolhido como referência visto que esteve presente em todos os espectros, não houve variação da largura de linha (ou seja, mesma área para intensidade 1) e não foi alvo direto no estudo das vias bioquímicas. Assim, todos os sinais dos metabólitos foram calculados através da integração dos picos (Origin 8.0), tendo como referência a área do sinal da glicina.

No segundo método de normalização, determinou-se o somatório de todas as amplitudes do espectro como igual a 1000, o que elimina a dependência de apenas um sinal, como ocorre no método acima. A partir desta normalização, fez-se a integração dos sinais de interesse, como mencionado no método acima.

As áreas relativas obtidas por ambos os métodos de normalização estão listados na Tabela 3, em que é possível observar que as áreas dos sinais foram similares em ambos os métodos de normalização, demonstrando a robustez dos mesmos. Assim, neste trabalho de doutorado, foi eleito o primeiro método para a realização das análises, devido a sua simplicidade e rapidez.

Tabela 3 - Comparação das áreas dos sinais dos metabólitos intracelulares de células de câncer de mama (MCF-7) obtidos pelos dois métodos de normalização espectral.

\begin{tabular}{lcc}
\hline Metabólitos & $\begin{array}{c}\text { Normalização } \\
\text { Referência em 3,78 ppm }\end{array}$ & $\begin{array}{c}\text { Normalização } \\
\text { Somatória dos sinais }\end{array}$ \\
\hline Lactato & 1,35 & 1,44 \\
\hline Treonina & 1,9 & 2,0 \\
\hline Alanina & 0,25 & 0,27 \\
\hline Acetato & 0,26 & 0,28 \\
\hline Acetona & 0,15 & 0,15 \\
\hline Creatina & 0,37 & 0,39 \\
\hline Colina & 0,85 & 0,87 \\
\hline Fosfocolina & 5,78 & 6,2 \\
\hline Taurina & 0,67 & 0,71
\end{tabular}




\subsection{Determinação da variabilidade da concentração dos metabólitos nas células de câncer de mama, por HR-MAS}

Para determinar a variabilidade da concentração dos metabólitos nas células de câncer de mama, foram feitas triplicatas das culturas para cada tipo de célula, com no mínimo uma semana de intervalo entre cada cultura (etapas independentes). $\mathrm{Na}$ Figura 22A e Figura 22B, são observados os três espectros para as células MCF-7 e MDA-MB-231 respectivamente. Pode-se observar que os espectros de HR-MAS, tanto para as células MCF-7 (Fig. 22A) quanto para as MDA-MB-231 (Fig. 22B), foram bastante similares nos três cultivos, indicando que o método utilizado para o cultivo celular foi reprodutivo.

$\mathrm{Na}$ Tabela 4, estão listados os valores de média e desvio padrão para os metabólitos estudados. Como se pode observar, a variação entre as análises está abaixo de $10 \%$ para a grande maioria dos metabólitos. Com os espectros da Figura 22 e os dados da Tabela 4, pode-se perceber a nítida diferença entre as células de câncer de mama MCF-7 e MDA-MB-231.

Entre as diferenças metabólicas encontradas (Fig.22 e Tabela 4), pode-se destacar que o teor de treonina, alanina, acetato e creatina foram maiores na MCF-7 do que na MDA-MB-231. Os teores de acetona e fosfocolina foram maiores na MDAMB-231. Os teores de lactato, colina e taurina foram parecidos em ambas linhagens celulares.

A fosfocolina foi o principal metabólito encontrado nos dois tipos de células tumorais analisados neste trabalho. Um alto teor de fosfocolina também foi observado na literatura quando se analisou por HR-MAS tecidos de 19 biopsias de carcinoma ductal, obtidos de pacientes com câncer de mama, quando comparados com tecidos de mama saudáveis ${ }^{41}$. A obtenção de alto teor de fosfocolina, tanto em culturas de células tumorais (in vitro) quanto em tecidos de biópsias, indica que a concentração de fosfocolina pode ser um biomarcador para detecção de câncer de mama ${ }^{41}$. 
Figura 22 - Triplicata dos espectros de HR-MAS das células de câncer de mama MCF-7 (A) e MDA-MB-231 (B). Em ambos os espectros é possível visualizar uma quantidade grande de sinais referentes aos metabólitos intracelulares presentes na região de 0,5 a 4,0 ppm.

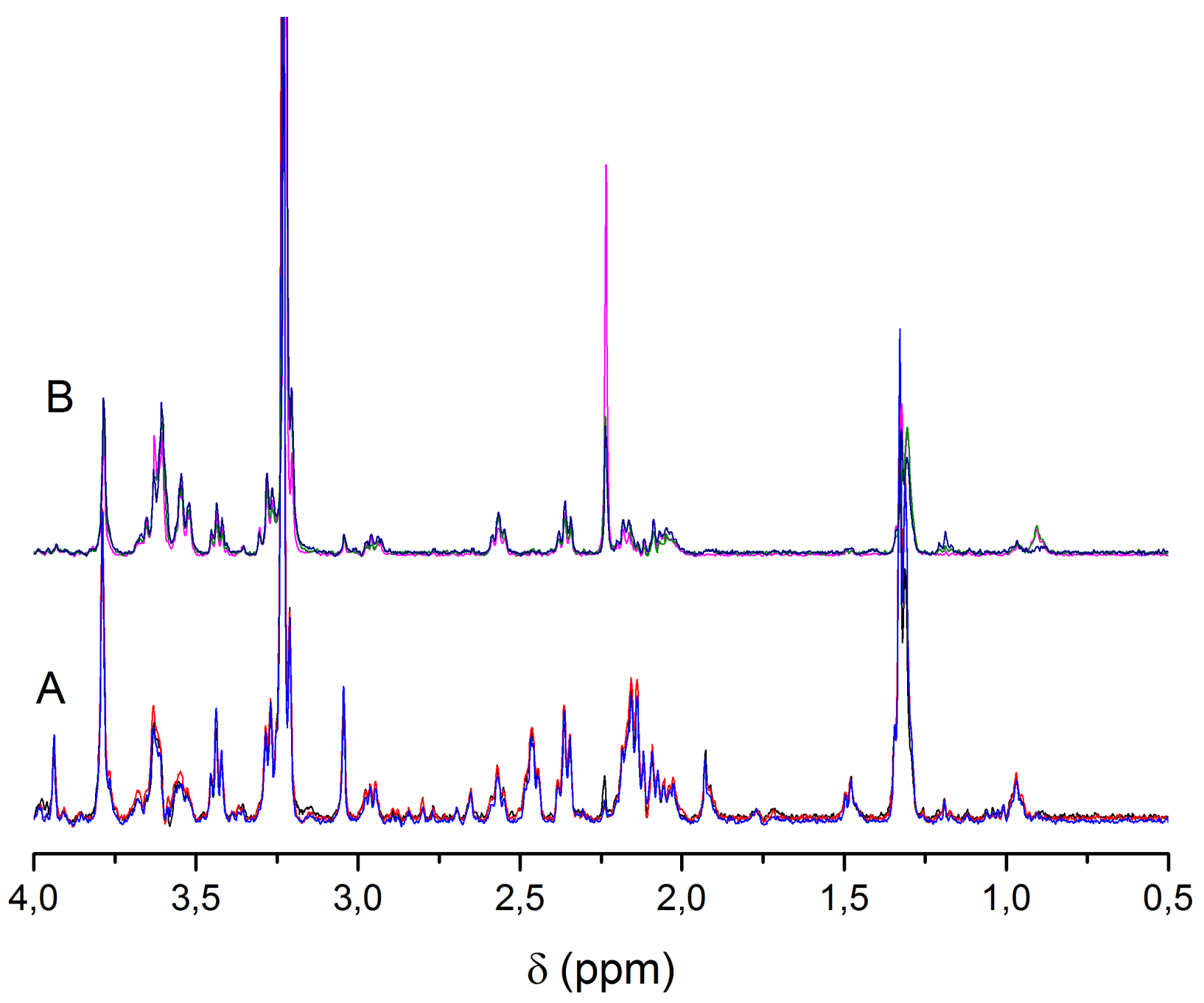


Tabela 4 - Quantidade relativa de alguns importantes metabólitos identificados no espectro de HR-MAS das células MCF-7 e MDA-MB-231. Valores obtidos pela comparação do sinal normalizado da glicina $(1,00)$.

\begin{tabular}{llll}
\hline & Metabólitos & MCF-7 & MDA-MB-231 \\
\hline G & Glicina & 1.00 & 1.00 \\
1 & Lactato & $1.67 \pm 0.3$ & $1.69 \pm 0.4$ \\
2 & Treonina & $2.06 \pm 0.1$ & $1.11 \pm 0.3$ \\
3 & Alanina & $0.30 \pm 0.04$ & $0.02 \pm 0.03$ \\
4 & Acetato & $0.26 \pm 0.02$ & ---- \\
5 & Acetona & $0.08 \pm 0.05$ & $1.56 \pm 1.05$ \\
6 & Creatina & $0.45 \pm 0.09$ & $0.14 \pm 0.01$ \\
7 & Colina & $0.80 \pm 0.1$ & $1.11 \pm 0.3$ \\
8 & Fosfocolina & $5.60 \pm 0.4$ & $11.22 \pm 1.3$ \\
9 & Taurina & $0.77 \pm 0.1$ & $0.62 \pm 0.1$ \\
& & & \\
\hline
\end{tabular}

\subsection{Variação do perfil metabólico em função do estresse}

Durante a proliferação celular, as células tumorais devem gerar energia suficiente e adquirir ou sintetizar biomoléculas em taxas adequadas para a demanda exigida nessa fase do ciclo celular. Dessa forma, para alcançar as exigências celulares durante a alta proliferação tumoral, há mudanças fundamentais nas vias bioquímicas que envolvem, por exemplo, o metabolismo energético e o consumo de nutrientes. Buscando verificar estas alterações, foi realizada uma análise do comportamento das células de câncer de mama (MDA-MB-231 e MCF-7) por HR-MAS, durante 5 horas no rotor sem suprimento de nutrientes e oxigênio.

Na Figura 23 e Figura 24, estão os cinco espectros de HR-MAS obtidos das células de câncer de mama MFC-7 e MDA-MB-231, sendo o intervalo de 1 hora entre as aquisições. Para melhor visualização, nas Figura 25, Figura 26, Figura 27 e Figura 
28, está apresentado a variação dos sinais de lactato, acetato, fosfocolina e colina para ambas linhagens. Na Figura 25, é possível observar que o lactato apresentou uma redução significativa de concentração tanto na MCF-7 quanto na MDA-MB-231. Normalmente, durante a hipóxia em células tumorais, ocorre a glicólise aeróbica ${ }^{36} 0$ que leva a um aumento da produção de lactato (Efeito Warburg). No entanto, observou-se um decréscimo do lactato nas células, sob stress nutricional e de oxigênio, o que indica que as células estão utilizando todos os substratos energéticos disponíveis ao seu metabolismo, devido a falta de suprimento adequado de glicose.

Na Figura 26, tem-se a variação do sinal do acetato em 1,92 ppm. É possível observar um decaimento da intensidade do sinal do acetato em ambas as linhagens. O acetato, quando ligado à coenzima $A$, está relacionado à síntese de colesterol e de ácidos graxos. O mecanismo do acetato em neoplasia é pouco conhecido, no entanto acredita-se que o acetato está relacionado a membrana lipídica das células tumorais, porque para o crescimento e proliferação celular, inevitavelmente necessita-se dos constituintes de membrana ${ }^{57}$.

Nas Figura 27 e Figura 28, observa-se que o teor de fosfocolina ficou praticamente constante e o da colina aumentou com o tempo de stress para as duas linhagens. 
Figura 23 - Espectro de HR-MAS de células de câncer de mama (MCF-7) obtidos em 5 aquisições consecutivas.

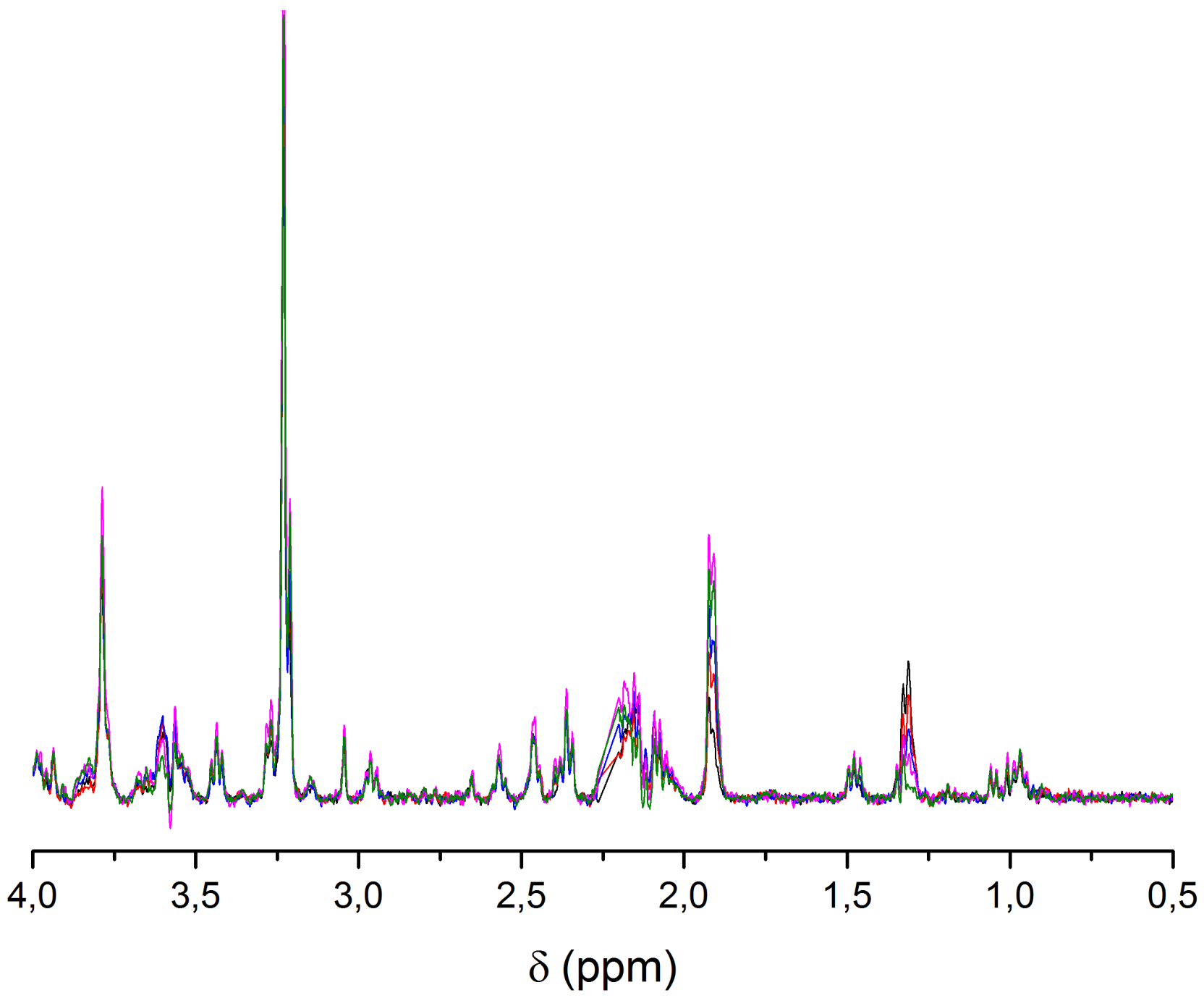


Figura 24 - Espectro de HR-MAS de ${ }^{1} \mathrm{H}$ das células de câncer de mama (MDA-MB-231) obtidos em 5 aquisições consecutivas.

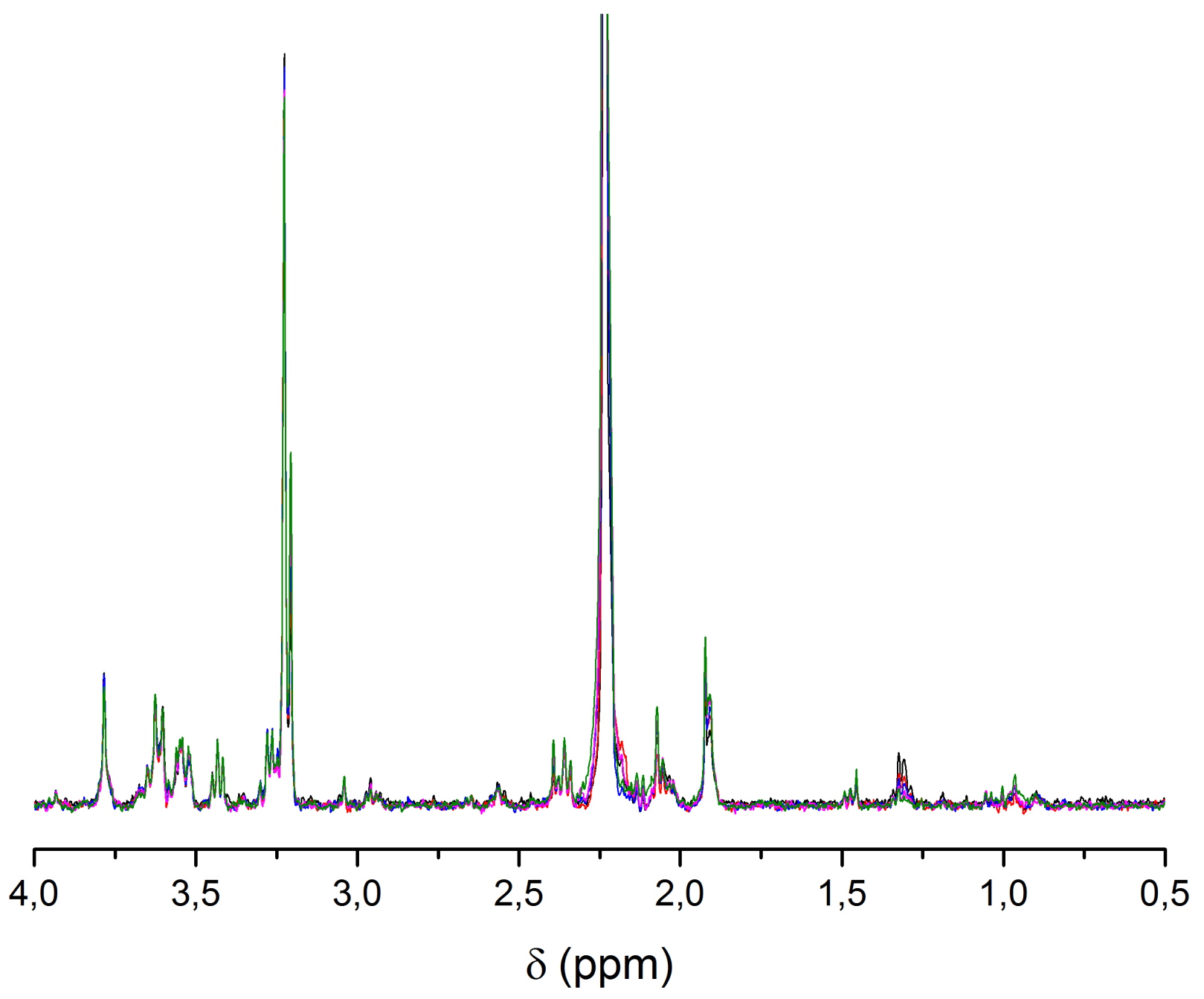


Figura 25 - Comparação do sinal em 1,32 ppm referente ao metabólito lactato nas células de câncer de mama (•MCF-7; •MDA-MB-231).

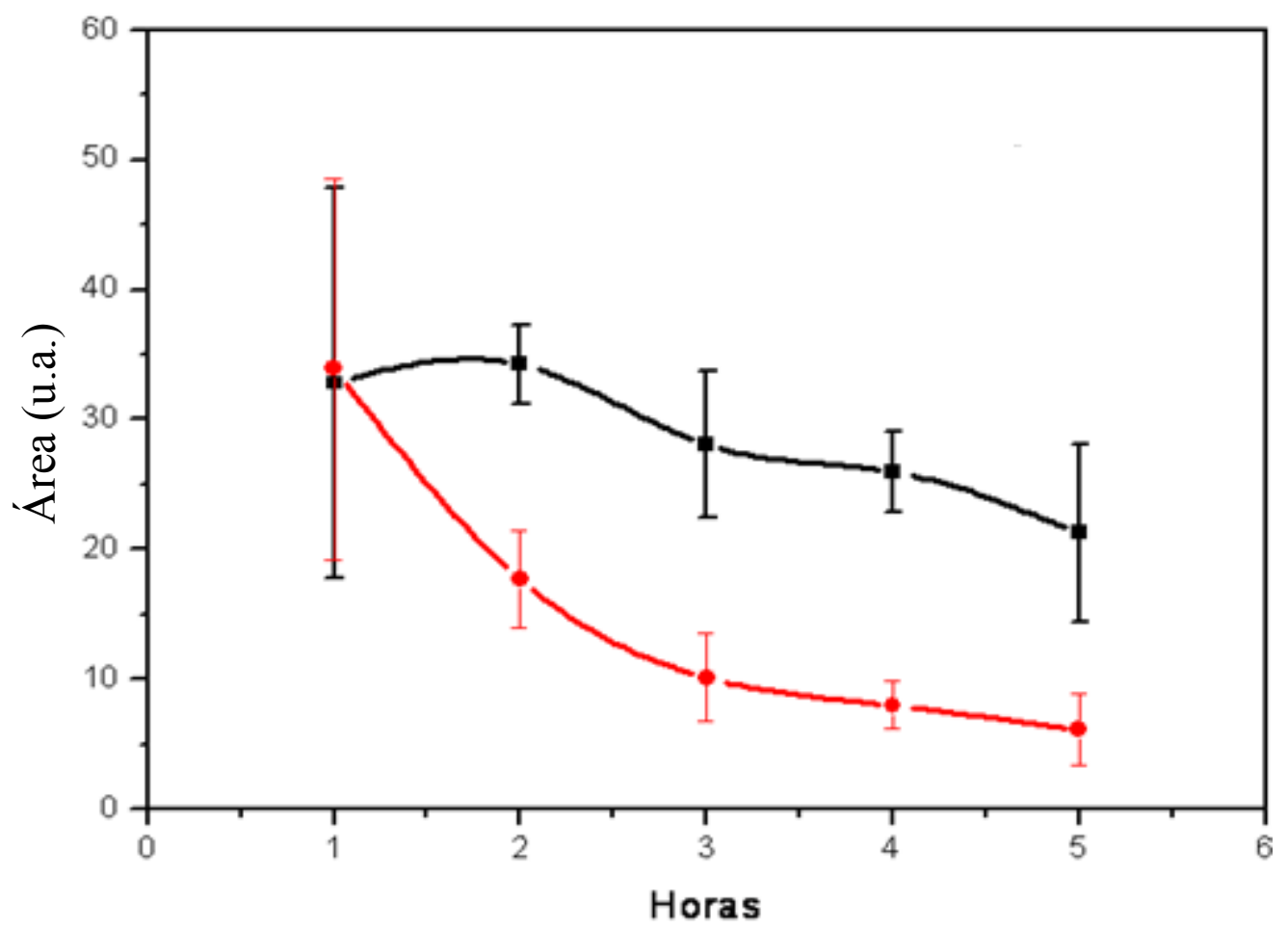

Figura 26 - Comparação do sinal em 1,92 ppm referente ao metabólito acetato nas células de câncer de mama (- MCF-7; • MDA-MB-231).

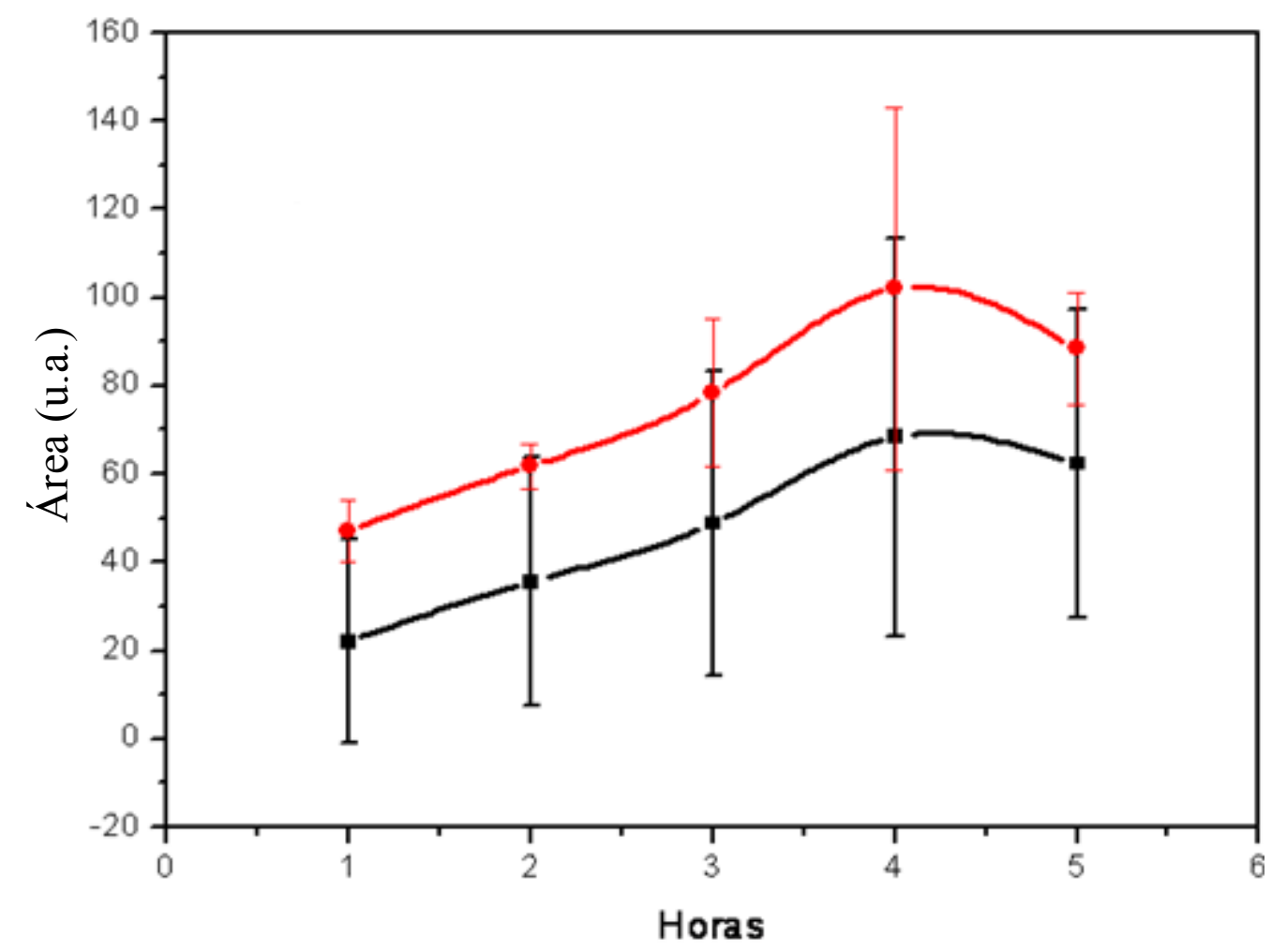


Figura 27 - Comparação do sinal em 3,22 ppm referente ao metabólito fosfocolina nas células de câncer de mama (ロ MCF-7; • MDA-MB-231).

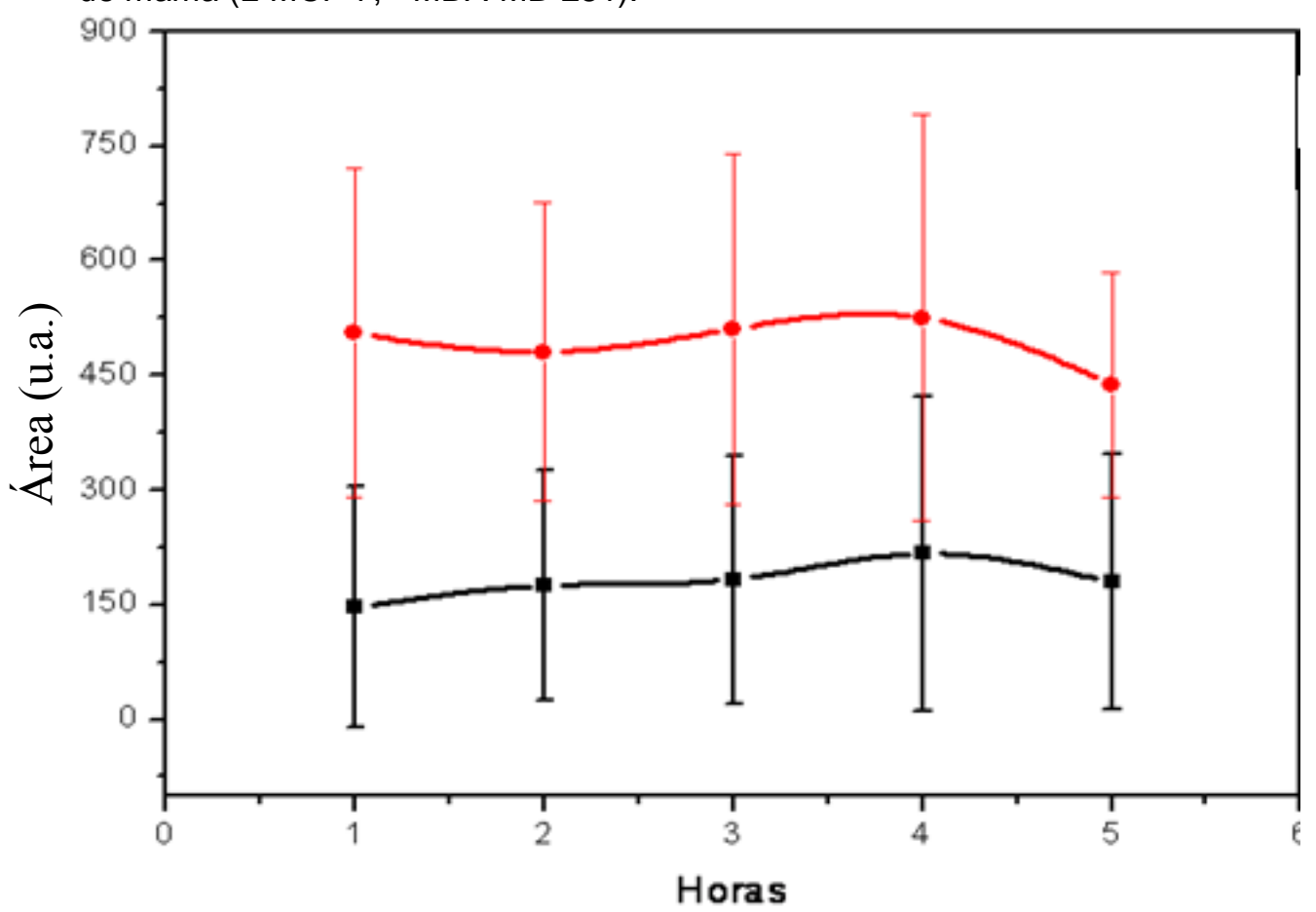

Figura 28 - Comparação do sinal em 3,20 ppm referente ao metabólito colina nas células de câncer de mama (घ MCF-7; • MDA-MB-231).

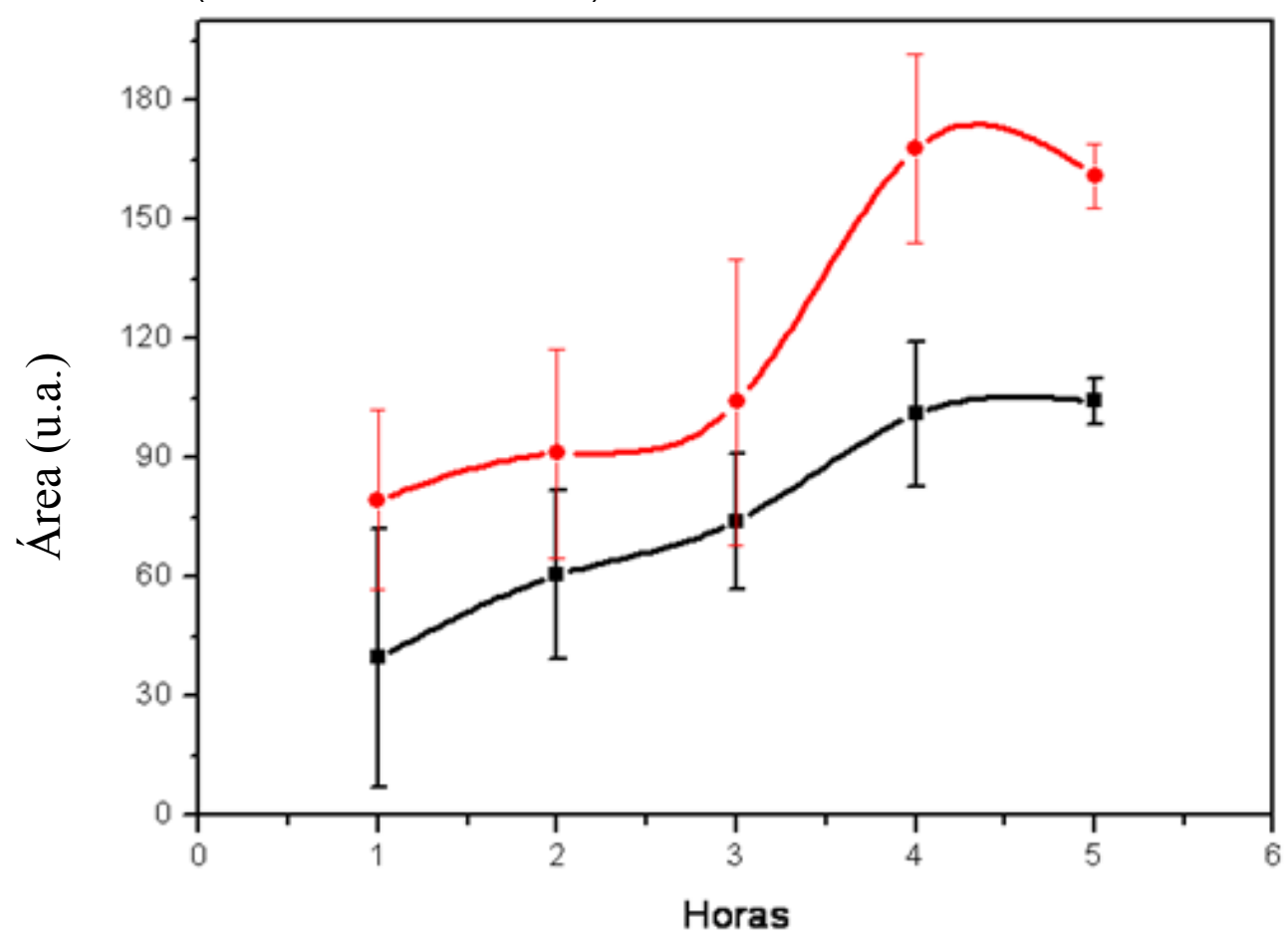




\subsection{Efeito do CLA no perfil metabólico das células tumorais}

Os estudos do efeito do CLA no metabolismo das células MCF-7 e MDA-MB-231 foram realizados por meio da exposição das culturas celulares à $50 \mu \mathrm{M}$ e $100 \mu \mathrm{M}$ de CLA $^{58}$. Nas Figura 29 e Figura 30, estão apresentados os espectros de HR-MAS das células de câncer de mama, MCF-7 e MDA-MB-231, submetidas à diferentes concentrações do CLA. Na Figura 29, observa-se que as células de câncer de mama MCF-7 da cultura controle (Fig. 29A) e com adição $50 \mu \mathrm{M}$ de CLA (Fig. 29B) tem espectros similares. No entanto, quando as células foram cultivadas na presença de $100 \mu \mathrm{M}$ de CLA, o nível de acetona aumentou significativamente (Fig. 29C). Na Figura 31, pode ser observado que as células de câncer de mama, MCF-7, submetidas a 100 $\mu \mathrm{M}$ CLA, tiveram um aumento do valor médio dos sinais da acetona em $90 \% \pm 12,75 \%$. Os espectros das células MDA-MB-231, submetidas ao CLA, foram similares e não apresentaram aumento da concentração de acetona (Fig. 30). Ao contrário, apresentaram uma diminuição do sinal da acetona na presença do CLA. Somente em uma das culturas observou-se um pequeno aumento do teor de acetona, Figura 32.

As análises dos espectros de HR-MAS de ambas as linhagens demonstraram que os sinais de fosfocolina decresceram com a adição do CLA (Fig.33 e Fig.34). Os resultados mostraram que houve a diminuição do valor médio dos sinais de fosfocolina em 32. $5 \pm 19.13 \%$ nas células MCF-7 quando submetidas a $100 \mu \mathrm{M}$ CLA. Os resultados reportaram também que este mesmo metabólito teve a diminuição de 33.5 $\pm 12.47 \%$ nas células MDA-MB-231 quando submetidas à mesma concentração do CLA. Considerando a fosfocolina como um biomarcador tumoral e sendo envolvido com a malignidade da doença, os resultados obtidos neste trabalho podem sugerir um efeito positivo do CLA nas células de câncer de mama analisadas ${ }^{59}$. Mais análises são necessárias para elucidar a relação entre os níveis de fosfocolina e o efeito anticarcinogênico do CLA. No nível mais amplo do metabolismo lipídico de membrana, as células devem coordenar os níveis de colesterol e fosfolipídios, já que há forte evidência indicando que estes estão em um controle recíproco positivo ${ }^{33}$. Assim como se observou uma redução da fosfocolina encontrada nas células analisadas, também poderia se supor que o colesterol decresceu com o uso do CLA. 


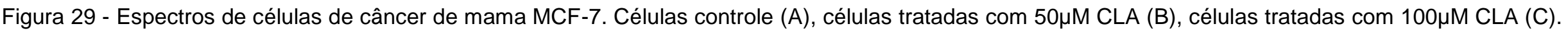

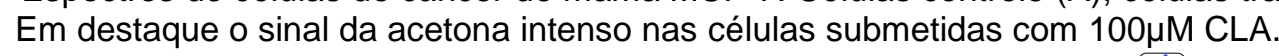

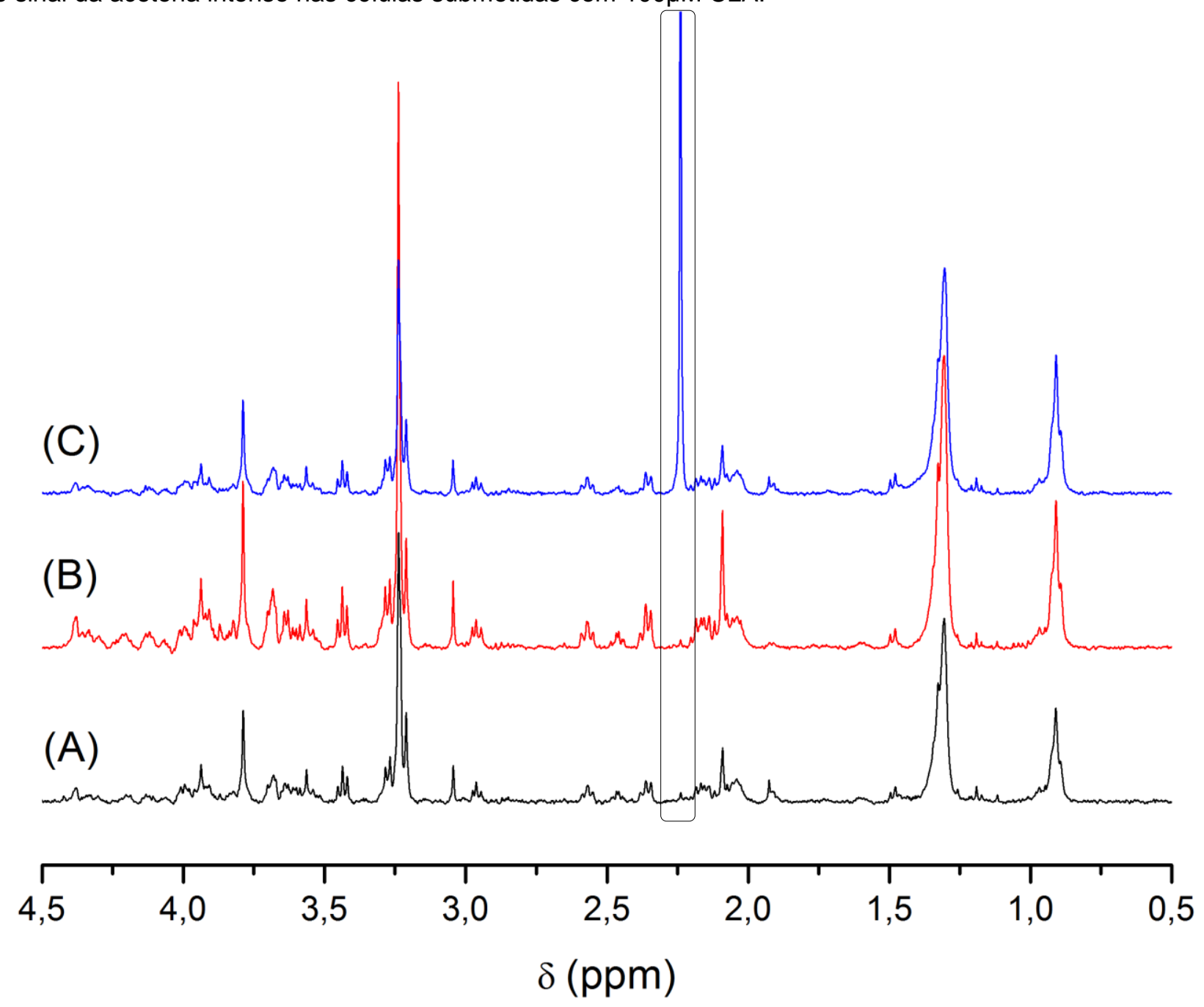




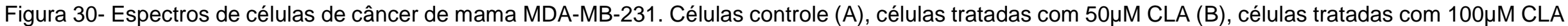
(C). Em destaque o sinal da acetona presente nas células controle (sem CLA)

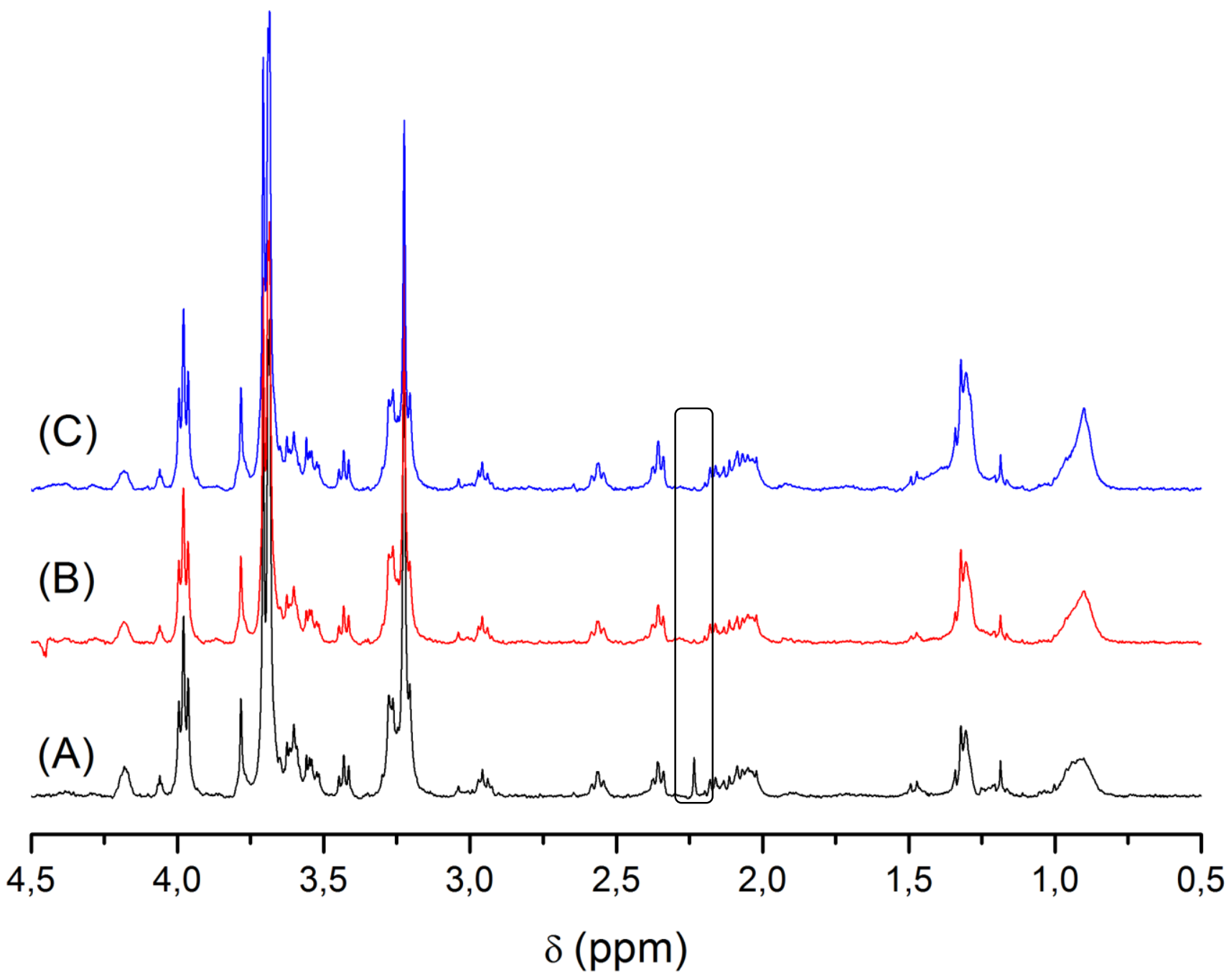


Figura 31 - Quantidade relativa da acetona presente no espectro de HR- MAS das células MCF-7 controle (sem o CLA) e submetidas ao CLA $(100 \mu \mathrm{M})$.

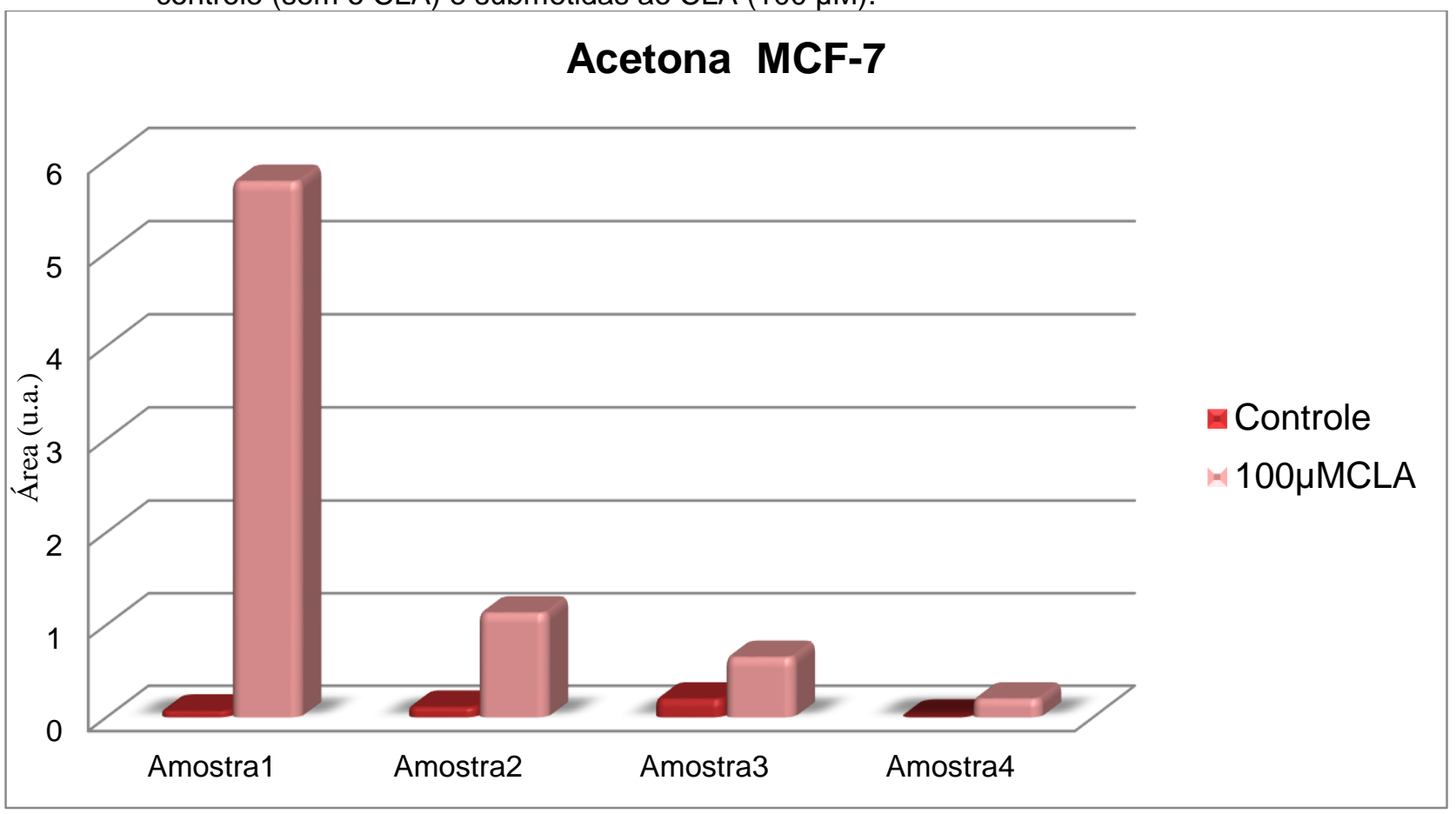

Figura 32 - Quantidade relativa da acetona presente no espectro de HR- MAS das células MDA-MB231 controle (sem o CLA) e submetidas ao CLA $(100 \mu \mathrm{M})$.

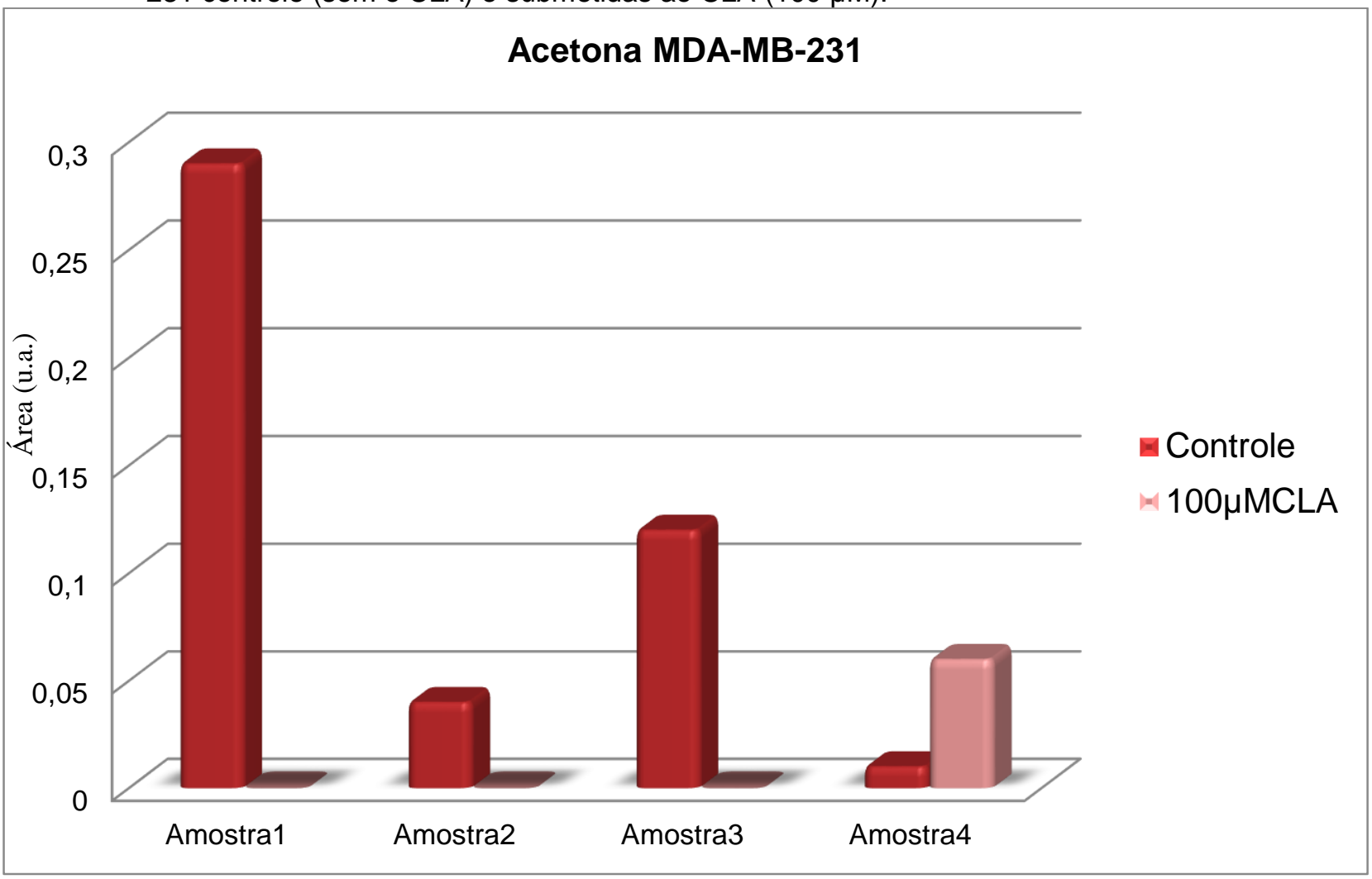


Figura 33 - Quantidade relativa da fosfocolina presente no espectro de HR- MAS das células MCF-7 controle (sem o CLA) e submetidas ao CLA $(100 \mu \mathrm{M})$.

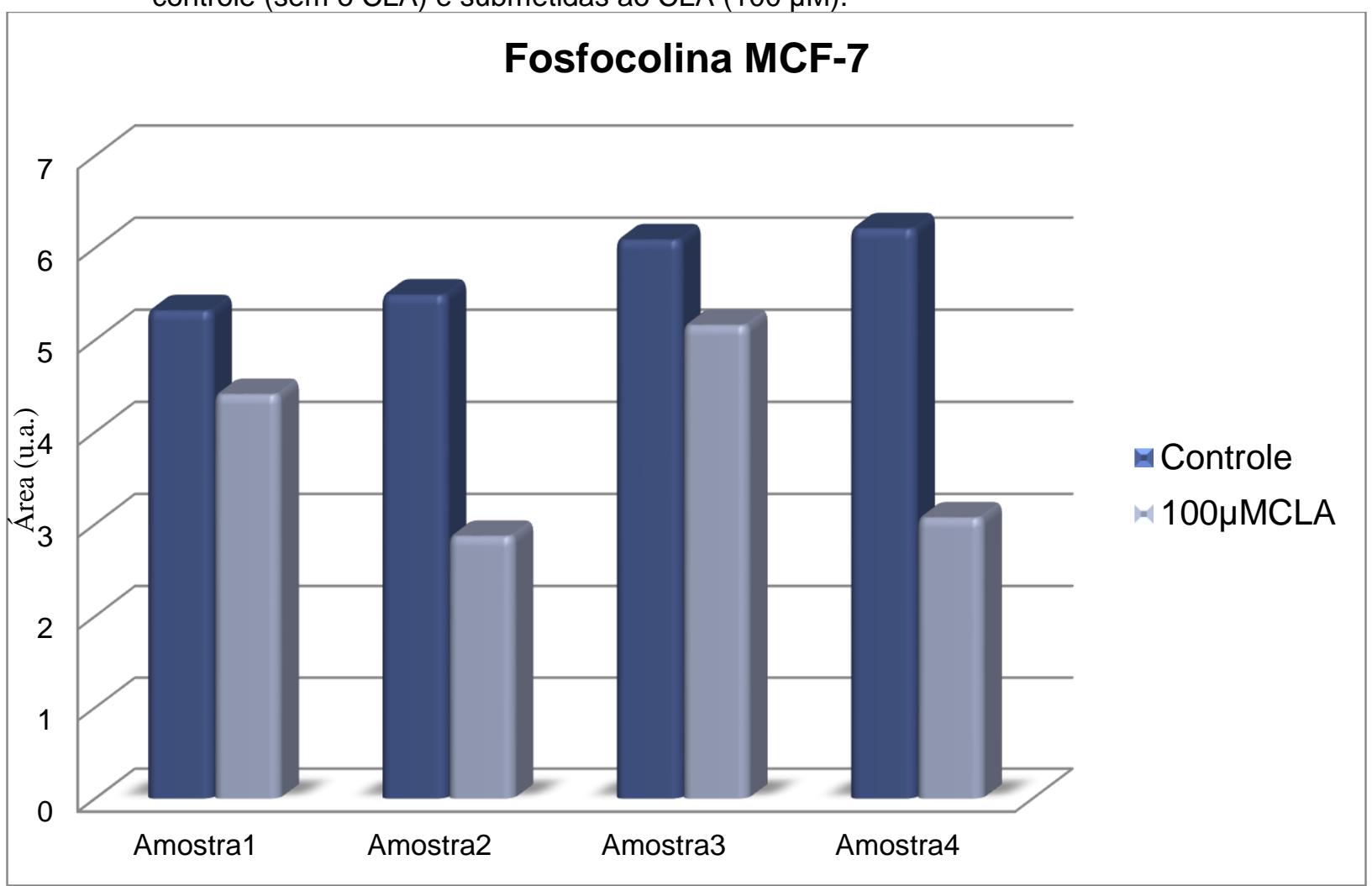

Figura 34 - Quantidade relativa da fosfocolina presente no espectro de HR-MAS das células MDA-MB231 controle (sem o CLA) e submetidas ao CLA (100 $\mu \mathrm{M})$.

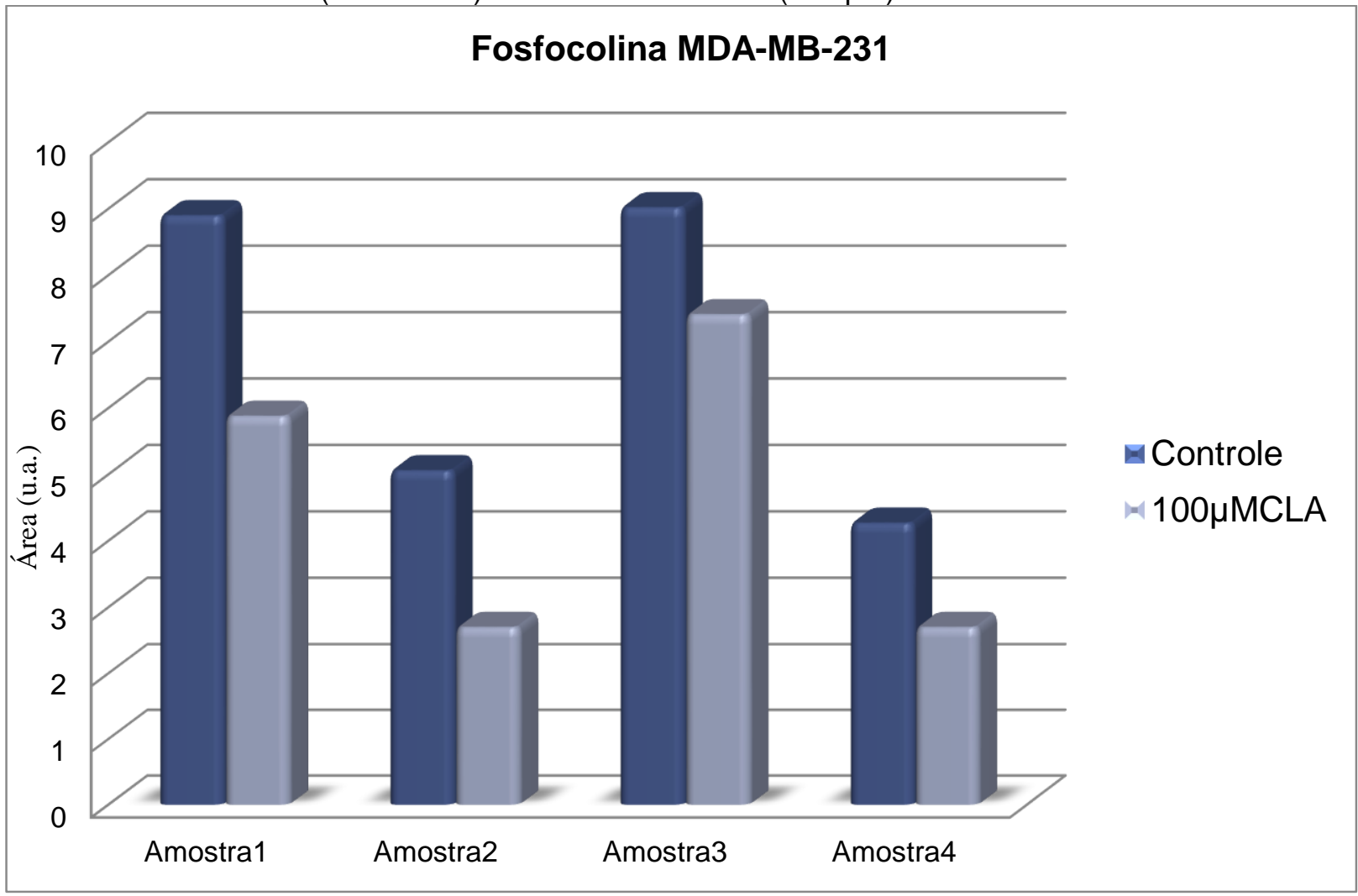




\subsubsection{Hipótese para as mudanças metabólicas causadas pelo CLA}

Na tentativa de elucidar a variação do perfil metabólico tanto nas células MCF7 quanto nas MDA-MB-231 submetidas ao CLA foi necessário uma abordagem das diferenças entre as linhagens celulares estudadas. A MCF-7 é uma linhagem de células de câncer de mama estrogênio positivo, enquanto que a MDA-MB-231 não responde a este hormônio, sendo então considerada estrogênio negativo ${ }^{61}$.

Esta diferença pode ser responsável pelas características distintas do perfil metabólico das células tratadas com CLA. Desta forma, será delineada a hipótese para explicar a produção da acetona pelas células MCF-7.

Como a principal diferença entre as células de câncer de mama analisadas neste trabalho consiste no receptor de estrogênio, é necessário abordar a via bioquímica do colesterol. Isto porque o colesterol é o principal precursor metabólico do hormônio esteroidal, substância que regula inúmeras funções fisiológicas (Fig.35).

Figura 35 - Esquema resumido da via bioquímica para a produção do colesterol e corpos cetônicos. As duas vias bioquímicas ocorrem paralelamente.

Metabolismo Piruvato $\quad$ Metabolismo Ácidos graxos

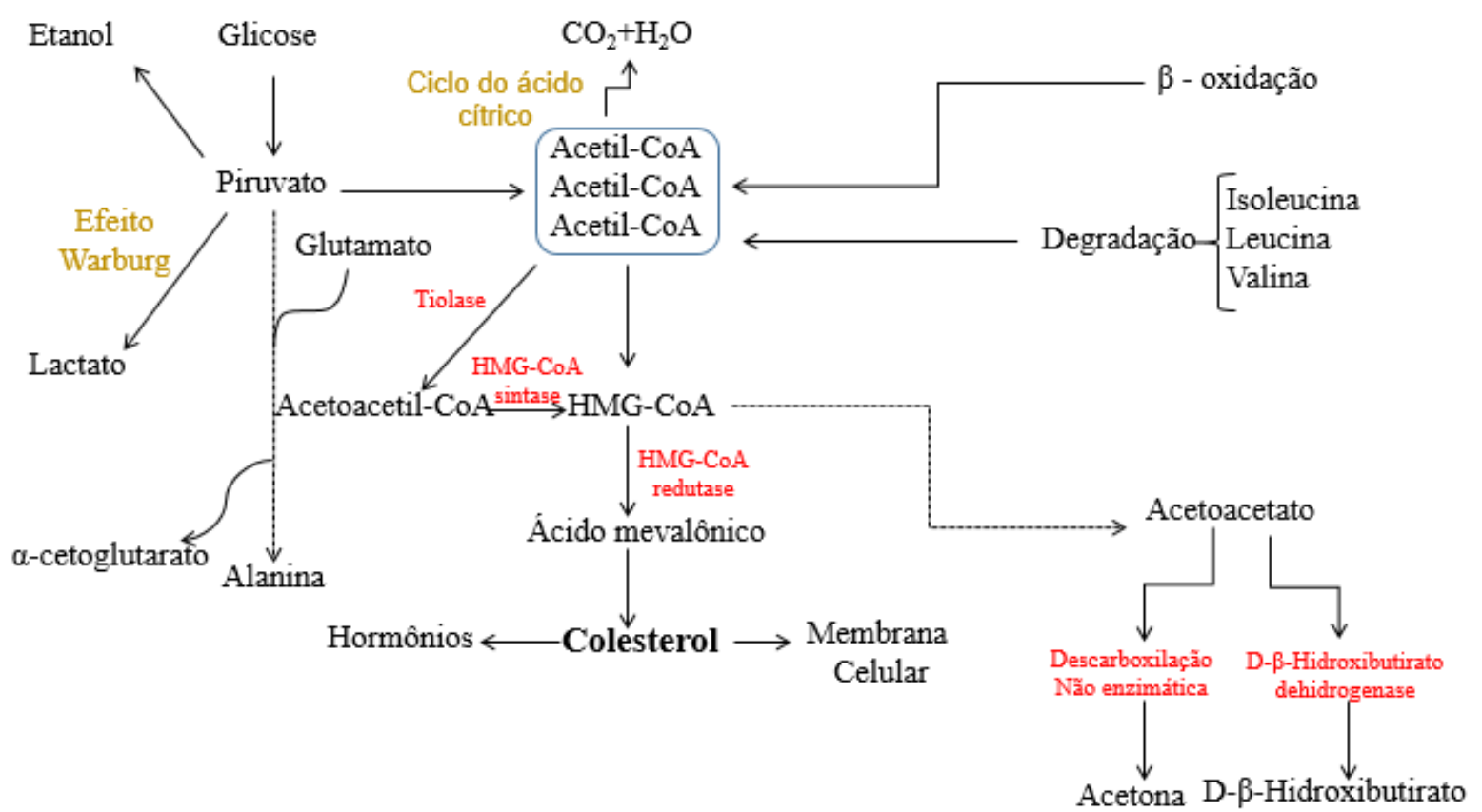


Ao comparar as vias bioquímicas descritas anteriormente, pode-se notar a presença comum do 3-hidroxi-3-metilglutaril-CoA (HMG-CoA) em destaque na Figura 35, composto importante na biossíntese do colesterol e na síntese de corpos cetônicos. Desta forma, tentou-se analisar a possível correlação do HMG-CoA com as diferenças metabólicas observadas.

\subsubsection{Inibição da HMG-CoA redutase como um dos mecanismos da atividade antitumoral do CLA}

Ácidos graxos poliinsaturados (PUFAs) são potentes inibidores da HMG-CoA redutase, que é uma enzima limitante na biossíntese do colestero|62. A síntese de colesterol está envolvida com vários processos celulares, incluindo a formação da membrana, biossíntese de hormônios e a ativação de proteínas reguladoras de crescimento e oncoproteínas. Além disto, alguns estudos reportam a suplementação de PUFAs em dietas e sugerem que a presença destes ácidos graxos podem inibir o crescimento do câncer de mama. Neste estudo, os autores atribuem este efeito à downregulation da enzima HMG-CoA redutase ${ }^{63}$.

A alta atividade da HMG-CoA redutase em tumores mamários de ratos tem sido reportada, quando comparada à tecidos mamários normais. Em adição, esta enzima exibe resistência ao mecanismo de controle por feedback em células tumorais ${ }^{64}$. Estas mudanças na atividade da enzima HMG-CoA redutase levam ao aumento da síntese do mevalonato, o qual pode contribuir para o desenvolvimento do fenótipo maligno ${ }^{61}$.

Neste contexto, compostos capazes de inibir a HMG-CoA redutase em células tumorais podem ser efetivos como agentes terapêuticos. O ácido linoleico conjugado, ácido graxo de cadeia longa, pode também inibir a HMG-CoA redutase. Desta forma, o CLA impediria a conversão do HMG-CoA a mevalonato, interferindo na síntese do colesterol (Fig. 36). Esta ação pode causar o bloqueio na via de biossíntese do colesterol, resultando assim em acúmulo de acetil-CoA, que pode se converter, após várias etapas, em acetoacetato, podendo ser reduzido para D- $\beta$-hidroxibutirato pela ação da enzima $\beta$-hidroxibutirato dehidrogenase ou sofrer decarboxilação espontânea, produzindo acetona. 
No entanto, para entender a formação da acetona em detrimento do hidroxibutirato, é necessário entender a relação entre o colesterol e os fosfolipídios. Durante a biogênese da membrana, a razão entre estes compostos permanecem relativamente constantes durante todo o tempo, sugerindo que o fluxo metabólico entre lipídios de diferentes espécies é sincronizado, existindo um controle positivo mútuo entre o colesterol e os fosfolipídios ${ }^{33}$.

Assim, a inibição da enzima HMG-CoA redutase pelo CLA causa mudanças na via metabólica para o acúmulo do acetil-CoA, consequentemente reduzindo a síntese do colesterol. Como mencionado anteriormente, estudos têm demonstrado que a inibição da síntese do colesterol tem levado à redução dos níveis de fosfolipídios ${ }^{33}$. Isto porque se demonstrou que a redução da síntese do colesterol altera a função da enzima citidiltransferase fosfocolina (CCT/CTP), resultando consequentemente também na redução dos níveis de produção da fosfocolina ${ }^{65}$ (Fig.36). Esta informação pode explicar os resultados obtidos nas análises da concentração de fosfocolina em ambas as linhagens estudadas.

Os resultados obtidos neste trabalho são consistentes com estes estudos prévios, pois os níveis de fosfocolina sofreram redução nos dois tipos celulares, MCF7 e MDA-MB-231, após a suplementação com o CLA. E a fosfaditilcolina (via Kennedy) é um ativador alostérico da enzima $D-\beta$ hidrobutirato dehidrogenase ${ }^{66}$, a qual atua na conversão do acetoacetato para hidroxibutirato. $\mathrm{Na}$ ausência ou em baixas concentrações deste modulador alostérico, a enzima D- $\beta$-hidroxibutirato dehidrogenase não atua sobre o acetoacetato e a via bioquímica é direcionada para a produção da acetona. Esta hipótese explica o motivo de as células MCF-7 produzirem acetona em detrimento ao hidroxibutirato, quando tratadas com CLA.

Em resumo, no tratamento das células com CLA pode haver um desvio na via bioquímica para formar acetoacetato, no lugar do colesterol, o qual pode culminar com a formação da acetona. Assim, a alteração na síntese do colesterol tem como alvo a redução da produção dos fosfolipídios (fosfocolina) devido ao controle positivo mútuo entre o colesterol e os fosfolipídios. Neste trabalho, observou-se que em todas as análises realizadas com o controle das células MCF-7, isto é, sem o CLA, a acetona estava presente em baixa concentração, e a fosfocolina em maior concentração. Através da suplementação das células com $100 \mu \mathrm{M}$ CLA, este perfil metabólico foi alterado. A intensidade do sinal da acetona aumentou, bem como o sinal da 
fosfocolina diminuiu, confirmando a hipótese de que a redução do colesterol induz à diminuição na formação dos metabólitos envolvidos na síntese da fosfatidilcolina.

Figura 36 - Via bioquímica resumida para a produção do colesterol e corpos cetonicos. A possível alteração do metabolismo pela presença do CLA e a influência da síntese do colesterol na formação da fosfocolina.

Metabolismo Piruvato

Metabolismo Ácidos graxos

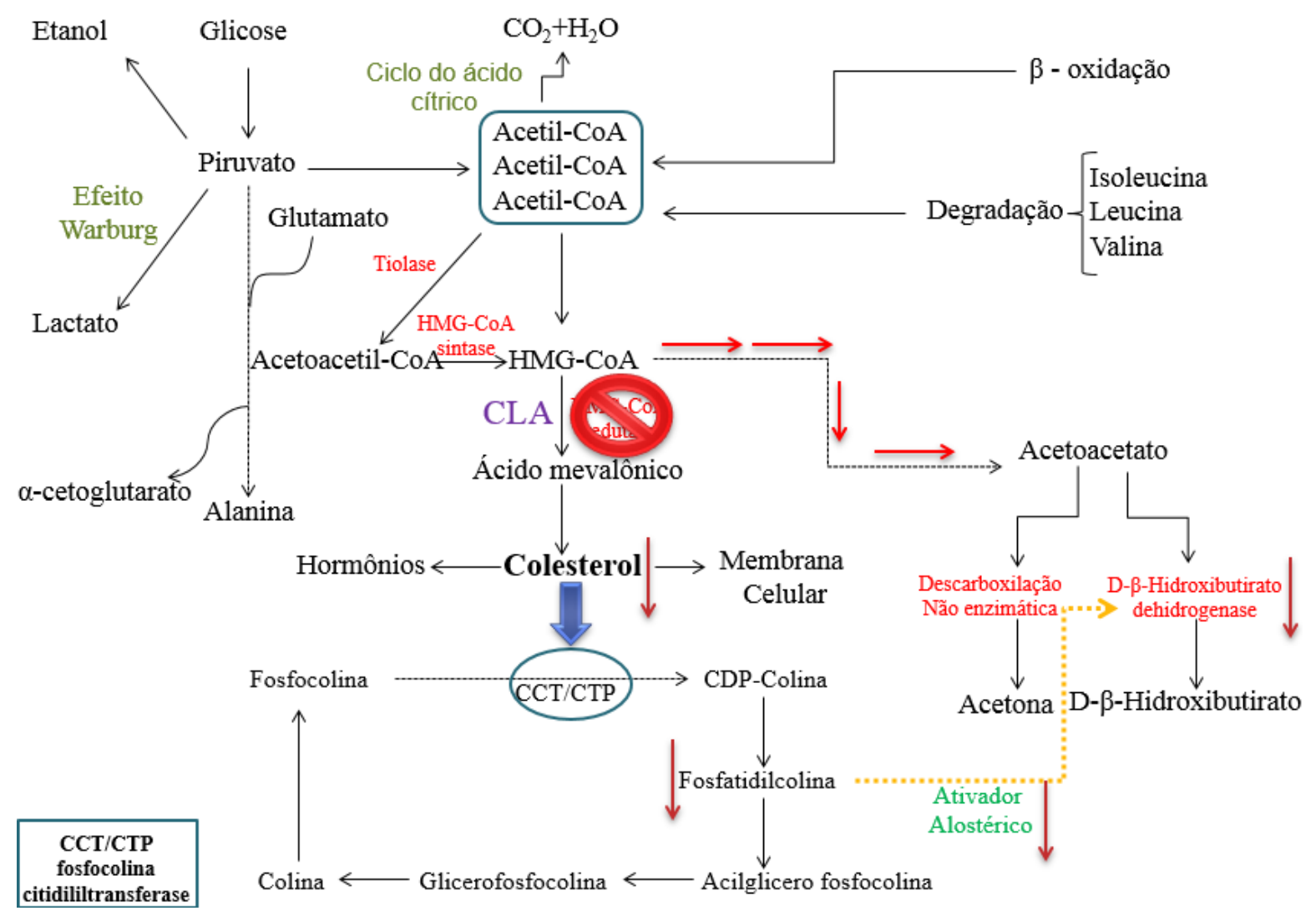

A variação da concentração de acetona, nas células de câncer de mama MDAMB-231, foi diferente ao encontrado na MCF-7. Enquanto que a variação do sinal da fosfocolina foi similar ao observado na MCF-7(Fig. 33 e 34). De acordo com os valores obtidos, percebeu-se que as células MDA-MB-231 submetidas ao tratamento com CLA também apresentaram diminuição dos níveis de fosfocolina. Possivelmente, o mecanismo interconectado com a regulação do colesterol foi afetado pela ação do CLA, interferindo na atividade da enzima CCT/CTP, como ocorreu com as células MCF-7.

Através da inibição da HMG-CoA redutase em células de câncer de mama, o CLA pode afetar o processo metabólico nestas células, aumentando a acetona e diminuindo a síntese de colesterol, influenciando processos como o crescimento celular, diferenciação, apoptose e transformação maligna. No entanto as células MDA- 
MB-231 não produziram a acetona, pois apresentam um metabolismo peculiar e mais ativo quando comparado a MCF-7, consumindo todos os substratos energéticos disponíveis.

\subsection{Modelagem da interação CLA - HMGR}

A HMG-CoA redutase (HMGR) é uma enzima que contém 887 aminoácidos, se encontra ligada à membrana do retículo endoplasmático e está sujeita à regulação de curto prazo, pela fosforilação reversível. A ligação do HMG à enzima HMGR ocorre, entre outras interações, através do terminal carboxilato da porção do HMG, que forma uma ponte salina com a Lys735 da HMGR (Fig.37) ${ }^{67}$.

Figura 37 - Ponte salina entre o terminal carboxilato da porção da HMG (verde) e a Lys735 da HMGR (amarelo).

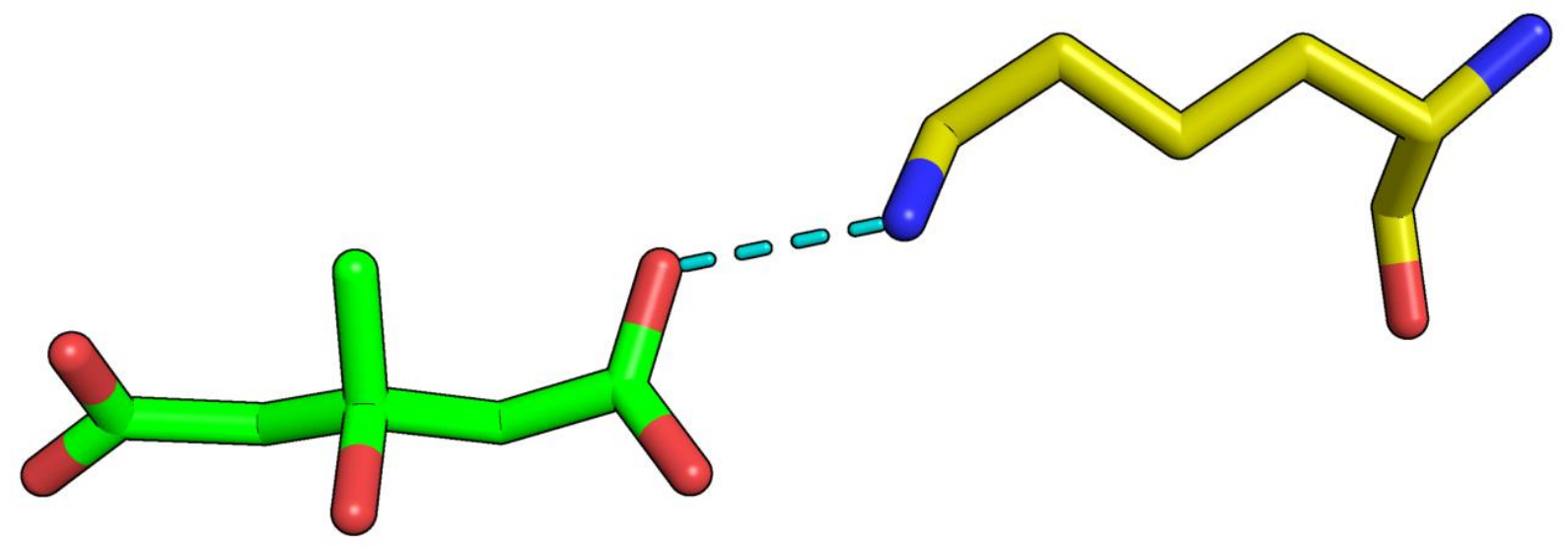

A HMGR é o principal ponto de regulação da biossíntese de colesterol ${ }^{26}$. Assim os estudos de modelagem da interação do CLA com a HMGR, usaram como modelo tanto as interações da HMG com a HMGR quanto às observadas com os inibidores competitivos, específicos e reversíveis da HMGR, denominadas de estatinas. $\mathrm{Na}$ Figura 38 é mostrada a estrutura da atorvastatina e da HMG. 
Figura 38 - Estrutura da Atorvastatina e da HMG, respectivamente.
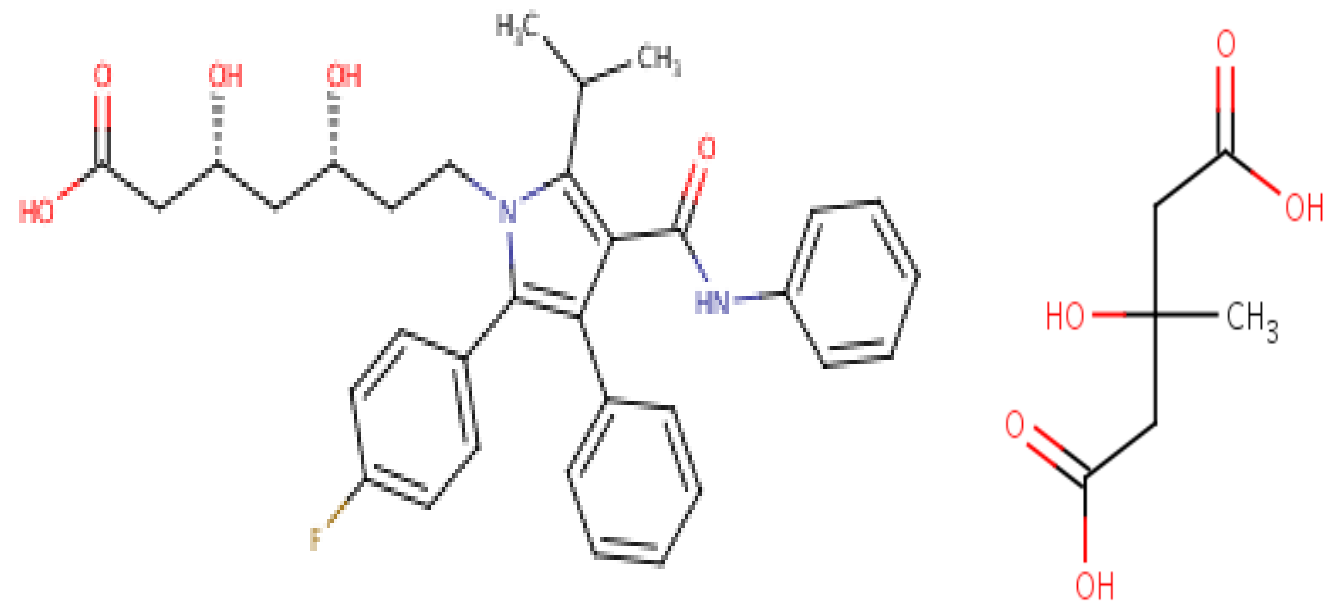

Como neste trabalho observou-se a produção de acetona, quando as células tumorais foram submetidas ao CLA, sugere-se um mecanimo de ação do CLA sobre a HMGR, semelhante ao HMG e as estatinas. Para isso, fez-se uma estudo de docking usando o programa GOLD. Com o programa GOLD estudou-se a interação do CLA e outros ácidos graxos com a cavidade do sítio ativo da enzima HMGR. Inicialmente, observou-se que apesar das insaturações, o CLA possui liberdade conformacional significativa, e como o sítio da HMGR é grande (Fig.39), não houve um efeito pronunciado da restrição conformacional imposta pelas duplas ligações.

Figura 39 - Posição ocupada pela atorvastatina (A) e o CLA (B) na enzima HMGR.

(A)

(B)
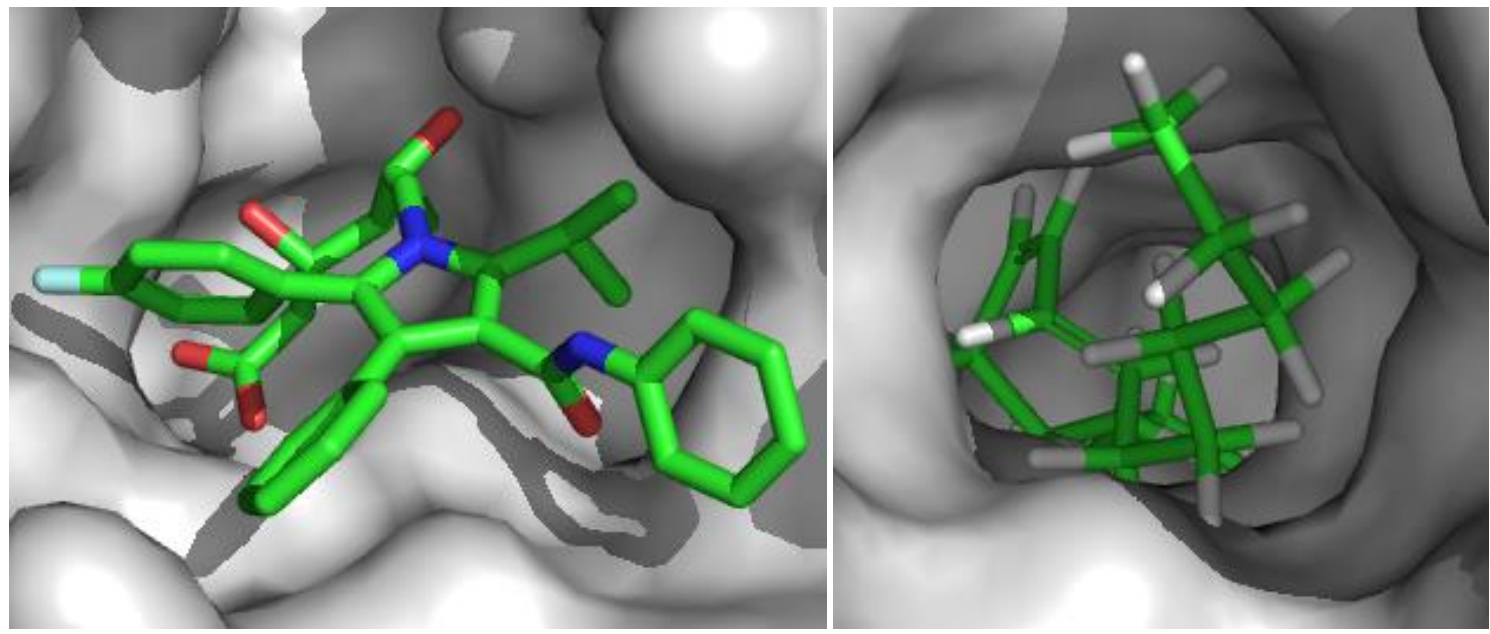

Na Figura 40, pode-se perceber que o CLA e o HMG-CoA ocupam posição similar na HMGR, e existe a hipótese de o grupo carboxílico do CLA poder interagir 
de forma similar ao grupo carboxílico da HMG com a Lys735 da HMGR (Fig. 41). Isto é, sugere-se que o CLA pode se tornar um inibidor competitivo da HMGR. Ao se ligar a HMGR, o CLA impediria a ligação do substrato, o HMG-CoA. Desta forma, a etapa da conversão do HMG-CoA para mevalonato ficará impedida, e consequentemente a biossíntese do colesterol.

Figura 40 - Posição ocupada pelo CLA (vermelho) e pelo HMG-CoA (verde) na HMGR.

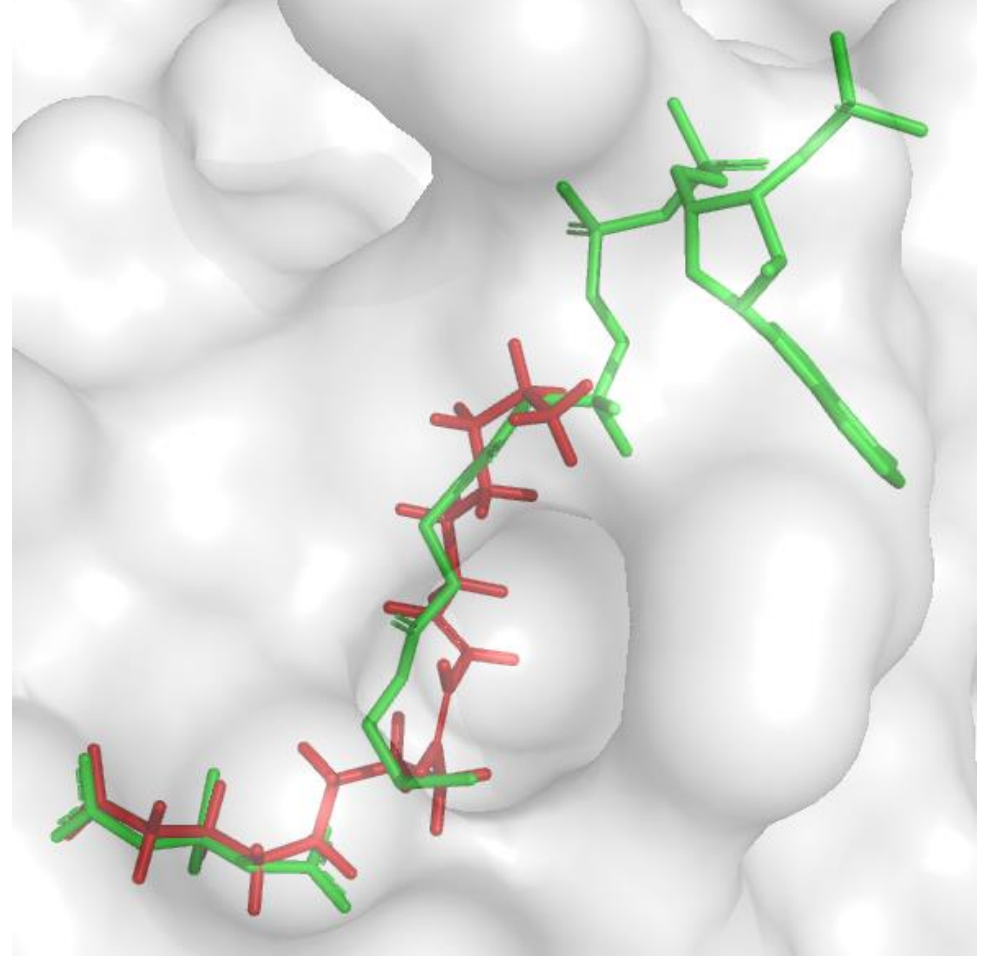

Figura 41- Hipótese da ligação do terminal carboxilato do CLA (verde) e a Lys735 da HMGR (amarelo). Interação similar entre o terminal carboxilato da porção da HMG e a Lys735 da HMGR.

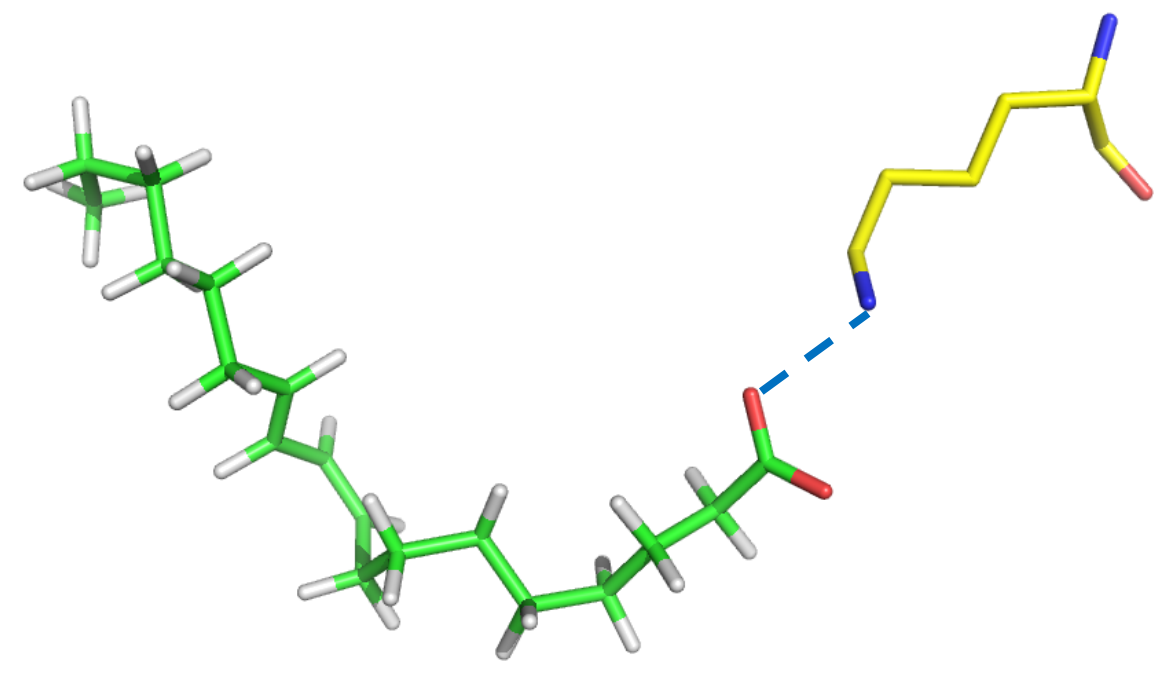


Também é plausível que outros ácidos graxos de cadeia longa se liguem a HMGR. Realizou-se o procedimento de docking do ácido eicosapentanóico (EPA) e o resultado apresentado sugere algumas conformações semelhantes ao CLA. A análise visual e os procedimentos de docking indicam que estes ácidos graxos poderiam se ligar ocupando uma posição similar a que o HMG ocupa na enzima.

Como mencionado anteriormente, as células de câncer de mama, MCF-7, submetidas a $100 \mu \mathrm{M}$ de CLA, apresentaram alteração no perfil metabólico, com a produção de acetona. Este fato corrobora com o estudo feito com diferentes concentrações de ácidos graxos em célula Reuber H35, onde foi verificado também que concentrações abaixo de $100 \mu \mathrm{M}$ de diversos ácidos graxos não apresentaram resultados significativos na atividade da enzima HMG-CoA redutase ${ }^{68}$. Neste mesmo estudo, verificou-se que quando as células Reuber H35 foram cultivadas com o ácido docosa-henaenóico (DHA) houve uma diminuição da atividade da HMG-CoA redutase causada pela inibição competitiva da enzima, bem como as estatinas. Adicionalmente, analisou-se também que células HepG2 quando submetidas ao tratamento com o ácido eicosapentaenóico (EPA) tiveram o mesmo comportamento que quando submetidas a lovastatina ${ }^{62}$.

Na Figura 42 apresenta-se o estudo mostrando a possível posição do CLA e do EPA na HMGR. Pode se observar que a conformação da HMG, CLA e EPA são muito similares indicando que possam ter o mesmo modo de atuação.

Observou-se um comportamento diferenciado quando se fez o docking com o ácido mirístico. Ao contrário do HMG (substrato natural) e dos outros ácidos graxos testados, na maioria das conformações, o ácido mirístico não apresentou a mesma posição na HMGR (Fig. 42). Talvez esta peculiaridade dos resultados possa ser explicado pelo menor tamanho deste ácido graxo, de forma que o programa deduza que ele prefira interagir com a parte hidrofóbica da cavidade, do que com a Lys 735. Pode ser que durante a dinâmica de interação desse substrato no sítio ativo, vários modos de ligação ocorram, principalmente para moléculas flexíveis como estas.

O ácido mirístico, juntamente com o ácido láurico e o ácido palmítico, é considerado hiper-colesterolêmico. Isto corrobora com o fato de a atividade da enzima HMG-CoA redutase aumentar quando células Reuber H35 foram submetidas à uma concentração 100-150 $\mu \mathrm{M}$ de ácido miristico ${ }^{68}$. 
Figura 42 - Ponte salina entre o terminal carboxilato da porção da HMG (laranja) e a Lys735 da HMGR (amarelo). Hipótese da ligação similar entre o terminal carboxilato do CLA (verde) e do ácido eicosanoide (magenta) e a Lys735. Posição do ácido miristico diferente dos demais compostos (Em destaque).

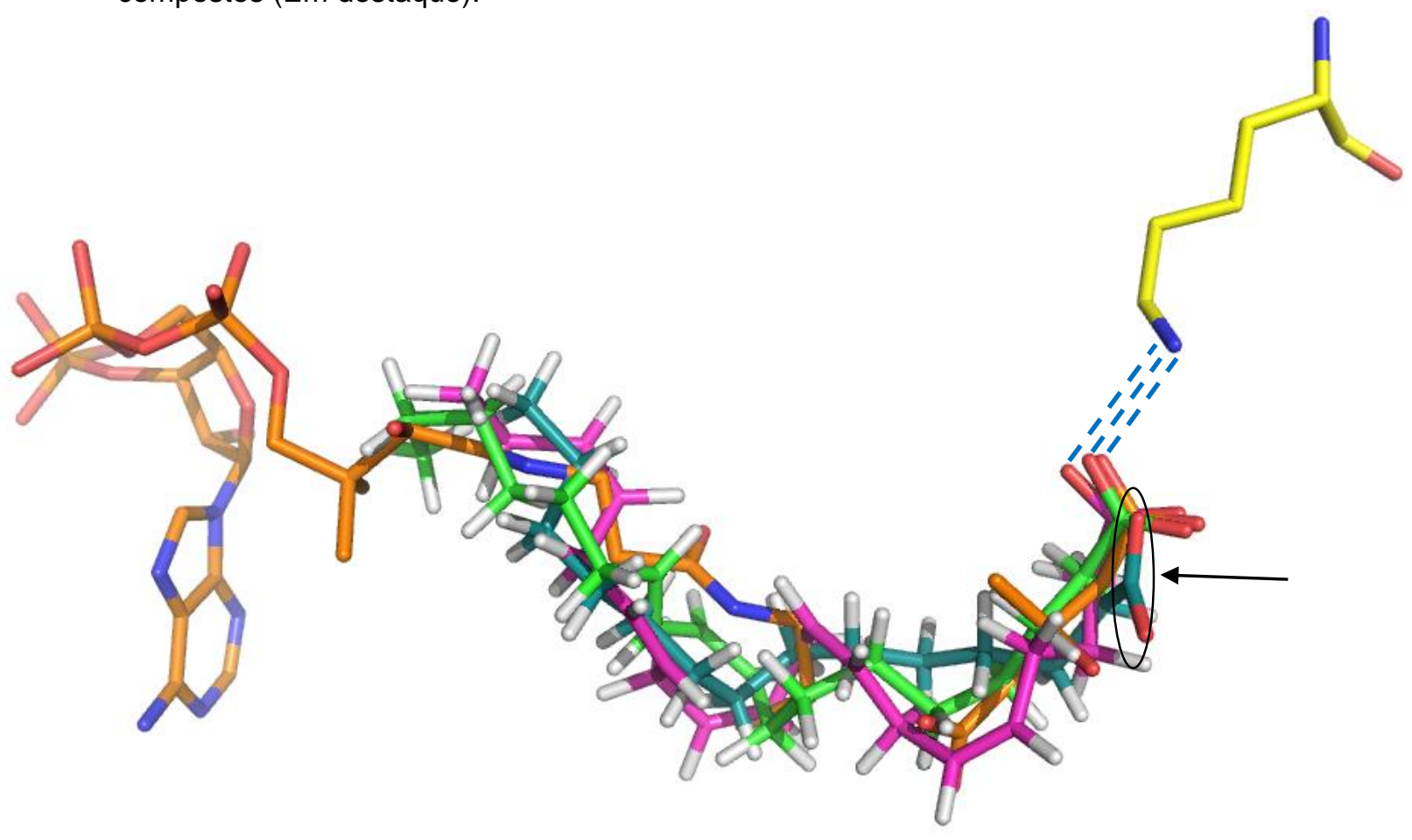

\subsection{Uso do método da diagonalização filtrada para processamento do sinal de HR-MAS, no domínio do tempo.}

Estudou-se também a viabilidade de se usar o método de diagonalização filtrada (FDM) para processar os sinais de RMN no domínio do tempo obtidos com a técnica HR-MAS como alternativa a transformada de Fourier. Como o FDM gera uma lista de parâmetros para cada sinal, como por exemplo, frequência, largura de linha e intensidade de fase, pode-se suprimir um ou mais componentes do espectro, removendo o parâmetro desejado da lista de dados, antes de construir o espectro no domínio da frequência. Com isso é possível eliminar sinais indesejados como o sinal da água ou linhas com larguras acima ou abaixo de um determinado valor.

Para avaliar a eficiência do método fez-se uma comparação do procedimento tradicional com supressão do sinal da água, filtro de $T_{2}$ e transformada de Fourier (Figura 43) e o uso do FDM para processar o sinal, sem supressão ou filtro $T_{2}$ (Figura 44). 
Na Figura 43 estão os espectros de HR-MAS de células de câncer de mama (MCF-7) processados com o algoritmo padrão da Transformada de Fourier (TF). Na Figura 43A nota-se que em 4,7 ppm tem-se um sinal intenso (água) que dificulta a identificação dos sinais pouco intensos. Na Figura 43B tem-se o espectro (TF) da mesma amostra, agora adquirido com HR-MAS e pré-saturação, de modo que o sinal da água foi suprimido. Ainda na Figura 43 (A e B) pode-se observar que ocorre a sobreposição de sinais largos e estreitos, por exemplo, em 1 ppm, dificultando a análise e identificação desses picos estreitos. Para minimizar os sinais largos tem-se na Figura 43C, o espectro de HR-MAS com pré-saturação e filtro de T2 (CPMG).

Na Figura 44 estão os espectros processados por FDM a partir do mesmo sinal no domínio do tempo, usado para obter o espectro da Figura 43A. Na Figura 44A está o espectro calculado apenas com os sinais com largura de linha a meia altura, FWHI (full width at half maximum) maior do que $0,1 \mathrm{~Hz}$. Assim, esse espectro não contém apenas sinais muito estreitos que podem ser considerados como ruídos. Na Figura 44B, está o espectro calculado apenas com os sinais de largura de linha a meia altura maior do que $5 \mathrm{~Hz}(\mathrm{FWHI}>5 \mathrm{~Hz})$. Esse espectro só contém os sinais com linhas largas e para se obter o espectro com TF é necessário utilizar na sequência um filtro de difusão ao invés de filtro de $\mathrm{T}_{2}$. Como as moléculas pequenas tem um tempo de autodifusão bem menor do que as moléculas grandes, pode-se obter um sinal HR-MAS, sem as linhas estreitas, que desapareceram com o filtro de difusão.

Figura $44 \mathrm{C}$ está um espectro com sinais $5 \mathrm{~Hz}>\mathrm{FWHI}>0,1 \mathrm{~Hz}$, que é equivalente a subtração do espectro A pelo espectro B. Nesse espectro pode-se ver que o sinal intenso e largo da água foi suprimido. Figura 44D está o espectro obtido com larguras de linhas entre $1 \mathrm{~Hz}$ e $5 \mathrm{~Hz}$ ou seja $1 \mathrm{~Hz}<\mathrm{FWHI}<5 \mathrm{~Hz}$. Esse filtro elimina as larguras de linha muito finas, abaixo de $1 \mathrm{~Hz}$ e é similar ao obtido com a técnica normal de HRMAS, com pré-saturação e filtro de $T_{2}$ (Fig. 43C). No entanto pode-se ver que a resolução do espectro da Figura 44D é muito superior ao da Figura 43C.

Na Figura 45, estão juntos os espectros das Figura 43C e Figura 44D, para uma melhor visualização da grande potencialidade da FDM para processar espectros de HR-MAS. Desta forma, o processamento por FDM, que não necessita de présaturação ou filtro de $T_{2}$, pode reduzir substancialmente o tempo de aquisição dos dados, contribuindo para manter a integridade da amostra, importante principalmente no caso de amostras biológicas. 
Figura 43 - Espectros de HR-MAS de células de câncer de mama (MCF-7) (A); espectro da mesma amostra (A) adquirido com HR-MAS e pré-saturação, de modo que o pico da água (4,7ppm) foi suprimido (B) e espectro de HR-MAS com pré-saturação do sinal da água e CPMG, possibilitando melhor analise dos picos estreitos. Nos três espectros são apresentados apenas a componente real e foram obtidos com a FT, processados no software ACD/NMR Processor 12.01

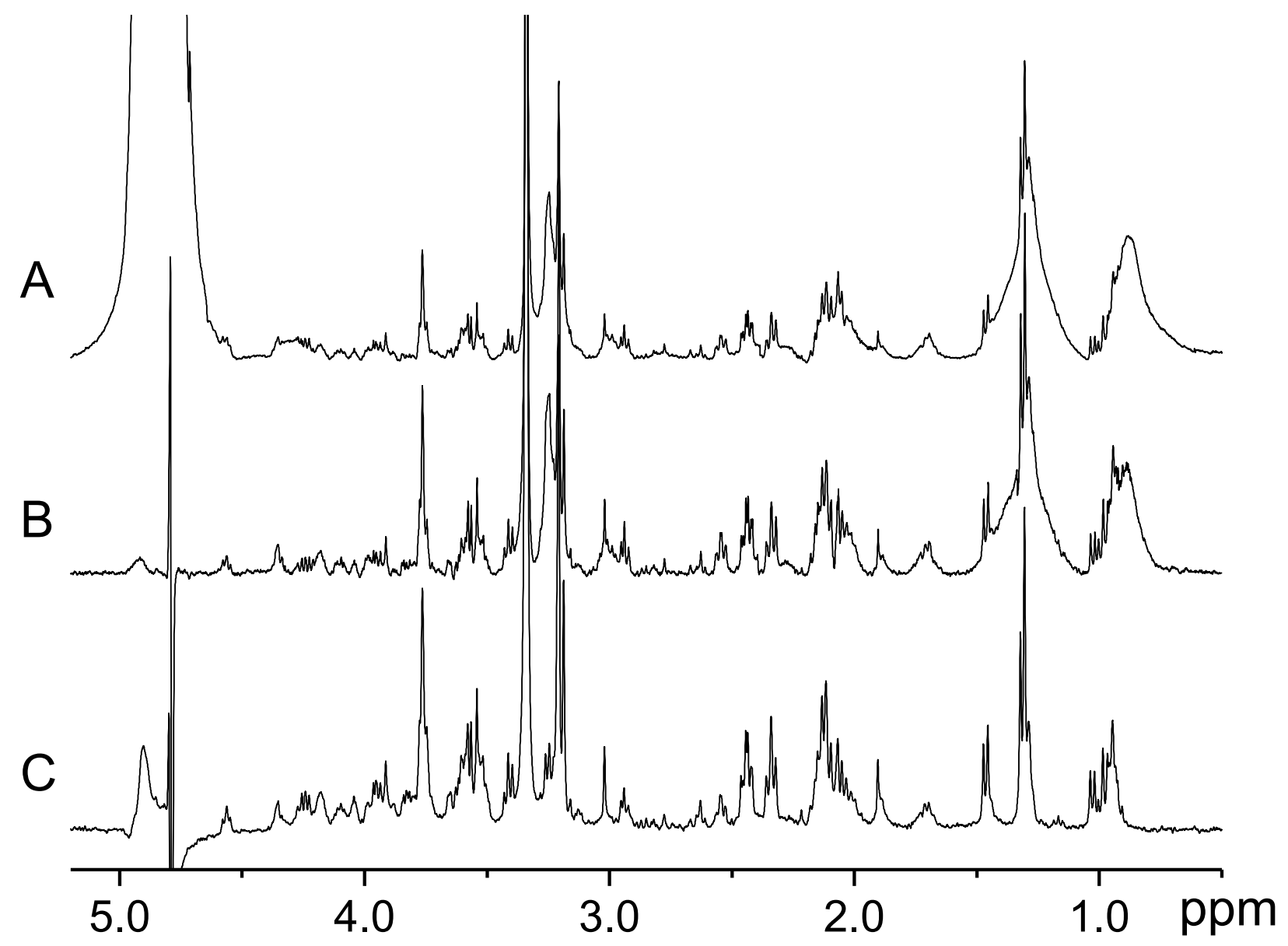

Fonte:MARIA,R.M.;MORAES,T.B.;MAGON,C.J.;VENÂNCIO,T.;ALTEI,W.F.;ANDRICOPULO,A.D.;COLNAGO,L.A.Processing of high resolution magic angle spinning spectra of breast cancer cells by the filter diagonalization method. Analyst,p.4547,2012 ${ }^{69}$. 
Figura 44 - Espectros de HR-MAS processados por FDM, após a remoção dos picos do solvente, calculado em diferentes condições de filtro. (A) Picos com $\mathrm{FWHI}>0,1 \mathrm{~Hz}$ foram negligenciados; (B) picos com $\mathrm{FWHI}<5 \mathrm{~Hz}$ foram negligenciados; (C) picos com $\mathrm{FWHI}>1 \mathrm{~Hz}$ ou $\mathrm{FWHI}<5 \mathrm{~Hz}$ foram negligenciados; (D) picos com $\mathrm{FWHI}<1 \mathrm{~Hz}$ e $\mathrm{FWHI}>5 \mathrm{~Hz}$ foram negligenciados. A soma dos espectros (B) e (C) resulta no espectro (A).

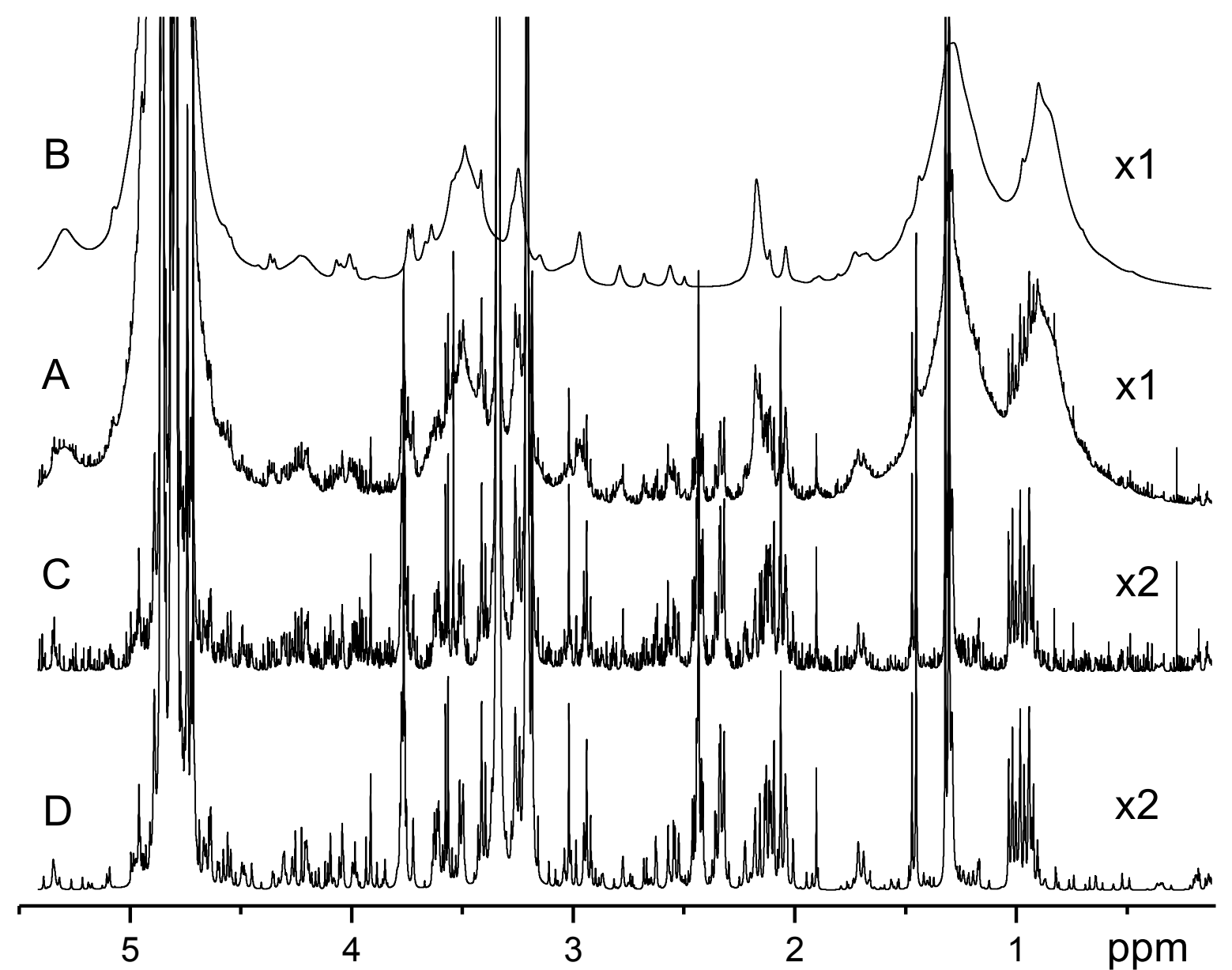

Fonte:MARIA,R.M.;MORAES,T.B.;MAGON,C.J.;VENÂNCIO,T.;ALTEI,W.F.;ANDRICOPULO,A.D.;COLNAGO,L.A.Processing of high resolution magic angle spinning spectra of breast cancer cells by the filter diagonalization method. Analyst, p. 4548, $2012^{69}$ 
Figura 45 - Espectro processado por FDM de HR-MAS da Figura 44D na faixa de 0,75 a 3,1 ppm. Para comparação o espectro da Figura 43C foi reproduzido.

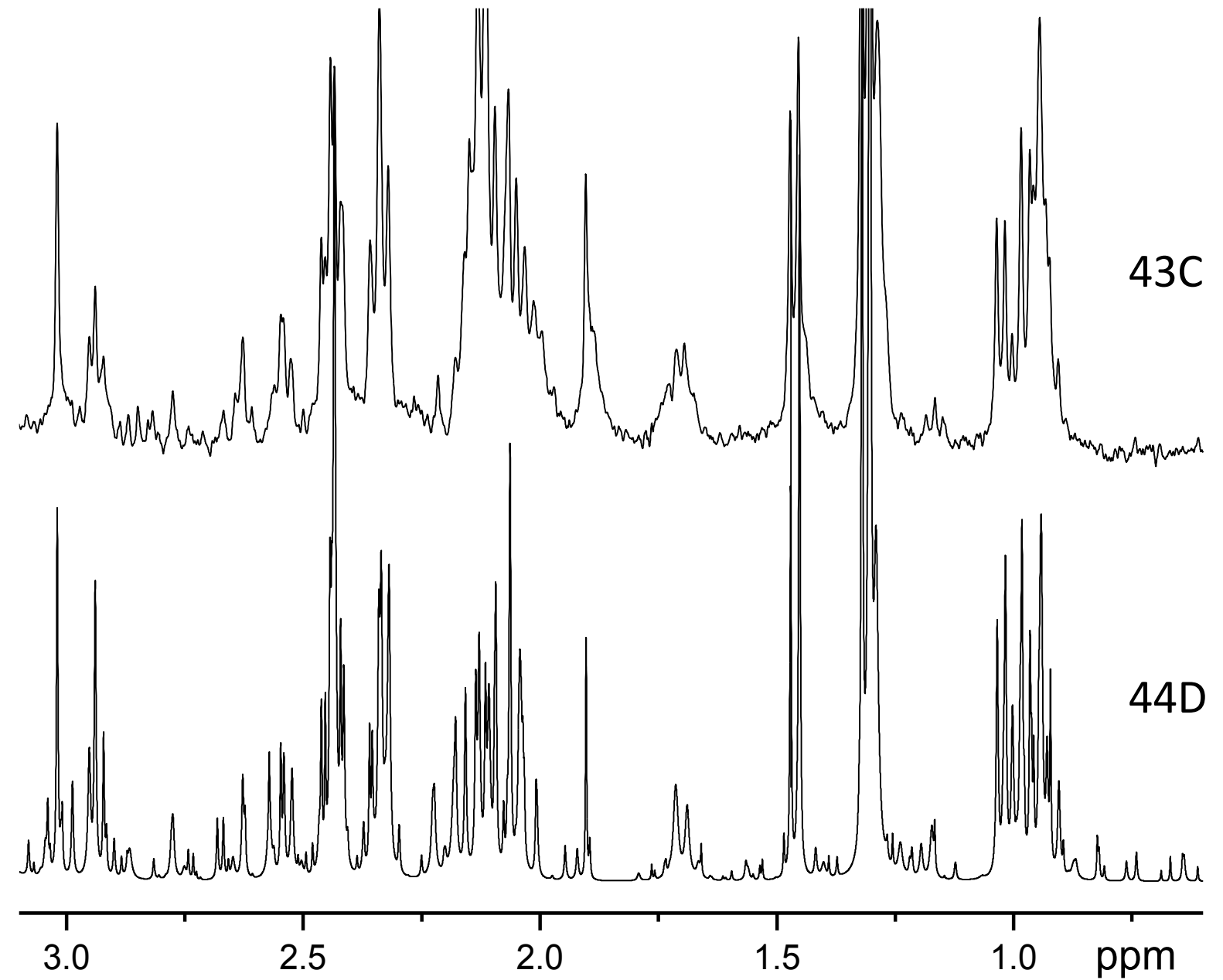

Fonte:MARIA,R.M.;MORAES,T.B.;MAGON,C.J.;VENÂNCIO,T.;ALTEI,W.F.;ANDRICOPULO,A.D.;COLNAGO,L.A.Processing of high resolution magic angle spinning spectra of breast cancer cells by the filter diagonalization method. Analyst,p. $4548,2012^{69}$ 


\section{CONCLUSÕES}

A técnica de HR-MAS, com pré-saturação do sinal da água e filtro de $T_{2}$ com a sequência de CPMG, mostrou ser uma ferramenta útil para identificação e quantificação do perfil metabólico das células de câncer de mama, MCF-7 e MDA-MB231. Também se concluiu que o processamento de espectros HR-MAS com FDM mostrou ser uma técnica eficaz e rápida, contribuindo principalmente para a manutenção da integridade da amostra, neste caso biológica. O HR-MAS foi uma técnica de alta repetibilidade, principalmente por se tratar de um método simples, que dispensou o pré-tratamento das amostras, evitando o consumo de tempo e reagentes para a extração dos metabólitos celulares, além de contribuir na manutenção da integridade da amostra. Também mostrou ser eficiente para identificar as variações metabólicas nas células MCF-7 e MDA-MB-231 tratadas com CLA.

Com os dados de HR-MAS demonstrou-se que O CLA alterou significativamente o perfil metabólico das duas linhagens celulares, com o aumento da produção de acetona, na MCF-7 e redução da fosfocolina em ambas as células, levantando a hipótese de que o CLA pode estar inibindo a enzima HMG-CoA redutase, de maneira similar as estatinas. Isso foi confirmado com uso de modelagem molecular onde se demonstrou que o CLA pode ser um inibidor da HMGR. Ao se ligar a HMGR, o CLA impede a ligação do HMG-CoA impedindo sua conversão para mevalonato e consequentemente a biossíntese do colesterol. Esse mecanismo pode explicar a redução da fosfocolina, uma vez que este componente possui controle positivo mútuo com o colesterol.

Com a inibição da HMGR, o HMG-CoA é então convertido para acetoacetato e posteriormente a acetona. Desta forma, pode-se concluir que a inibição da HMGR pelo CLA pode ser uma hipótese do mecanismo bioquímico tanto de sua ação anticarcinogênica quanto das atividades antidiabética, antiadipogênica e antiaterogênica, relatadas na literatura.

Como propostas futuras, pretende-se através da técnica de RMN, fazer o rastreamento das vias bioquímicas de células de câncer de mama quando submetidas a diversos quimioterápicos (doxorrubicin, tamoxifen e estatinas), comparando o perfil metabólico obtido com os resultados obtidos neste trabalho de doutorado, na tentativa de elucidar possíveis falhas na terapêutica aplicada. 


\section{REFERÊNCIAS BIBLIOGRÁFICAS}

1-INSTITUTO NACIONAL DO CÂNCER. Estatísticas do câncer. Vigilância do câncer e fatores de risco.Incidência 2012.Disponível em: http://www.inca.gov.br/estimativa/2012/>.Acesso em: 20 jun.2013.

2-MIROSLAVA, C.; DAVID, A.B.; CULF, A.S.; CHUTE, I. Cell culture metabolomics: applications and future directions. Drug Discovey Today,v. 15,n.15-16,p. 610-621, 2010.

3-KIM, Y.S.; MARUVADA, P. Frontiers in metabolomics for cancer research : proceedings of a national cancer institute workshop. Metabolomics,v. 4, p. 105-113, 2008.

4-ROBERTSON,D.G. Metabonomics in toxicology: a review. Toxicological Sciences,v. 85, p.809-822, 2005.

5-YURAWECZ, M. P.; KRAMER, J. K. G.; MOSSOBA, M. M.; ROACH, J. A. G.; SEHAT, N.; EULITZ, K.; FRITSCHE, J.; KATAOKA, A. ; KU, Y. Analytical methodology for CLA. In: INTERNTIONAL CONFERENCE ON CLA, 1., 2001, Alesund. Proceeding... Alesund: Natural ASA, 2001. p. 14.

6-CHOUINARD, P.Y.; BAUMAN, B.A.; BAUMGARD, M.A. An update an conjugated linoleic acid. In: CORNELL NUTRITIONAL CONFERENCE FEED MANUFACTORY, 1., 1999, Ithaca. Proccedings... Ithaca: Cornell university, 1999. p. 93-101.

7-SCHMID, A.; COLLOMB, M.; SIEBER, R.; BEE, G. Conjugated linoleic acid in meat and meat products: a rewiew. Meat Science, v. 73, p. 29-41, 2006.

8-KEPLER, C. R.; HIRONS, K. P.; MCNEILL, J. J.; TOVE, S. B. Intermediates and products of the biohydrogenation of linoleic acid by Butyrivibrio fibrisolvens. Journal of Nutrition Biochemistry, v. 241, p. 1350-1354,1996.

9- TANAKA, K. Occurrence of conjugated linoleic acid in ruminant products and its physiological functions. Animal Science Journal, v.76, p. 291-303, 2005.

10-ROACH, J.A.G.; MOSSOBA, M.M.; YURAWECZ, M.P.; KRAMER, J. K.G. Chromatografic separation and identification of conjugated linoleic acid isomers. Analytica Chimica Acta, v. 465, p. 207-226, 2002.

11-MARIA,R.M.; COLNAGO, L. A.; FORATO,L. A.; BOUCHARD, D. Fast and simple nuclear magnetic resonance method to measure conjugated linoleic acid in beef. Journal of Agricultural and Food Chemistry, v. 58, p. 6562-6564, 2010.

12-EYNARD, A.R.; LOPEZ, C.B. Conjugated linoleic acid (CLA) versus saturated fats/cholesterol: their proportion in fatty and lean meats may affect the risk of developing colon cancer. Lipids Health Disease, v. 2, p. 1476-1511,2003. 
13-MACDONALD, H.B. Conjugated linoleic acid and disease prevetion: a rewiew of current knowledge. Journal of the American College of Nutrition, v.19, n. 90002, p. 111-118, 2000.

14-IP, C. CLA and cancer prevention. In: INTERNATIONAL CONFERENCE ON CLA, 1.,2001, Alesund, Proceedings... Alesund: Natural ASA, 2001. p. 6-7.

15-PARIZA, M. W.; HARGRAVES, W. A. A beef-derived mutagenesis modulator inhibits initiation of mouse epidermal tumors by 7,12-dimethylbenzanthracene. Carcinogenesis, v. 6, p. 591-593,1985.

16-HA, Y. L.; GRIMM, N. K.; PARIZA, M. W. Anticarcinogens from freid ground beef: heat-altered derivatives of linoleico acid. Carcinogenesis, v. 8, p. 1881-1887, 1987.

17-WAHLE, K.W.J.; HEYS, S.D. Cell signal mechanisms, conjugated linoleic acids (CLAs) and anti-tumorigenesis. Prostaglandins, Leukotrienes and Essential Fatty Acids, v. 67, n. 2-3, p. 183-186, 2002.

18- BELURY, M.A. Inhibition of carcinogenesis by conjugated linoleic acid: Potential mechanisms of action. The Journal of Nutrition, v. 132,n.10, p. 2995-2998,2002.

19- MAJUNDER, B.; WAHLE, K.W.J.; MOIR, S.; SCHOFIELD, A.; CHOE, S.N.; FARQUHARSON, A.; GRANT, I.; HEYS, S. D. Conjugated linoleic acids (CLAs) regulate the expression of key apoptotic genes in human breast cancer cells. The FASEB Journal, v.16, p. 1447-1449, 2002.

20-ISLAM, M.A.; KIM, Y. S.; JANG, W. J.; LEE, S. M.; KIM, H. G.; KIM, S. Y.; KIM, J. O.; HA, Y. L. A mixture of trans, trans conjugated linoleic acid induces apoptosis in MCF-7 human breast cancer cells with reciprocal expression of Bax and Bcl-2. Journal of Agricultural and Food Chemistry, v. 56, p. 5970-5976,2008.

21-OU, L.; IP, C.; LISAFELD, B.; IP, M.M. Conjugated linoleic acid induces apoptosis of murine mammary tumor cells via Bcl-2 loss. Biochemical and Biophysical Research Communication, v. 356, p. 1044-1049, 2007.

22-IP, C. CLA and cancer prevention. In: INTERNATIONAL CONFERENCE ON CLA, 1.,2001, Alesund. Proceedings... Alesund: Natural ASA, 2001. p. 6-7.

23-MASSO-WELCH, P.A.; ZANGANI, D.; IP, C.; VAUGHAN, M.M.; SHOEMAKER, S.; RAMIREZ R. A.; IP. M.M. Inhibition of angiogenesis by the cancer chemopreventive agent conjugated linoleic acid. Cancer Research, v. 62, p. 4383-4389, 2002.

24-SIKORSKI, A.M.; HEBERT, N.; SWAIN, R.A. Conjugated Linoleic Acid (CLA) inhibits new vessel growth in the mammalian brain. Brain Research, v. 1213, p. 3540,2008.

25-CAIRNS,R.A.;HARRIS,I.S.;MAK,T.W. Regulation of cancer cell metabolism. Nature Reviews,v. 11, p. 85-95, 2011. 
26- NELSON, D.L.; COX,M.M. Lehninger principios de bioquímica. 3.ed. São Paulo: Sarvier, 2002. 975 p.

27- VOET,D.; VOET,J.G.;PRATT,C.W. Fundamentos de bioquímica. Porto Alegre : Artmed, 2002. $931 \mathrm{p}$.

28- WARBURG,O.; POSENER,K.; NEGELEIN,E. Uber den Stoffwechsel der tumoren. Biochemistry, v.152, p.319-344, 1924.

29-MERZ, A.L.; SERKOVA, N.J. Use of nuclear magnetic resonance-based metabolomics in detecting drug resistance in cancer. Biomark Medicine, v. 3, n. 3, p. 289-306,2009.

30-GLUNDE, K.; JIANG,L.; MOESTUE,S.A.;GRIBBESTAD, I.S. MRS and MRSI guidance in molecular medicine: targeting and monitoring of choline and glucose metabolism in câncer. NMR in biomedicine, v. 24, p. 673-690, 2011.

31- GLUNDE,K.;BHUJWALLA,Z.M.; RONEN,S.M. Choline metabolism in malignant transformation. Nature Reviews Cancer, v.11, n.12, p.835-848,2011.

32-ELIYAHU, G.;KREIZMAN, T.;DEGANI, H. Phosphocholine as a biomarker of breast cancer: Molecular and biochemical studies. International Journal of Cancer, v. 120, n. 8, p. 1721-1730, 2007.

33-NOHTURFFT, A.; ZHANG, C. Coordination of lipid metabolism in membrane biogenesis. Annual Review of Cell and Developmental Biology, v. 25, p. 539$566,2009$.

34-RANG,H.P.;DALE, M.M.; RITTER,J.M.;FLOWER,R.J. Farmacologia. Rio de Janeiro: Elsevier, 2007. 829 p.

35-HU, J.; ZHANG, Z.; SHEN, W.; AZHAR, S. Cellular cholesterol delivery, intracellular processing and utilization for biosynthesis of steroid hormones. Nutritione Metabolism, v. 7, n. 47,p. 1-25, 2010.

36-GRIFFIN, J.L.; SHOCKCOR, J.P. Metabolic profiles of cancer cells. Nature Reviews, p. 551-561,2004.

37-OAKMAN,C.;TENORI,L.;BIGANZOLI,L.;SANTARPIA,L.;CAPPADONA,S.;

LUCHINAT,C.;LEO, A.D. Uncovering the metabolomic firgerprint of breast cancer. The International Journal of Biochemistry and Cell Biology,v. 43, n. 7, p. 1010$1020,2011$.

38-DUARTE, I.F.; MARQUES, J.; LADEIRINHA, A.F.; ROCHA, C.; LAMEGO, I.; CALHEIROS, R.; SILVA, T.M.; MARQUES, M.P.M.; MELO, J.B.; CARREIRA, I.M.; GIL, A.M. Analytical approaches toward successful human cell metabolome studies by nmr spectroscopy. Analytical Chemistry, v. 81, p. 5023-5032,2009.

39- KROEMER,G.;POUYSSEGUR,J. Tumor cell metabolism:cancer's Achilles 'heel. Cancer Cell, v.13, p. 472-482, 2008. 
40-SITTER,B.; BATHEN, T.F.; TESSEM, M.; GRIBBESTAD, I.S. High resollution Magic angle spinning (HR MAS) MR spectroscopy in metabolic characterization of human cancer. Progress in Nuclear Magnetic Resonance Spectroscopy, v. 54, p. 239-254,2009.

41-CHENG, L.L.; CHANG, I.; SMITH, B.L.; GONZALEZ, R.G. Evaluation human breast ductal carcinomas with high-resolution magic angle spinning proton magnetic resonance spectroscopy. Journal of Magnetic Resonance, v. 135, p.194-202, 1998.

42-BROBERG, A.; KENNE, L. Use of high-resolution magic angle spinning nuclear magnetic resonance spectroscopy for in situ studies of low-molecular compounds in red algae. Analytical Chemistry, v. 284, p. 367-374, 2000.

43-SANDERS, J.K.M.; HUNTER, B.K. Modern NMR spectroscopy:a guide for chemists. Oxford: Oxford University, 1993. v. 25, p. 328.

44-KEMP, W. NMR in chemistry, a multinuclear introduction. London: The Macmillan Press, 1986. p.120.

45-CLARIDGE, T.D.W. High resolution NMR techniques in organic chemistry. Amsterdam:Pergamon, 1999. 382 p.

46-PRICE,W.S. Water suppression in NMR spectroscopy . Annual Reports on NMR Spectroscopy, v. 38, p. 284-354,1999.

47-CHENG, L.L.; LEAN, C.L.; BOGDANOVA, A.; WRIGHT, S.C.; JR.; ACKERMANM J.L.; BRADY, T.J.; GARRIDO, L. Enhanced resolution of proton NMR spectra of malignant lymph nodes using magic-angle spinning. Magnetic Resonance Medicine, v.36, p. 653-658, 1996.

48-MILLIS, K.K.; MAAS, W.E.; CORY, D.G.; SINGER, S. Gradient, high-resolution, magic angle spinning nuclear magnetic resonance spectroscopy of human adipocyte tissue. Magnetic Resonance Medicine, v. 38, p. 399-403, 1997.

49-CHENG,L.L.; CHANG,I.; LOUIS,D.N.; GONZALEZ,G. Correlation of high resolution Magic angle spinning proton magnetic resonance spectroscopy with histopathology of intact human brain tumor specimens. Cancer Research, v. 58, p. 1825-1832,1998.

50-CHENG,L.L.; WU, C.; SMITH,M.R.; GONZALEZ, R.G. Non-destructive quantitation of spermine in human prostate tissue samples using HR MAS ${ }^{1} \mathrm{H}$ NMR spectroscopy at 9.4T.FEBS Letters, p.112-116,2001.

51-TESSEM, M.; SWANSON, M.G.; KESHARI,K.R.; ALBERS, M.J.; JOUN, D.; TABATABAI, L.; SIMKO, J.P.; SHINOHARA, K.; NELSON, S.J.; VIGNERON, D.B.; GRIBBESTAD, I.S.; KURHANEWICZ, J. Evaluation of lactate and alanine as metabolic biomarkers of prostate cancer using ${ }^{1} \mathrm{H}$ HR-MAS spectroscopy of biopsy tissues. Magnetic Resonance Medicine, v. 60, n. 3, p. 510-516, 2008.

52-MIRBAHAI, L.; WILSON, M.; SHAW, C.S.; McCONVILLE, C.; MALCOMSON, R.D.G.; GRIFFIN, J.L.; KAUPPINEN, R.A.; PEET, A.C. ${ }^{1}$ Hmagnetic resonance 
spectroscopy metabolites as biomarkers for cell cycle arrest and cell death in rat glioma cells. The International Journal of Biochemistry e Cell Biology, v. 43, n. 7, p. 9901001, 2011.

53- MEADOWS, A.L.; KONG,B.; BERDICHEVSKY, M.; ROY, S.; ROSIVA, R. BLANCH, H.W.; CLARK, D.S. Metabolic and morphological differences between rapidly proliferating cancerous and normal breast epithelial cells. Biotechnology, v. 24, p. 334-341, 2008.

54-MANDELSHTAM, V. A. FDM: the filter diagonalization method for data processing in NMR experiments. Progress in Nuclear Magnetic Resonance Spectroscopy, v. 38, p. 159-196, 2001.

55-MANDELSHTAM, V. A.; TAYLOR, H. S. Harmonic inversion of time signals and its applications. Journal of Chemical Physics, v. 107, p. 6756-6769, 1997.

56-HUMAN METABOLOME DATABASE 2005-2013 . Disponivel em : <http://www.hmdb.ca/metabolites/HMDB01659>. Acesso em: 20 jun.2013.

57-YOSHIMOTO, M.; WAKI, A.; YONEKURA, Y.; SADATO, N.; MURATA, T.; OMATA, N.; TAKAHASHI, N.; WELCH, M.J.; FUJIBAYASHI, Y. Characterization of acetate metabolism in tumor cells in relation to cell proliferation: Acetate metabolism in tumor cells. Nuclear Medicine and Biology, v.28, n.2, p. 117-122, 2001.

58- NAJBJERG, H.; YOUNG, J. F.; BERTRAM,H. C. NMR-Based metabolomics reveals that conjugated double bond content and lipid storage efficiency in hepG2 cells are affected by fatty acid cis/trans configuration and chain length .Journal of Agricultural and Food Chemistry, v. 59, n.16, p. 8994-9000,2011.

59- RIDGWAY, N. D. The role of phosphatidylcholine and choline metabolites to cell proliferation and survival. Critical Reviews in Biochemistry and Molecular Biology, v. 48 , n. 1 , p. $20-38,2013$.

60- PIERRE, A.-S.; MINVILLE-WALZ, M.; FEVRE, C.; HICHAMI, A.; GRESTI, J.; PICHON, L.; BELLENGER, S.; BELLENGER, J.; GHIRINGHELLI, F.; NARCE, M.; RIALLAND, M. Trans-10, cis-12 conjugated linoleic acid induced cell death in human colon cancer cells through reactive oxygen species-mediated ER stress. Biochimica Et Biophysica Acta-Molecular and Cell Biology of Lipids, v.1831, n. 4, p. 759-768, 2013.

61- SPINK, D.C.; ZHANG,F.; HUSSAIN, M.M.; KATZ,B.H.; LIU, X.; HILKER,D.R.;BOLTON, J.L. Metabolism of equilenin in MCF-7 and MDA-MB-231 human breast cancer cells. Chemical Research in Toxicology, v.14, p. 572-581, 2001.

62- NOTARNICOLA, M.; MESSA, C.; REFOLO, M. G.; TUTINO, V.; MICCOLIS, A.; CARUSO, M. G. Polyunsaturated fatty acids reduce fatty acid synthase and hydroxy- 
methyl-glutaryl coA-reductase gene expression and promote apoptosis in hepG2 cell line. Lipids in Health and Disease, v. 9, p.1-8, 2010.

63- DUNCAN, R. E.; EL-SOHEMY, A.; ARCHER, M. C.Regulation of HMG-CoA reductase in MCF-7 cells by genistein, EPA, and DHA, alone and in combination with mevastatin. Cancer Letters, v. 224, n. 2,p. 221-228,2005.

64- EL-SOHEMY,A.; ARCHER, M.C. Inhibition of N-methyl-N-nitrosourea-and 7,12dimethylbenz[a]ãnthracene-induced rat mammary tumorigenesis by dietary cholesterol is independent of Has-Ras mutations. Carcinogenesis, v. 21, p. 827831,2000 .

65- YOSHIMUNE,S.; HOUWELING,M.; ZHA, X.; TABAS, I. Stimulation of CTP: Phosphocholine Cytidyltransferade by free cholesterol loading of macrophages involves signaling through protein dephosphorylation. The Journal of Biological Chemistry, v. 270, p. 29894-29903, 1995.

66- PROTEIN KNOWLEDGEBASE 2002-2013. Disponível em: <http://www.uniprot.org/uniprot/Q02338>. Acesso em : 10 mar.2013.

67-ISTVAN.E.S.; DEISENHOFER,J. Structural mechanism for statin inhibition of HMG-CoA reductase. Science, v. 292, n. 5519, p. 1160-1164, 2001.

68-GARCIA-PELAYO,M.C.; GARCIA-PEREGRIN, E.; MARTINEZ-CAYUELA, M. Modification of phospholipids fatty acid compostion in reuber $\mathrm{H} 35$ hepatoma cells: effect on HMG-CoA reductase activity. Journal of Cellular Biochemistry, v. 90, p. 586-591, 2003.

69-MARIA,R.M.; MORAES,T.B.; MAGON,C.J.; VENÂNCIO,T.; ALTEI,W.F.;

ANDRICOPULO,A.D.; COLNAGO,L.A.Processing of high resolution magic angle spinning spectra of breast cancer cells by the filter diagonalization method. Analyst, v.137, n.19, p. 4546-51, 2012. 